\title{
Genetic evaluation of cytochrome P450 expression in smoking and nonsmoking women
}

\author{
Satya Vijayanand Vadlamuri \\ West Virginia University
}

Follow this and additional works at: https://researchrepository.wvu.edu/etd

\section{Recommended Citation}

Vadlamuri, Satya Vijayanand, "Genetic evaluation of cytochrome P450 expression in smoking and nonsmoking women" (2001). Graduate Theses, Dissertations, and Problem Reports. 1419.

https://researchrepository.wvu.edu/etd/1419

This Dissertation is protected by copyright and/or related rights. It has been brought to you by the The Research Repository @ WVU with permission from the rights-holder(s). You are free to use this Dissertation in any way that is permitted by the copyright and related rights legislation that applies to your use. For other uses you must obtain permission from the rights-holder(s) directly, unless additional rights are indicated by a Creative Commons license in the record and/ or on the work itself. This Dissertation has been accepted for inclusion in WVU Graduate Theses, Dissertations, and Problem Reports collection by an authorized administrator of The Research Repository @ WVU.

For more information, please contact researchrepository@mail.wvu.edu. 


\title{
GENETIC EVALUATION OF CYTOCHROME-P450 EXPRESSION IN SMOKING AND NONSMOKING WOMEN.
}

\section{Satya Vijayanand Vadlamuri}

\author{
Dissertation \\ Submitted to the \\ College of Agriculture Forestry and Consumer Sciences \\ at \\ West Virginia University \\ in Partial fulfillment of the Requirements for \\ The Degree of \\ Doctor of Philosophy \\ in \\ Genetics and Developmental Biology Program
}

\author{
Dr. Joginder Nath, Ph.D., Chair \\ Dr. Knox Van Dyke., Ph.D. \\ Dr. R. E. Stitzel., Ph.D. \\ Dr. Sharon L Wenger., Ph.D. \\ Dr. Walter Kaczmarczyk., Ph.D.
}

Morgantown, West Virginia.

2001 


\title{
ABSTRACT \\ GENETIC EVALUATION OF CYTOCHROME-P450 EXPRESSION IN VARIOUS REGIONS OF HUMAN UTERUS IN SMOKERS AND NONSMOKERS.
}

\author{
Satya Vijayanand Vadlamuri
}

1.Regiospecific expression of CYP1A1 and CYP1B1 in human uterus of nonsmokers:

CYP1A1 and CYP1B1, isoforms of Cytochrome P450 enzyme, are of significant

toxicological importance due to their role in catalytic activation of several procarcinogens. The goal of this study was to investigate the expression of these isoforms in different regions of the human uterus. Expression was determined in the endometrium, endocervix and squamous (exocervix) regions from six nonsmoking women by using RT-PCR. The transcripts encoding for CYP1A1 were significantly higher $(\mathrm{p}<0.05)$ in the squamous (exocervix) region compared to other areas. However the expression of CYP1B1 was significantly higher $(\mathrm{p}<0.05)$ in the endometrium. CYP1B1 expression appeared to be extremely low in a woman in the secretory stage of the menstural phase, relative to the endometrium of the other patients who were all in the proliferative stage at hysterectomy. CYP1B1 mRNA was expressed in only $2 / 6$ patients in the squamous (exocervix) region and 3/5 patients in the cervix. CYP1A1 was also uniformly expressed in the endometrium of all except one patient, in whom expression was minimal in the other regions. It appears that variability in the expression of these isoforms may be responsible for the differential susceptibility to cancer in women.

2. Influence of menstrual phase and smoking status on expression of CYP1A1 and CYP1BI in different regions of the uterus:

CYP1A1 and CYP1B1 isoforms exhibit significant role in the catalytic activation of procarcinogens during metabolism of PAH compounds and in estrogen metabolism. The goal of this study was to investigate the expression of these isoforms in different regions of the uterus from smokers and nonsmokers. Uterine tissue was obtained from women $(n=22)$ undergoing hysterectomy. Sections of endometrium (ENDO), endocervix (CERV) and squamous region (SR) were isolated, stored at $-70^{\circ} \mathrm{C}$ and expression was determined by RT PCR and relative mRNA levels were measured with respect to $\beta$-actin. A 12-fold increase in CYP1A1 expression was apparent in the CERV from smokers compared to nonsmokers. In the ENDO and SR a much smaller induction of $<2$-fold was observed. No differences for CYP1A1 mRNA were explicit in the 3 regions when comparing the proliferative and secretory phases of the menstrual cycle. A significantly higher $(\mathrm{p}<0.005)$ expression of CYP1B1 $(\sim 20$-fold $)$ was observed in ENDO from patients in the proliferative phase compared to secretory phase. CYP1B1 expression appeared to be lower in smokers (by $\sim 3$-fold) in the ENDO and no measurable expression was observed in the SR. These results indicate that CYP1A1 and CYP1B1 are expressed variably in different regions of the human uterus. The expression of CYP1B1 may be susceptible both to hormonal control and cigarette smoking. The variability in the expression of these isoforms may be responsible for the differential susceptibility to cancer in some women.

3. The effect of menstrual phase on CYP3A expression in human endometrium:

The CYP3A family consists of four closely related proteins. Of these, CYP3A3/4 is the most abundant $\mathrm{P} 450$ isoform and is responsible for metabolizing estrogen as well as a variety of 
therapeutic agents, whereas CYP3A7, the fetal liver form, is involved in the biosynthesis of estriol. The goal of this study was to evaluate the expression of these two major CYP3A isoforms in human uterine tissue during the proliferative (PROL) and secretory (SEC) phases of the menstrual cycle. Human endometrial tissue was collected from women undergoing hysterectomy $(n=34)$, and frozen at $-70^{\circ} \mathrm{C}$. Total mRNA was extracted, quantified and RT PCR was carried out by using consensus primers to express CYP3A. The PCR product of 453bp was transferred to nylon membrane and was hybridized with specific internal oligo probes for CYP3A/4 or CYP3A7 labeled with ${ }^{32} \mathrm{P} \gamma$ ATP. The relative intensity of hybridization for individual samples was determined after autoradiography and using image quant software. Expression of CYP3A7 was significantly increased (17-fold) in the PROL compared to SEC phase, whereas no differences were observed $(\mathrm{p}>0.05)$ for CYP3A3/4. No significant differences were observed for either of the CYP3A isoforms in overall comparison regardless of phase. However, CYP3A3/4 expression was significantly decreased $(30$-fold) in smokers compared to nonsmokers $(p<0.05)$ in SEC phase. Furthermore, a 40-fold and a 20-fold higher expression of CYP3A7 and CYP3A3/4, respectively were observed in the PROL relative to the SEC phase in smokers. Differential expression of CYP3A isoforms in the menstrual phase between smokers and nonsmokers could determine the toxicological role of these enzymes in women. Expression of CYP3A7 in endometrium appeared to be several fold higher $(\sim 10$-fold $)$ in the proliferative phase compared to the secretory phase. CYP3A4 expression was comparable between the two phases of the menstrual cycle. Relatively minimal expression of both enzymes was observed in the cervix. The RTPCR results indicated differential expression of CYP3A7 in various phases of the menstrual cycle. These results indicate that CYP3A isoforms may be subject to hormonal regulation during the menstrual cycle in endometrium of premenopausal women.

Key words: CYP1A1, CYP1B1, CYP3A3/3A4, CYP3A7, Human Uterus, Endometrial cancer, Cervical cancer.

Supported by NCI grant \# CA-62369 


\section{DEDICATION}

\section{Dedicated}

to

\section{Bagwan Sri Satya Sai Baba - my spiritual guide}

All my teachers who taught me to reach this stage

$$
\text { and }
$$

My father and mother, brothers and Sister, my wife and children for their love 


\section{ACKNOWLEDGEMENTS}

I am extremely fortunate to have the teaching and guidance from Dr. Joginder Nath. I acknowledge with pride and appreciation his leadership and the training and discipline imparted to me. I express my deep sense of gratitude to my committee members for their guidance and encouragement. I am grateful to Dr. Robert Stitzel for the invaluable support. I appreciate the support of Dr. Knox Vandyke for enhancing my scientific advancement. I am very grateful to Dr. Sharon Wenger for inspiration, encouragement and help provided to reach my goal. I am grateful to Dr. Walter Kaczmarczyk for his support not only scientifically but also emotionally. I cherish the memories of Dr. Dennis Overman.

I received immense support, guidance and encouragement from Dr. Kerry Odell, Assoc. Dean who has a special place in my heart through out my career.

I have received scientific support from many in Health sciences center during my study. I fondly remember Dr. Mohamadi A Sarkar who was my supportor and mentor without whom this document couldn't have been possible. I thank Dr. Don Sense for the use his facilities and expertise many times. I thank Dr.Gunel for helping me in statistical analysis and JMP software. I acknowledge the help of various Pathologists for providing uterine tissues for this research. I am ever so grateful to Dr. S.N.Jagannathan who helped me to reenter the world of research. My gratitude to those I might have missed inadvertantly.

Finally I acknowledge the support of my wife and my children to put up with me and without me during the last few years in my endeavor to get this degree. 


\section{TABLE OF CONTENTS}

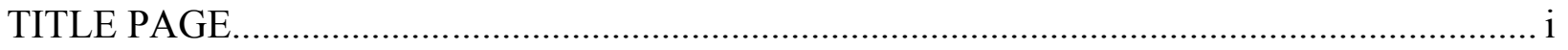

ABSTRACT....

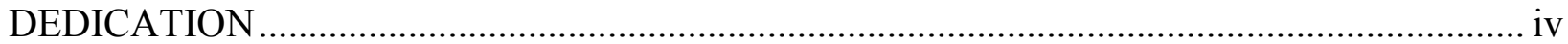

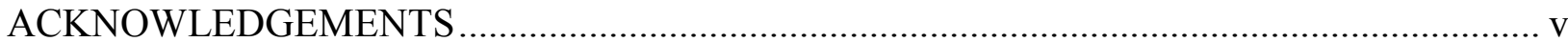

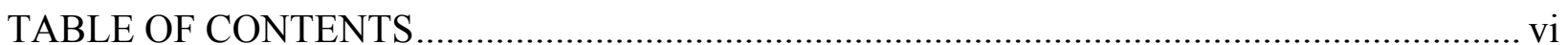

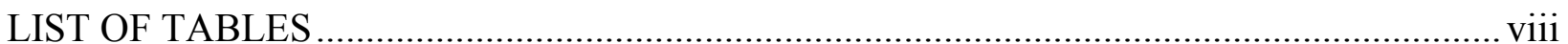

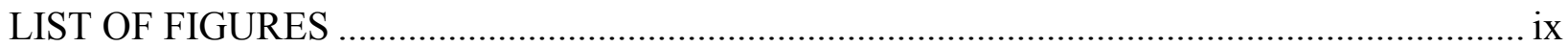

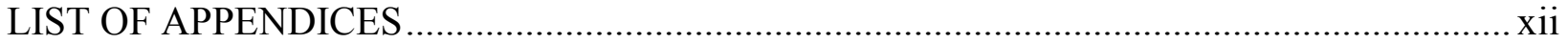

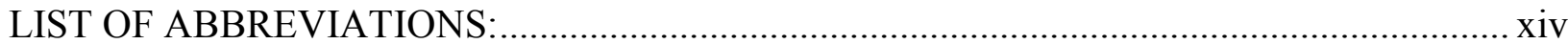

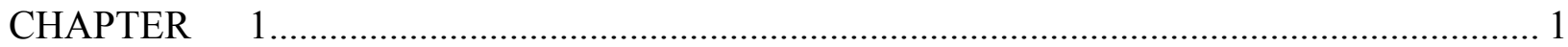

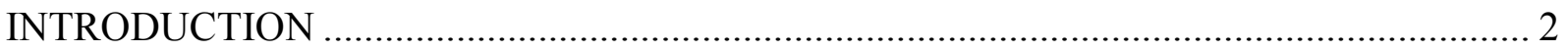

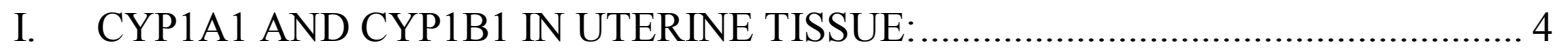

II. CYP1A1 and CYP1B1 IN SMOKERS AND NONSMOKERS: ................................ 5

III. $\quad$ CYP3A3/3A4 AND CYP3A7 IN UTERUS:.................................................

IV. CYP3A3/3A4 AND 3A7 IN NONSMOKERS AND SMOKERS:......................... 7

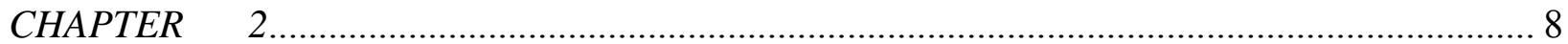

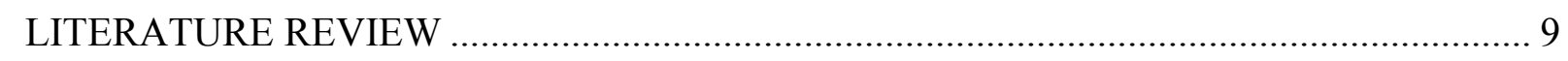

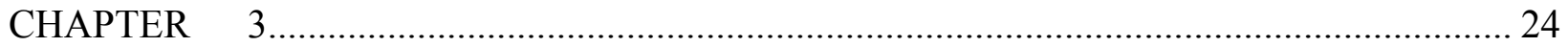

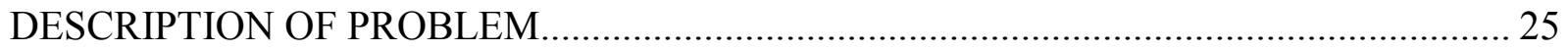

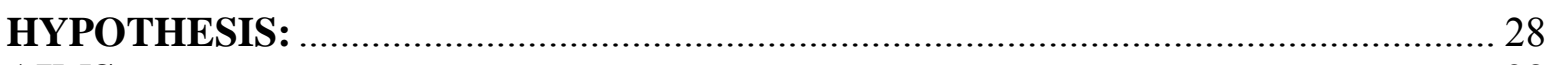

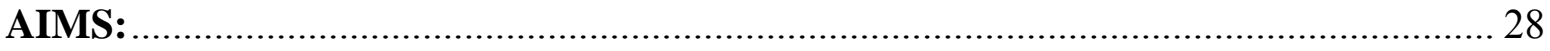

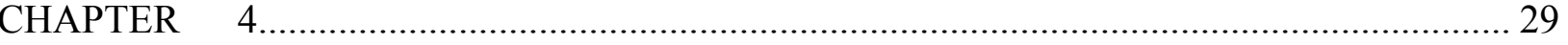

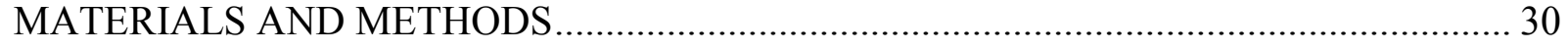

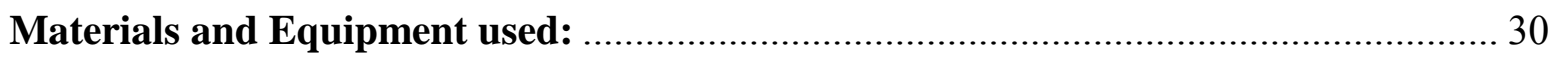

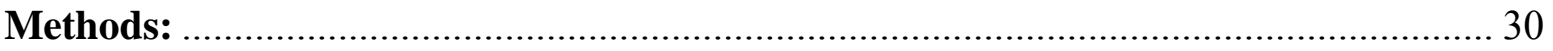

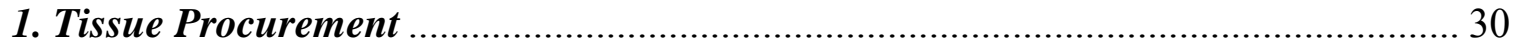

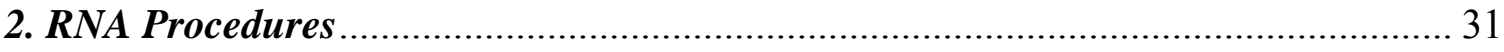

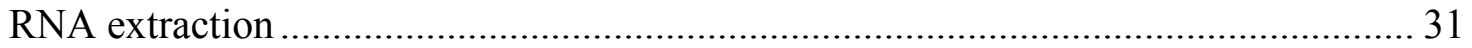

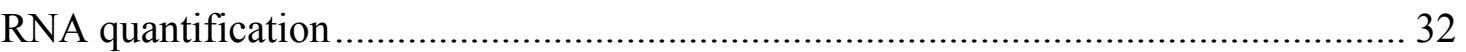

RNA quality analysis ......................................................................... 32

3. Reverse - Transcription polymerase chain reaction (RT-PCR) of CYP $m R N A s$..... 32

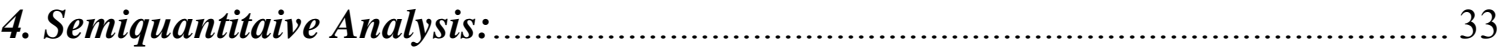

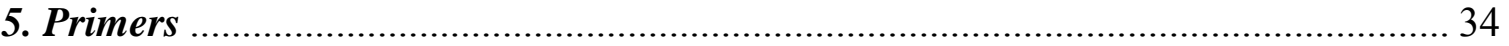

6. Endometrial dating - proliferative and secretory endometrium ............................. 34

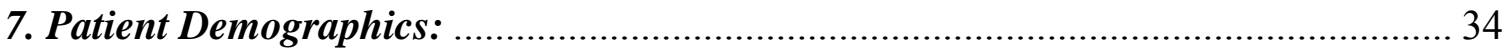

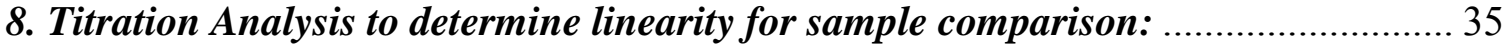

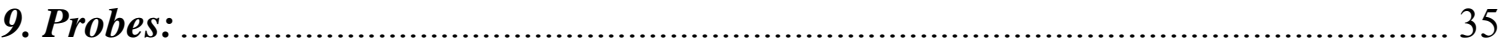

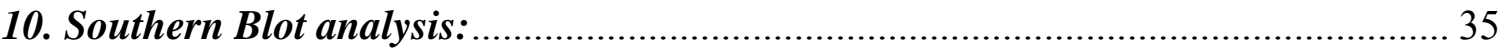

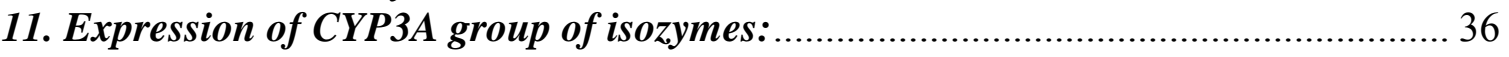

12. Primer Design for CYP3A group of isozymes: .......................................... 38

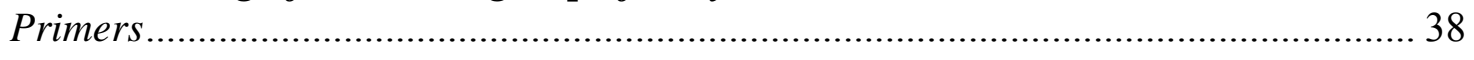


Probes

13. Reverse - Transcription polymerase chain reaction (RT-PCR) of CYP3A mRNAs 39

14. Hybridization analysis: ................................................................... 40

15. Reconfirmation of the probe specificity: ................................................ 41

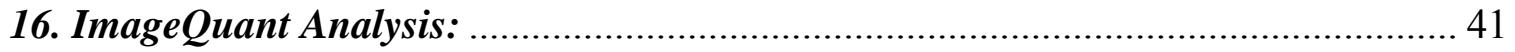

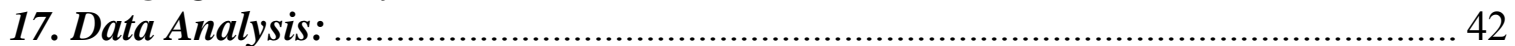

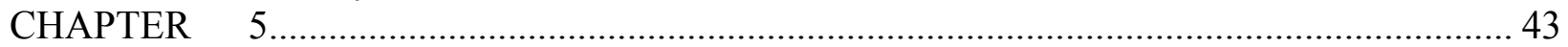

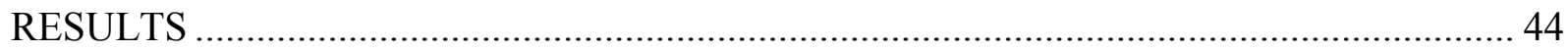

1. Expression of CYP1A1 and CYP1B1 in nonsmokers: ..................................... 44

2. Expression of CYP1A1 and CYP1B1 in Nonsmokers and Smokers and with respect

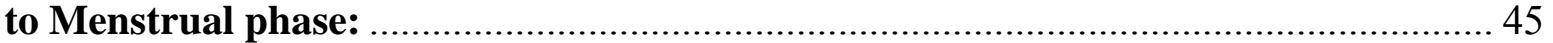

CYP1A1 and CYP1B1 in the Endometrium: ................................................ 45

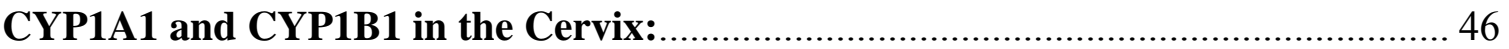

CYP1A1 and CYP1B1 in the Squamous (exocervix) Region: ............................ 47

3. Expression of CYP3A3/A4 and CYP3A7 in Endometrium and Cervix: ................ 47

4. Expression of CYP3A3/A4 and CYP3A7 in Nonsmokers and Smokers: .............. 48

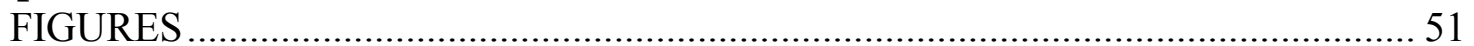

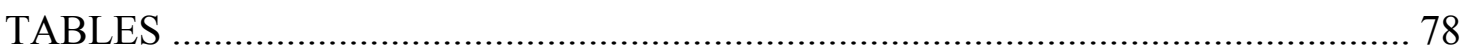

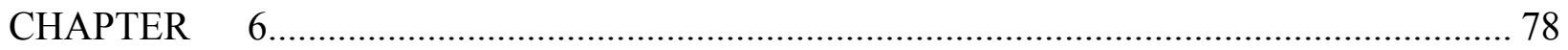

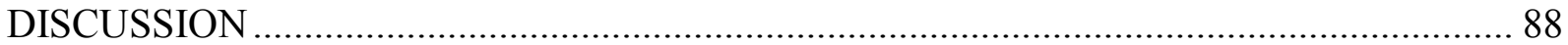

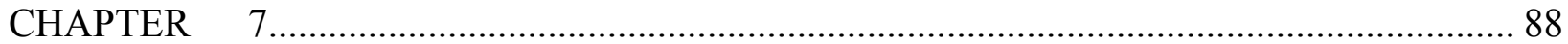

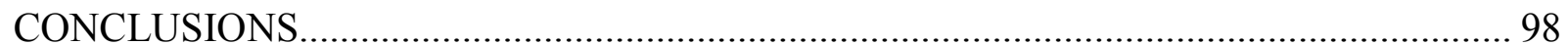

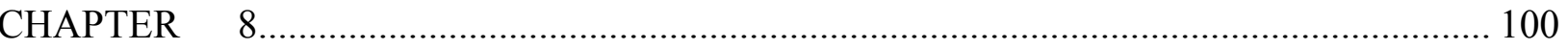

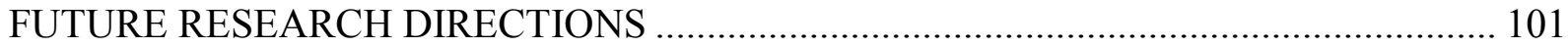

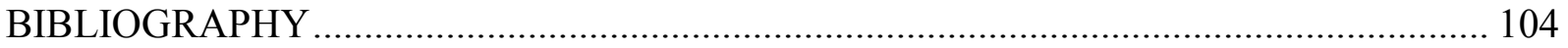

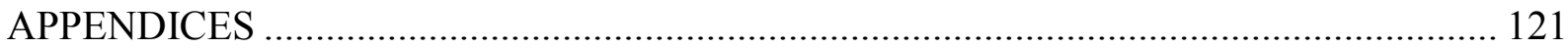




\section{LIST OF TABLES}

Table\# Description

Page \#

Table 1 Demographic data of patients - nonsmokers for CYP1A1 and CYP1B1 78

Table 2 Demographic data of patients analyzed for CYP1A1 and CYP1B1 during various stages of menstrual cycle and smoking status

Table 3 CYP expression levels in various regions as a ratio with $\beta$-actin

Table $4 \quad$ CYP1B1 expression levels in various regions as ratio with $\beta$-actin

Table 5 Demographic data of patients used for CYP3A expression

$83-84$

Table 6 The measured levels of CYP3A3/A4 and CYP3A7 as ratios with

respective $\beta$-actin levels - Endometrium and Cervix

$85-86$ 


\section{LIST OF FIGURES}

Figures Description

Figure 1.1 Uterus

Figure 2.1 Sequence of events leading to carcinogenic effects from cigarette smoke

Figure 2.2 Estrogen, Progestin impact on metastasis

Figure 3.1 Proposed bio-transformation scheme for Benzo(a)pyerene (BP)

Figure 3.2 Proposed metabolic scheme for estrogens

Figure 4.1 Tissue sampling procedure

Figure 4.2 CYP3A group sequence alignment

Figure 5.1 Expression of CYP1A1 mRNA in nonsmokers in three regions of uterus - Gel

Figure 5.2 Expression of CYP1B1 mRNA in nonsmokers in three regions of uterus - Gel

Figure 5.3 CYP1A1 and CYP1B1 expression in uterus - Graph

Figure 5.4 Expression of CYP1A1 mRNA in smokers in three regions of uterus - Gel

Figure 5.5 Expression of CYP1B1 mRNA in smokers in three regions of uterus - Gel

Figure 5.6 Expression of CYP1A1 and CYP1B1 in endometrium, comparison between nonsmokers and smokers - Gel 56

Figure 5.7 Expression of CYP1A1 and CYP1B1 in cervix, comparison between nonsmokers and smokers - Gel 57 
Figure 5.8 Expression of CYP1A1 and CYP1B1 in squamous (exocervix) region, comparison between nonsmokers and smokers - Gel

Figure 5.9 Ratio of CYP1A1/ $\beta$-actin mRNA levels among nonsmokers and smokers 59

Figure 5.10 Ratio of CYP1A1/ $\beta$-actin mRNA levels among proliferative and secretory phases

Figure 5.11 Ratio of CYP1B1/ $\beta$-actin mRNA levels among nonsmokers and smokers 61

Figure 5.12 Ratio of CYP1A1/ $\beta$-actin mRNA levels among proliferative and secretory phases

Figure 5.13 CYP3A expression in endometrium with probes

Figure 5.14 CYP3A3/A4 and CYP3A7 expression in endometrium

Figure 5.15 CYP3A3/A4 and CYP3A7 expression in cervix

Figure 5.16 Expression of CYP3A3/4 and CYP3A7 in proliferative endometrium 66

Figure 5.17 Expression of CYP3A3/4 and CYP3A7 in secretory endometrium 67

Figure 5.18 CYP3A expression in endometrium 68

$\begin{array}{lll}\text { Figure 5.19 CYP3A expression in cervix } & 69\end{array}$

Figure 5.20 Levels of CYP3A3/4 by nonsmokers and smokers in endometrium 70

Figure 5.21 Levels of CYP3A7 by nonsmokers and smokers in endometrium 71

Figure 5.21b Levels of CYP3A7 in proliferative and secretory endometrium in nonsmokers and $\begin{array}{ll}\text { smokers } & 72\end{array}$

Figure 5.22 Levels of CYP3A3/4 by nonsmokers and smokers in cervix 73

Figure 5.23 Levels of CYP3A7 by nonsmokers and smokers in cervix 74

Figure 5.24 Expression of CYP3A3/4 and CYP3A7 in endometrium in nonsmokers 
and smokers

Figure 5.25 Expression of CYP3A3/4 and CYP3A7 in cervix in nonsmokers and smokers

Figure 6.1 The comparative analysis of CYP3A expressions in ENDO and CERV

95 


\section{LIST OF APPENDICES}

Appendix \#

Appendix A

Appendix B

Appendix C

Appendix D

Appendix E

Appendix F

Appendix G.1

Appendix G.2

Appendix G.3

Appendix G.4

Appendix G.5

Appendix G.6

Appendix G.7

Appendix G.8

\section{Description}

Quality of mRNA from three regions of uterus

$\beta$-Actin expression in three regions of uterus

Titration Analysis

124

Materials, Equipment and Buffers used

Patient information - nonsmoker/ smoker- format

RNA concentrations from the tissues and

identifications of all patients

131

Master Data - Expression levels of CYP3A3/A4 and CYP3A7

as ratio to $\beta$-Actin and the relative differences

132

Expression of CYP3A3/A4 - Model with no interaction

Expression of CYP3A3/A4 - Model with interaction

Expression of CYP3A7 - Model without interaction

136

Expression of CYP3A7 - Model with interaction

The Differential expression of CYP3A3/A4 from ENDO

and CERV among nonsmokers

The Differential expression of CYP3A3/A4 from ENDO

and CERV among smokers

$141-142$

The Differential expression from CYP3A3/A4 to CYP3A7

among nonsmokers

$143-144$ 
Appendix G.9 The Differential expression from CYP3A3/A4 to CYP3A7

among smokers

$145-146$

Appendix G.10 VITA

$147-150$ 


\section{LIST OF ABBREVIATIONS:}

AC Endometrial Adenocarcinoma

AHH Aryl Hydrocarbon Hydroxylase

BP Benzo (a) Pyrene

CBG Coritocosteroid Binding Globulin

CERV Cervix

CIN Cervical Intraepithelial Neoplasia

CIN III Cervical Intraepithelial Neoplasia $3^{\text {rd }}$ stage.

CYP Cytochrome P450

DDT Dichloro-diphenyl-trichloroethane

DES Diethyl Stilbestrol

DHEA Dehydroepiandrosterone

DTT Dithiothreitol

ENDO Endometrium

EH Epoxide Hydrolase

HP Endometrial Hyperplasia

HPV Human Papilloma Virus

3-MC 3-Methylcholanthrene

M-MLV Moloney Murine Leukemia Virus

PAH Polycyclic Aromatic Hydrocarbons

PCB Polychlorinated Biphenyls

PCR Polymerase Chain Reaction

PROL Proliferative stage

RT PCR Reverse Transcription Polymerase Chain Reaction

SCC Squamous cell carcinoma

SE Squamous epithelium

SEC Secretory stage

TCDD Tetrachlorodibenzo-p-dioxin 


\section{CHAPTER 1}

\section{INTRODUCTION}




\section{INTRODUCTION}

In the United States, uterine cancer is still one of the most predominant and prevalent cancers among women. About 50,000 cases of uterine cancer were diagnosed in 1998 of which 36,100 were endometrial cancers and 13,700 were cervical cancers. World-wide about 400,000 cases of cervical cancer and 500,000 cases of endometrial cancer were estimated (American Cancer Society, 1998).

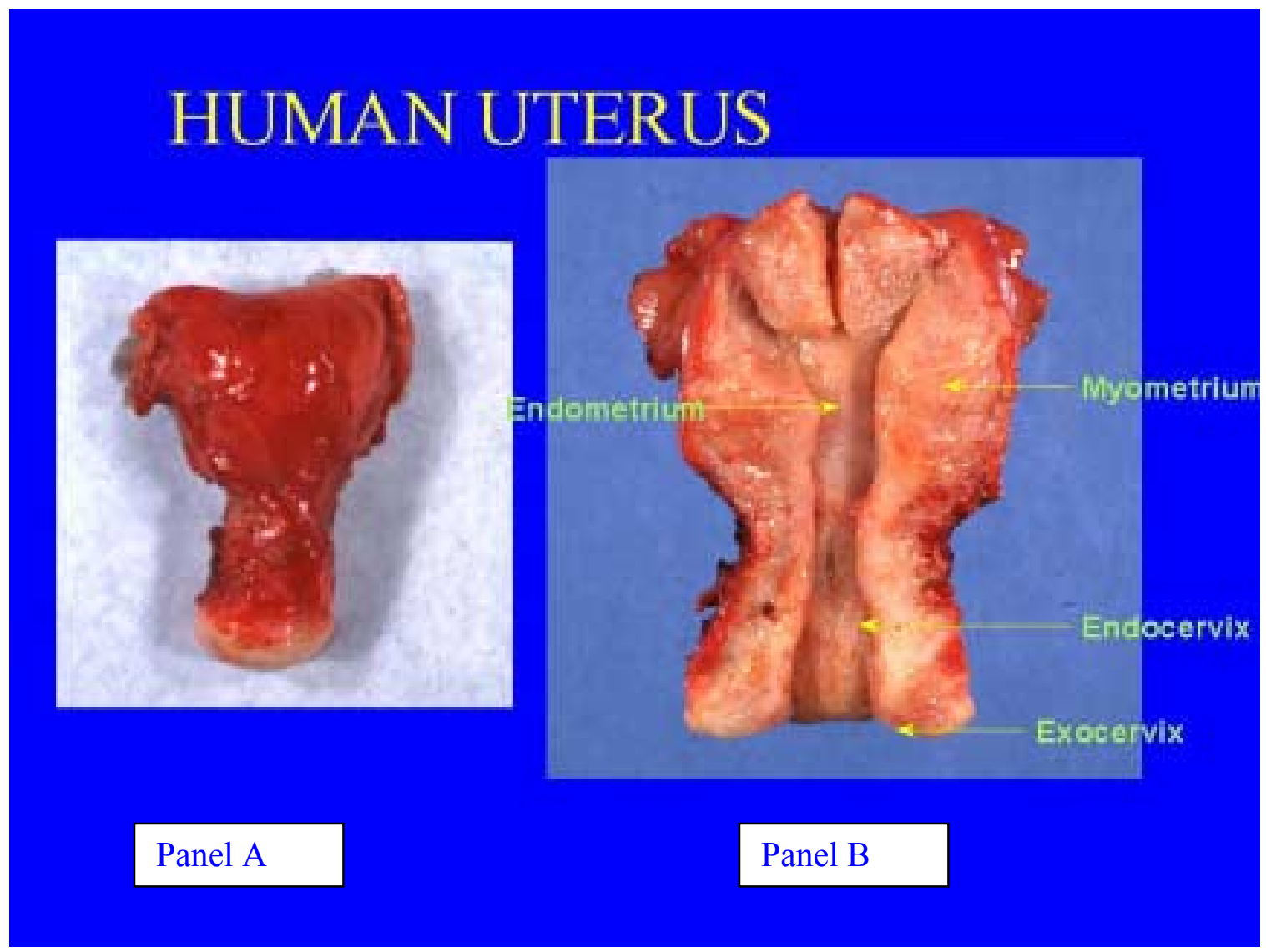

Figure: 1. UTERUS: Uterine organ in Panel A and Cross Section of uterus in Panel B.

Figure 1 shows the structure of human uterus. Uterine cervix and endometrium are about

$10 \mathrm{~cm}$ apart the same organ, which show different degrees of susceptibility to cancer. Among 
smokers, the risk of cervical cancer increased by 3 -fold $(\mathrm{p}<0.05)$ whereas the risk of endometrial cancer decreased by almost 50\% (relative odds ratio 0.57)(Brisson et al. 1994; Austin et al. 1993). Therefore, with increased cigarette consumption there is a significant increase in the risk of cervical cancer and statistically significant decrease in risk of endometrial cancer (Baron et al. 1986).

The risk factors for cervical cancer are human papilloma virus, older age, multiple sexual partners, etc., whereas for endometrial cancer the risk factors are obesity, estrogen use, clinical conditions causing hyper estrogenism, anovulation, nulliparity, etc. (Yager et al. 1996).

Polycyclic hydrocarbons (PAHs) such as Benzo (a) Pyrene (BP) and nitrosamines are considered to be promutagenic. Cigarettes contain 10-50mg of BP per cigarette, smoked foods have 100mg BP per kg, and environmental pollutants have PAHs as major components. Several of the most common cancers occur in hormonally responsive tissues, including breast, endometrium and ovary in women and prostate in men (Yager et al. 1996). The uterus, especially, endometrium, undergoes profound cell multiplication and cell differentiation at regular intervals, which are influenced by hormonal effects.

Cytochrome P450s (CYPs) are hemeproteins, which are induced in human tissues to metabolize various xenobiotics, hormones and other substrates. CYPs oxidize the substrates through a process of oxidation and electron transport from NADPH. Some of these CYPs activate chemical carcinogens to their electrophilic forms, which can bind to DNA covalently and cause mutations that trigger carcinogenesis. A principal goal of this research was to investigate this mechanism, which may explain these observations. 
It is well established that cigarette smoke is one of the main causes of lung cancer. The convincing reason is the presence of benzo (a) pyrene like procarcinogens present in cigarette smoke are reactivated by phase I metabolizing enzymes of Cytochrome P450 s and usually detoxified by epoxide hydrolase/ glutathione - S- transferase. The BP is metabolically activated to BP-7, 8 diol- 9, 10-epoxide (BPDE) which is highly reactive and forms covalent adducts with cellular DNA which may result in mutations and/ or malignant transformation. Similar mechanism of bulky DNA adduct formation could be responsible in explaining possible endometrial and cervical cancers. Cytochromes exhibit an active oxidizing role in estrogen metabolism. Smoking induces these CYPs and localized expressions of these CYPs in the uterine tissue could exhibit variability in inactivation, which is possible through differential degrees of inducement due to smoking or non-smoking.

\section{CYP1A1 AND CYP1B1 IN UTERINE TISSUE:}

Considering uterine sensitivity to estrogenic stimulus, it is valid to assume that any changes in the localized metabolism of the estrogens may significantly affect both the physiologic and toxicological outcome. It has been shown that enhanced metabolism of endogenous estrogens to catechols by Tetrachlorodibenzo-p-dioxin (TCDD) induced enzymes may lead to increased oxidative DNA damage and hence contribute to TCDD-mediated hepatocarcinogenicity in female rats (Tritscher et al. 1996). TCDD and other related carcinogens exert their effect by interacting with the Ah-receptors, which induce the expression of the cytochrome P450 family 1 genes - CYP1A1 and CYP1A2 (Walker et al.1995), as well as a recently characterized new member of the family, CYP1B1 (Sutter et al. 1994; Tritscher et al.1996). 
Recent evidence suggests that CYP1B1 may be the primary E2 -4-hydroxylase (Hayes et al. 1996). Although the 4-hydroxylation is a minor metabolic pathway and represents a relatively small fraction of the total urinary catechol-estrogen content (Fishman 1976), it has tissue specific importance. For example, the 4-hydroxylation of $\mathrm{E}_{2}$ is significant in the metabolic control of estrogen homeostasis and in the human uterus the rate of $\mathrm{E}_{2}$-4-hydroxylation approaches or exceeds that of 2-hydroxylation (Liehr et al. 1995). Therefore, it is likely that localized inactivation of the estrogens in the uterus is an important determinant in the physiological as well as toxicological outcomes. To date, only one report (Hakkola et al. 1997) exists in literature regarding the presence of these isoforms in one region within the uterus, but no information exists regarding the expression of both isoforms in all regions within the human uterus.

\section{CYP1A1 and CYP1B1 IN SMOKERS AND NONSMOKERS:}

CYP1A1 is the key activating enzyme, which carries out both oxidation steps required to form the most carcinogenic metabolite of BP, $( \pm)$ benzo (a) pyrene-7, 8-diol-9, 10-epoxide (BPDE). This diol-epoxide can form DNA adducts which may lead to mutations and eventually trigger a cascade of events leading to malignant transformations (Nesnow et al. 1995). Furthermore since the higher levels of CYP1A1 are induced in smokers (Conney 1982), the likelihood of exposure to reactive metabolites is increased even further. Likewise, the reported genetic polymorphism for CYP1A1 (Rannug et al. 1995; Nebert et al. 1996) may result in variations in the activation of chemical carcinogens explaining differences in individual susceptibility (Ikawa et al. 1995; Kaderlik et al. 1995). It is possible that the higher incidence of 
cervical cancer in smokers and some endometrial cancer cases may be a result of exposure to BP or other PAHs from cigarette smoke.

Unopposed estrogens are considered as a major risk factor in the etiology of endometrial cancer (Key et al. 1988; Miller et al. 1990). Isoforms of the CYP1 family play a major role in generating catechol estrogens (Dannan et al. 1986; Spink et al. 1994), e.g. human CYP1A1, which is involved in the activation of BP and also metabolizes estrogens (Eugster et al. 1993). Recently, CYP1B1 (Spink et al. 1992) has been reported to be linked to 4-hydroxylation (Hayes et al. 1996) of estradiol.

\section{CYP3A3/3A4 AND CYP3A7 IN UTERUS:}

The CYP3A subfamily of enzymes has been established as the most abundant CYP subfamily in humans, representing about 30\% of all hepatic CYPs (Slaughter et al. 1995). So far four major isoforms have been identified in humans. They are CYP3A3, CYP3A4, CYP3A5 and CYP3A7, of which CYP3A4 is the predominant hepatic isoform having 98\% homology with CYP3A3. CYP3A7 is a human fetal liver form, first isolated as a 16- $\alpha$-dehydroepiandrosteronesulfate hydroxylase (Kitada et al. 1987). While several CYP450 isoforms have been implicated in estrogen biotransformation, CYP3A4 is probably the major isoform (Aoyama et al. 1990; Brian et al. 1990). CYP3A7 has been found to catalyze 16- $\alpha$-hydroxylation of DHEA sulfate (Kitada et al. 1987). It is believed that DHEA-s is a precursor to estrogen biosynthesis and also in high concentrations, DHEA-s inhibits cell proliferation (Herrington et al.1990), interferes with cellular respiration (Mohan et al. 1989), promotes cervical ripening (Sakyo et al. 1987) and inhibits placental progesterone biosynthesis (Powell et al. 1986). Therefore CYP3A7 might be indirectly involved in several physiologically relevant processes in the uterus. 
Menses is generally regarded as ischemic necrosis of a functional layer caused by contraction of spiral arteries dependent on sex hormone concentrations. The endometrium undergoes its cycle of proliferation, differentiation and desquamation, based on levels of either estrogen alone or of both estrogen and progesterone. Since the endometrium undergoes a constant dynamic growth phase, and cyclic variability of other enzyme expressions has been noted in literature (Otsuki et al. 1994), it is possible that CYP450 might also undergo similar cyclic variability. The goal of this research was to evaluate the expression of the glucocorticoid inducible (Schultz et al. 1993) CYP3A isoforms in the endometrium and cervix to investigate whether these isoforms undergo cyclic expression during different phases of the menstrual cycle. IV. CYP3A3/3A4 AND 3A7 IN NONSMOKERS AND SMOKERS:

There are no references on smoking related activation of CYP3A. Substrate specificity of CYP3A individual isozymes has not been fully elucidated. CYP3A was thought to be important in modulating in vivo antitumor activity and levels of host toxicity. A study in rats and hamsters has shown that there is no significant change in CYP3A isoforms in liver (Koide et al 1999). However in another study preferential induction of CYP3A was noticed by DDT in a sex-related manner, which suggested that CYP regulation could play an important role in endocrine disruption (SierraSantoyo et al. 2000). This evidence suggests a possible role for CYP3A in smokers. 


\section{CHAPTER 2}

LITERATURE REVIEW 


\section{LITERATURE REVIEW}

BACKGROUND: In 1958 Martin Klingenberg reported the first evidence of $\mathrm{P} 450$ as a subcellular fraction of rodent liver, and thereafter during last 40 years there has been an explosive growth of investigations on Cytochrome P450 (CYP) (Costas 1996). Earlier studies with human adult and fetal liver as well as human placenta (Kapitulnik et al. 1977a; Kapitulnik et al. 1977b; Peldonen 1975) provided indirect evidence about the presence of multiple forms of CYPs. Nebert $(1987,1989)$ claimed that, the P450- mediated monooxygenase system in mammals can be compared to the immune system, due to the fact that a seemingly endless array of chemical specificities for CYPs are possible. The techniques of molecular biology for cloning, and determining the nucleotide sequence of P450 proteins and genes (Fujii-kuriyama et al. 1982; Kawajiri et.al. 1984; Sogowa et al. 1985) provide the means to reveal the presence of multiple forms which couldn't be determined by conventional biochemical methods.

UTERUS: As shown in Figure 1 the body of the uterus is $1 \mathrm{~cm}$ to $1.5 \mathrm{~cm}$ thick which is the muscular portion called the myometrium. This myometrium is covered by a thin layer of mucous membrane called the endometrium. Endometrial tissue consists of two types of cells - glandular cells and stromal cells. A narrow neck is opened to the upper end of the vagina, which is called cervix and this is richly covered with squamous epithelium. Cervix has many cellular types. At the junction of cervix and endometrium is a squamous columnar junction (endocervix), which is typically made up of a combination or continuous transformation of columnar cells and squamous cells. Endometrium is always in a dynamic state of cyclic changes and is subjected to various levels of estrogen and progestrone influence on the development, and differentiation of the tissue during menstrual phase. The endometrium is a rapidly proliferating tissue, which is 
always in an active state of mitotic changes under the influence of various hormones, cytokines, enzymes and various genes. During this process, DNA adducts, if present, could be activating oncogenes or inactivating tumor suppressor genes that lead to neoplastic transformations. There is no published evidence on this to date, although speculations are made by many.

CARCINOGENESIS in UTERUS: Exposure to diethyl stilbestrol (DES) has resulted in cervico vaginal clear cell carcinoma in women and testicular cancer in men (Henderson et al. 1988; Berne, 1992) while prolonged use of anabolic steroids and oral contraceptives is associated with increased risk for developing hepatocellular adenomas and carcinomas. The most widely acknowledged effect of estrogens is increased cell proliferation (Nandi et al. 1995; Ethier, 1995). Recently, it was reported that catechol estrogens can generate metabolites that can directly or indirectly, through redox cycling process, generate reactive radical species causing oxidative DNA damage (Liehr, 1994; Liehr and Roy 1990; Li et al. 1994). Breast cancer has been linked to various environmental xenobiotics or their metabolites, some with estrogenic or androgenic agonist and antagonist activities (Falck et al. 1992; el-Bayoumy 1992; Kelce et al. 1995; MacMahon, 1994; Safe, 1995).

Smoking is known to be causative for many different types of cancers- mouth, pharynx, larynx, oesophagus, lung, pancreas, kidney, bladder, pelvis and uterus (Schwab et al. 1997). Cancer of the urinary bladder is a distant cancer where smoking is also considered to be a causative factor (Hoffman et al. 1976; Molgavkar 1981). The relationship between smoking related cancers like oral, lung, bladder, and cervical cancer has been postulated (Newell et al. 1974; Bailar 1963). An excess of urinary bladder tumors was seen among patients with cervical cancer (Bailair 1963). There is 5-to 6 -fold higher risk of developing subsequent cases of oral 
and pharyngeal tumors among patients with cervical cancer (Newell et al. 1975). Further evidence from Storm and Ewertz (1985) supported that risk of cancers of the lung, oesophagus, bladder, and kidney occurred significantly above expectations in patients who suffered cervical cancer. Among smokers, cigarette smoking appears to be a major risk factor in cervical intra epithelial neoplasia (CIN) and invasive cervical cancer (Hellberg 1986; Nischan et al. 1988). Habitual smoking and number of pregnancies increased the risk of cervical cancer (Hirose et al. 1996). A statistically significant dose-response relationship between cigarette smoking and mortality rate due to uterine cancer was established (Akiba et al. 1990). No rationale has been provided for explaining the relationship between smoking and cervical cancer. There is overwhelming epidemiological evidence linking both of them. In spite of the reported evidence suggesting that the metabolic pathway involving CYP and BP inactivation are implicated in etiology of squamous cell carcinoma of the lung and the relationship of smoking to altered incidence of various malignancies in uterine tissues, an exhaustive online and manual search of biomedical literature for the past 50 years has shown only eleven original research articles reporting CYP450 activity in human or animal uterine tissue. The previous literature until 1985 revolved around characterization of BP metabolism and DNA adduct formation (Dorman et al. 1981; Mass et al. 1981). It was reported that BP metabolites bind to DNA in endometrial tissue cultures (Kaufman et al. 1980; Wilbanks et al. 1980; Dorman et al. 1981; Mass et al. 1981).

The role of BP is linked with lung cancer. The schematic representation of carcinogenic effect from cigarette smoke is given in following Figure 2.1, as summarized by Mohamadi A Sarkar in 1992 in the grant "Role of P450 \& Detoxification Enzymes in Uterine Cancer". 


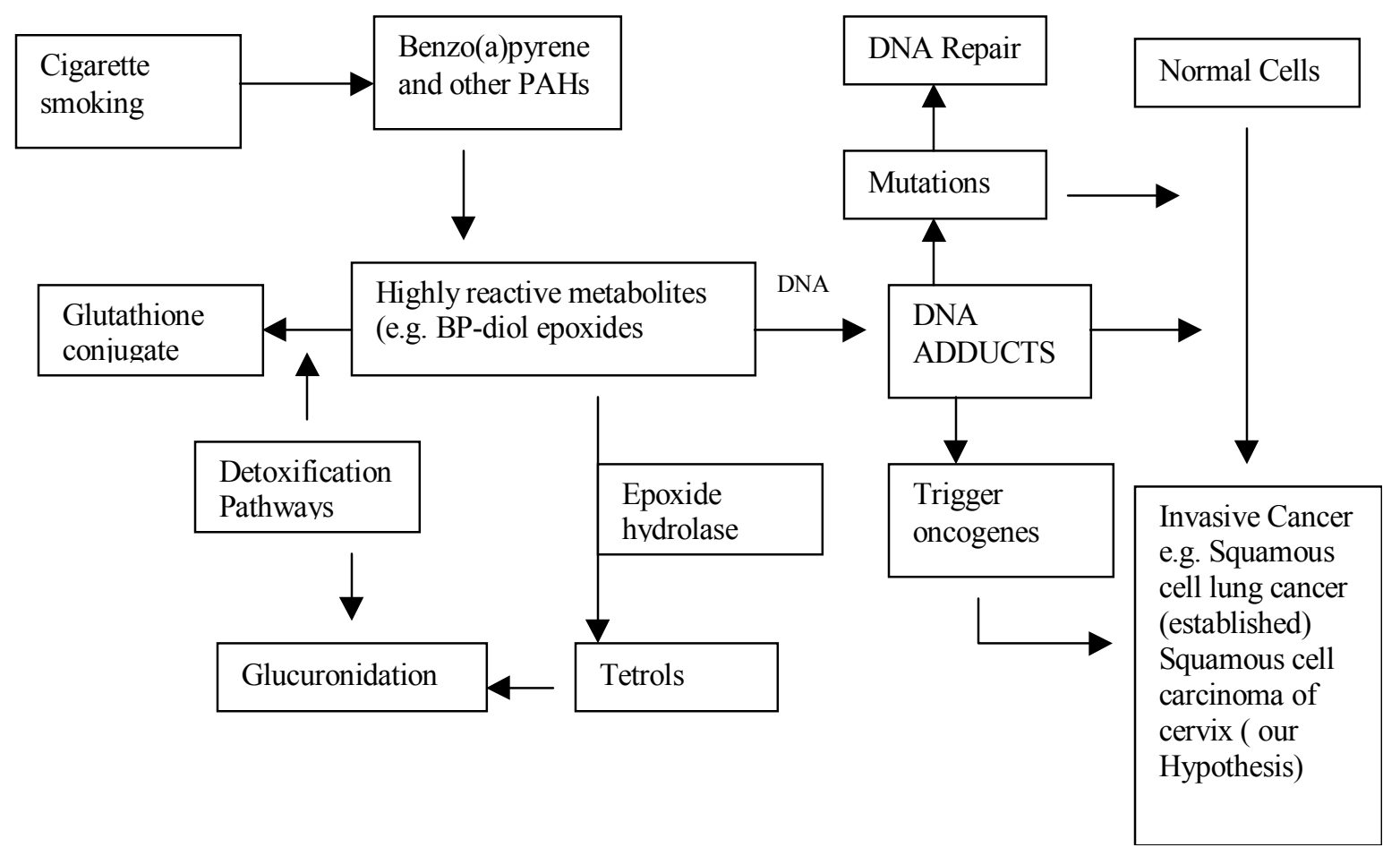

Figure: 2.1 Sequence of events leading to carcinogenic effects from cigarette smoke (MASarkar, 1992)

Carcinogenesis and cellular transformation is a multistep process, starting with initial DNA lesions progressing through impairment and finally loss of normal cellular growth control and gain of invasive and metastatic properties. A number of specific p53 mutations have been identified in many human cancers. The molecular spectrum of p53 mutations has been documented well especially in hepatic cancers, skin and lung cancers. Cigarette smoking is a major risk factor for the incidence of lung cancer. Benzopyrene in cigarette smoke, causes p53 hot spot mutations at codons 157, 248 and 273 in lung cancer. A dose responsive increase of $G$ to T transversion mutations in p53 has been reported in lung cancer (Takeshima et al. 1993). 
Cigarette smoke contains many procarcinogens like (BP), which is a widely studied compound. BP present in cigarette smoke is activated by CYP p450 enzymes such as CYP1A1 to form epoxides which are potentially toxic. These are converted to comparatively less toxic substances such as trans-dihydro diols by enzymes like epoxide hydrolase (EH). Subsequent oxidation results in formation of diol-epoxides, which are toxic. $(+)$ anti-BP-7,8 diol 9,10-epoxide (BPDE) exhibits remarkable potency as a carcinogen on mouse skin and lungs of newborn mice. DNA-BPDE adducts modify normal DNA structure and function (Peldonen et al. 1980). These adducts also have carcinogenic potency in many animal and in vitro systems (Brookes et al. 1964; Goshman et.al. 1967; Shen et al. 1980; Nakayama et al.1984). BPDE- DNA adducts have also been found in the squamous cells of invasive cervical carcinoma patients (Shamsuddin et.al.1988). Although the correlation between CYP1A1 and BP metabolism was well established, carcinogenicity depends on various other related mechanisms like DNA repair mechanisms, alternative detoxifying mechanisms and individual susceptibility, etc. Therefore, it is possible that individual variation in the activity of CYP enzymes could activate the procarcinogens in cigarette smoke and make some of the smoking patients predisposed to uterine cancer.

DRUG METABOLIZING ENZYMES, SMOKING and UTERINE CANCER:

Cigarette smoking can alter the activity of drug metabolizing enzymes like cytochromes, which are involved in metabolizing procarcinogens. Lung cancer patients who were heavy smokers have exhibited higher activities of aryl hydrocarbon hydroxylase (AHH) and epoxide hydroxylase (EH) than nonsmokers. In recent smokers, AHH in lung tissue was positively 
correlated with level of tobacco smoke derived DNA adducts. Epidemiological evidence suggests that cervix and endometrium may be differentially affected by cigarette smoking. Differences in enzyme activity in combination with other factors like DNA repair, genetic polymorphisms in p4501A1 enzymes (Nebert et al. 1989), HPV infections, and immunological status of the individuals will determine the individual susceptibility to uterine cancers. There is ample evidence suggesting that there is correlation between cervical cancer and human papilloma virus (HPV) (Durst et al. 1983; Shiratori et al. 1987). DNA ploidy patterns were reported to be correlated with cervical intraepithelial lesions (Bibbo et al.1989). It can be speculated that HPV infection could be an initiating factor whereas smoking related adduct formation could serve as promoters of the neoplastic lesions. The reduced risk of endometrial cancer in smokers was linked to alterations in the levels of endogenous estrogens (MacMahon et al. 1982). Therefore it was argued that reduced risk of endometrial cancer among smokers could be due to reduced exposure to free or total estrogenic activity (Barber et al. 1989; Khaw et al. 1988). Recent evidence suggests that metabolites of estrogens such as reactive quinones generated from catechol estrogens may act as chemical carcinogens by binding to DNA forming DNA adducts (Li et al. 1994; Liehr et al. 1990). Therefore, it is possible to have many confounding factors in the etiology of uterine cancer, and cigarette smoking could be one of many such factors.

A nonspecific substrate for various CYP enzymes has been reported in uterine tissues, which was formed by hydroxylation of cyclohexane (Senler et al. 1985). These investigators studied only myometrium and leiomyoma conditions possibly due to the abundance of tissue availability and incidence of clinical cases. It is therefore likely that more proliferative 
endometrial epithelium and cervical squamous and columnar cells may have measurable CYP activity especially after being exposed to prolonged smoking, which is likely to induce the enzyme. Recent studies revealed the role of CYP enzymes in uterine tissue especially CYP3A7, which was observed in six out of seven cases correlating to steroid metabolism (Schuetz et al. 1993). Tissues obtained in late proliferative or early secretory phase of menstrual cycle had the highest activity of BP binding to DNA whereas no significant difference on BP metabolites were observed on similar evaluation of endometrial tissue cultures of smokers and nonsmokers (Mass et al. 1981).

One of the earlier experiments involved insertion of a bee's wax thread soaked in 3-methylcholanthrene (3-MC) into the uterus of rabbits. When inserted in a fixed position at various sites of uterine cavity, 3-MC has shown carcinogenic effect on endometrium and cervix (Merriam et al. 1960; Wentz et al. 1981). This suggested that the neoplastic transformation could be due to local activation of PAHs like 3-MC by CYP enzymes.

There are other constituents in cigarette smoke like nitrosamines and other PAHs, which are carcinogenic. However, the focus is on BP which is a more potent carcinogen and commonly seen in the environment also. Its metabolism has attracted a great interest for investigations in animals (Gelboin et al.1980) and in humans (Shimada et al. 1989; McManus et al.1990). CYP1A1 and CYP1A2: $\quad$ BP in cigarette smoke is metabolized primarily by CYP1A1 and CYP1A2, which form reactive metabolites yielding covalent adducts that are likely to result in mutagenicity. In heavy smokers, this possibility is aggravated by activating these CYP enzymes in some tissues leading to various degree of predisposition. So, cigarette smoking not only results in exposure to procarcinogens like BP, but also increases the levels of CYP enzymes in various 
tissues. CYP1A2 is also significantly induced in smokers. This isozyme activates 2acetylaminofluorene (AF), 2-naphthylamine (NA), 4-aminobiphenyl (ABP) and several other heterocyclic amines to their proximate N-oxide metabolites (Butler et al. 1989). The arylamines, NA and ABP are also found in cigarette smoke along with BP which are procarcinogenic. CYP1A2 is less understood than CYP1A1 because of the difficulty in studying it, owing to lack of expression in established cell lines and rapid decrease of expression in isolated hepatocytes. Nuclear run on analysis has indicated that induction of CYP1A2 by aryl hydrocarbons doesn't occur through a transcriptional mechanism but through mRNA stabilization process (Kimura et al. 1986; Pasco et al.1988; Silver et al. 1988). The role of several CYP450 isoforms in catalyzing the hydroxylation of cortisol, testosterone, androstendione, estradiol and progesterone has been established (Berliner et al. 1956; Guengerich et al. 1988; Turkey et al. 1985; Lipman et al.1962). However, it is not clear whether these reactions in the liver have any physiological importance, if any, or simply serve as accessory elimination pathways. We have shown in our lab that the uterus, specifically endometrium and cervix, expressed differential transcription levels of CYP1A1 and CYP1B1 mRNA (Vadlamuri et al. 1998) and it is likely that these extrahepatic CYP450 participate in tissue specific biotransformations which might be of physiologic relevance.

CYP1B1: Recently cDNA clones of mouse, rat, and human CYP1B1 have been reported (Savas et al. 1994; Sutter et al. 1994). CYP1B1 enzyme is constitutively expressed in low levels in many tissues including heart, brain, liver, placenta, lung, kidney, skeletal muscle, spleen, thymus, prostate, testes, ovary, small intestines, colon, and peripheral blood leucocytes. The enzyme was inducible by TCDD in a keratinocyte cell line. Its role in rat has been reported to be 
by oxidation of 7,12 dimethylbenz[a]anthracene (Savas et al. 1994). The human CYP1B1 was recently characterised whose role has been suggestive in estradiol metabolism (Suter et al 1994; Trischer et al. 1996). Recent evidence suggests that CYP1B1 may be primarily involved as $\mathrm{E}_{2}-4-$ hydroxylase enzyme, although the 4-hydroxylation is a minor metabolic pathway and represents a relatively minor level of urinary catechol estrogen content (Fishman et al 1976). It has tissue specific importance, for example the 4-hydroxylation of $E_{2}$ is significant in the metabolic control of estrogen homeostasis and in the human uterus the rate of $\mathrm{E}_{2}$-4-hydroxylation approaches or exceeds that of 2-hydroxylation (Liehr et al. 1995). Therefore, it is likely that localized inactivation of the estrogens in the uterus may be an important determinant in the physiological as well as toxicological outcome. The existence of different isoforms of CYPs in various levels in different regions, impart specificity and characterstic metabolic capacity to each organ. Therefore, the role of these enzymes was considered important in our studies.

CYP3A group: $\quad$ Existence of CYP3A enzymes in the human endometrium was reported by Schuetz et al. (1993) through positive reactivity on immunoblots with antibodies of CYP3A7. However very little CYP3A3/4 was observed in the endometrial tissues. The catalytic specificity of estradiol has not yet been established, however similar to other CYP3A enzymes, CYP3A7 mediates testosterone $6 \beta$-hydroxylation. CYP3A7 has been found to catalyze $16 \alpha$ hydroxylation of dihydroepiandrosterone to estrogen. This finding adds a new dimension to etiology of endometrial carcinoma since high levels of CYP3A7 will result in increased estrogenic exposure which is likely to predispose the individual to development of endometrial cancer. Recently CYP3A7 and CYP3A4 were observed in endometrial tissues where they induced DNA adduct formation during tamoxifen therapy (Hukkanen et al. 1998). In a study 
conducted by Environmental Epidemiology branch of National Cancer Institute, it was reported that the relative risk of cervical cancer in heavy smokers is about four times as great than that of nonsmokers (Brinton et al. 1986). The mucus obtained by cervical washing from smokers was tested to be mutagenic in in vitro testing (Holly et al. 1986). Further, in smokers with intraepithelial neoplasia, levels of nicotine and its major metabolite cotinine, both of which are present in cigarette smoke, were detected in cervical mucus at levels similar to those seen in serum (Hellberg et al. 1988). This evidence confirms that some chemicals and metabolites present in cigarette smoke reach distant organs in the body like the cervix. The evidence that BPDE-DNA adducts are seen in squamous cells of patients with invasive cervical carcinoma indicate that BP in cigarette smoke reaches the uterus (Shamsuddin et al. 1988). Although there is vast evidence correlating HPV infection with cervical cancer, the population studied didn't include smokers. Recent papers suggest that HPV may be less of a risk factor than once thought (Reeves et al. 1989). Thirty percent of patients who were tested negative for HPV had high-grade cervical intraepithelial neoplasia compared to $15 \%$ who were HPV positive. This implies that there is a mechanism, other than HPV, which is important in cervical cancer. It could be possible that a pro carcinogenic mechanism was initiated first and then neoplastic transformation was done with the help of HPV. A similarity could be drawn for this hypothesis with the findings of 1938 where malignancy was experimentally induced with exposure of benign lesions to papilloma virus. It was shown that coal tar induced benign skin lesions in rabbits which were rapidly converted into malignant tumors when rabbit papilloma virus was given by intravenous injection (Rous and Kidd 1938). Therefore, if the cells in cervical squamosa respond to carcinogens like BP from cigarette smoke, as the cells in lung, a similar mechanism could exist 
for both cervical and endometrial cancer. There is evidence that women who smoke reach menopause earlier than those we don't (Daniell et al. 1978). Also, decreased levels of endogenous estrogens in smokers imply that reduced incidence of endometrial cancer could be due to reduced tissue exposure to total estrogenic activity (Barber et al. 1989; Khaw et al. 1988). This is further supported by epidemiological data on increased risk of endometrial cancer among the users of conjugated estrogens (Ziel et al. 1975). The role of estrogen receptors has yet to be investigated since estrogen receptor antagonists like tamoxifen used in breast cancer patients didn't limit the incidence of uterine cancers, particularly endometrial cancers (Fornander et al 1989; Spinelli et al. 1991). Therefore, it is likely that other mechanisms may contribute to endometrial cancers.

CYTOCHROME P450, ESTROGEN METABOLISM and UTERINE CANCER: The metabolic pathways of estrogens reveal that CYP 450 enzymes are involved in various stages of menstrual cycle through hydroxylation reactions. The CYP dependent hydroxylations produce inactive catechol estrogens such as 2-hydroxy estradiol or estrogen agonist like $16 \alpha$ hydroxyestradiol (Michnovicz et al. 1986). In humans estradiol metabolism is primarily mediated by CYP1A2 (Dannan et al. 1986) and to a lesser extent by CYP1A1 and CYP3A4 (Guengerich et al. 1987; Roy et al. 1991). There is evidence that $16 \alpha$ hydroxylation has correlation with cases of endometrial cancer (Fishman et al. 1984). Increased 2-hydroxylation is linked to reduced risk of endometrial cancer (Michnovicz et al. 1986). These findings suggest that shunting the estrogenic pathway in such a way that reducing $16 \alpha$ hydroxylation and in turn increased 2-hydroxylation by CYP1A2 and CYP3A4, could possibly reduce the risk of endometrial cancer. It was shown in rats that 2-hydroxy estrone gets converted to 2, 3 estradiol quinone, which binds tightly to 
CYP1A1. This binding results in elimination of $A h$ hydroxylase activity in kidney as reported by Roy et al. in 1991. So, if the endometrium behaves like kidney, BP activation through CYP1A1 is likely to be bypassed because formation of BPE, a procarcinogen, is not accomplished. These CYP enzymes have in particular links with estrogen metabolism. The smokers have shown a marked increase of 2- hydroxylation of estradiol in liver (Michnovicz et al. 1986). This hydroxylation was modulated by CYP1A2 (Dannan et al. 1986) and also by CYP1A1 (Roy et al. 1991) and CYP3A4 (Guengerich et al. 1988). During a reversible metabolic pathway, estradiol produces 2-hydroxy estrones and 2-methoxy estrones or $16 \alpha$ hydroxyestrone and estriol. These possess potent estrogenicity (Michnovicz et al. 1986). The 2-hydroxylation of estrogens are devoid of peripheral estrogenic activity and high levels of estrogens in plasma are linked to endometrial cancer (Fishman et al. 1984). Therefore, smokers who have excessive 2hydroxylation might be showing reduced incidence of endometrial cancer. Recent evidence suggests that 2-hydroxylated metabolites could be converted to quinones, which inactivate CYP1A1 at least in hamster kidney (Roy et al. 1992). The CYP3A4 which has a wide substrate specificity was implicated in activation of hepatocarcinogen like aflatoxin, so this isozyme may have an active influence along with other CYPs. Estrogens were the main driving force for carcinogenesis with progestins reversing or preventing some of these changes (King 1983) as shown below in the Figure 2.2. 
NORMAL

ESTROGEN

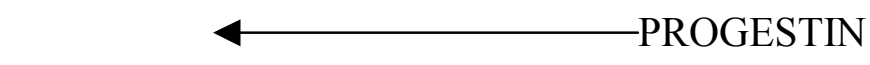

PROLIFERATIVE

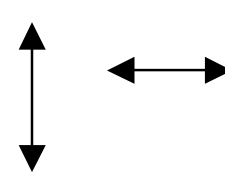

SECRETORY
CANCER

HIGH DOSE OF PROGESTIN
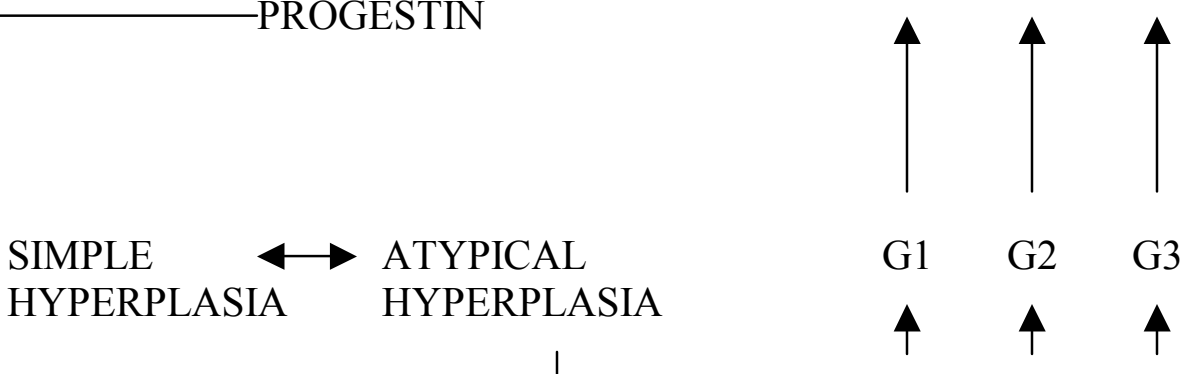

G1 G2 G3

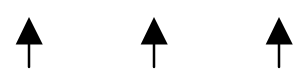

$\downarrow$

INVASION /METASTASIS

Figure: 2.2 Estrogen and Progestin impact on metastasis (king et al. 1983).

Increased proliferation assists in generation of errors such that genetic changes are accelerated (Loeb et al. 1994; Eshleman et al.1995). Estrogens induce apoptosis in the endometrium. Any disruptive change can disturb this link. A pivotal gene linking proliferation and apoptosis is p53 gene, which was inactivated in $20 \%$ of endometrial carcinomas (Homesley et al. 1994). As menstruation is a consequence of progesterone production and withdrawal, inadequate menstrual loss could explain some more risk factors. Estrogens sensitize the cells to progestin action by increasing PR levels, while progestins downregulate estrogen effects by decreasing ER levels through increasing the catabolism of estradiol by induction of estradiol dehydrogenase and differentiation (King et al.1983). Both estrogens and progestins influence proliferation via their own receptors, which are nuclear transcription factors (King et al. 1992) 
Cervical carcinoma is a sporadic cancer for which no familial form has yet been identified, and which so far has not been associated with any inherited syndrome. Loss of heterozygosity ( $\mathrm{LOH})$ in primary cervical carcinomas was initially reported on chromosome 3 in the region 3p14-21 in a small series of nine heterozygous cases (Yokota et al. 1989). A common region of deletion was identified at chromosome 3p13-14.3 with 6 out of 7 cases showing loss of heterozygosity at this region. Chromosome 11 holds promise of another tumor suppressor gene important in cervical carcinomas. $\mathrm{LOH}$ has been described in $36 \%$ of cases at c-Ha-ras locus on chromosome 11p (Riou et al. 1988). Similarly there could be involvement of other tumor suppressor genes in cervical cancer which calls for further investigation.

There are in vitro studies of DNA adduct formation in endometrial cells, which are influenced by hormonal status (Dorman et al. 1981). Cigarette smoke contains many pro carcinogens like PAHs (BP) which are strongly implicated in cancer incidence. Other substances like nitrosamines and 4-methyl nitrosamino-1- (3-pyridyl)-1-butanone (NNK) are also present in significant levels among other 50 or more carcinogens present in tobacco smoke. BP is 200 times more potent than the other carcinogens (Lavoie et al. 1987; Hecht et al.1988). The proposal to study in controlled environment with animal models is not feasible due to the small size of uterus, and thereafter, small amounts of tissues in various regions of uterus render such studies virtually impossible. Further menstruation is unique to primates and in laboratory models we miss this regulatory mechanism which might elicit an important mechanism. The mechanism of BP causing cancer can't be established by direct studies in humans. However indirect evidence suggests the BP activation can initiate carcinogenesis. 100\% of animals receiving low intravenous doses of BPDE developed tumors in lung (Conney et al. 1982). 
There is ample evidence that smoking is associated with lung cancer in humans. AHH activity as a measure of CYP1A1 was found to be high in smokers and its association with peripheral adenocarcinoma of lung was well established (Anttila et al. 1991). Smokers have shown greater BPDE-DNA adducts which are suggestive of carcinogenic precurssors (Geneste et al. 1991). The smokers with homozygous rare allele of CYP1A1 locus exhibited higher risk for lung cancer in comparison with other genotypic combinations (Kawajiri et al. 1990). Therefore, based on the similar mechanism of lung cancer we would like to evaluate the genetic make up of uterine cancer with respect to toxicological activation by CYP enzymes especially CYP1A1, 1B1 and $3 \mathrm{~A} 3 / 3 \mathrm{~A} 4$ and or $3 \mathrm{~A} 7$. The relative abundance of these important isozymes will be studied in designated regions of uterus among smokers and nonsmokers. 


\section{CHAPTER 3}

DESCRIPTION OF PROBLEM 


\section{DESCRIPTION OF PROBLEM}

It was widely reported that cervical cancer is predominantly seen among women with a history of prolonged smoking whereas the incidence of endometrial cancer is decreased by almost 50\% in post-menopausal women who are smokers. These two regions - endometrium and cervix, are less than $10 \mathrm{~cm}$ apart in the same organ yet exhibit different carcinogenic property. This differential disposition could be explained through metabolic pathways of cytochrome P450 (CYP). Some of these CYP s activate chemical carcinogens to their electrophilic forms which can bind to DNA covalently and cause mutation that trigger carcinogenesis. Among the various CYP s, CYP1A1, CYP1B1, and the CYP3A family are primarily implicated due to their metabolic pathways involving polycyclic aromatic hydrocarbons such as benzo (a) pyrene, estrogens, steroids etc. Therefore, the goal of the study was to investigate the expression of these CYP isoforms in different regions of the uterus among smoking and nonsmoking women.

$\mathrm{BP}$ as already known, is usually metabolized by CYP enzymes - CYP450 1A1 and 1A2

(Figure 3.1). We propose that BP, the potent procarcinogen present in cigarette smoke, gets transported to many tissues in the body including uterus. It gets metabolized into BPDE through metabolizing enzymes such as CYP1A1 and CYP1A2 and CYP3A3/A4 in various tissues such as lungs, uterus, etc. The BPDE, thus available in some parts of uterus, is likely to bind to DNA in the various regions of uterine tissue, which can cause mutation or activate oncogenes.

The proposed scheme of BP metabolism relevant to our hypothesis is given in the following diagram as shown in the NCI grant \# CA-62369 by Mohamadi A Sarkar. 


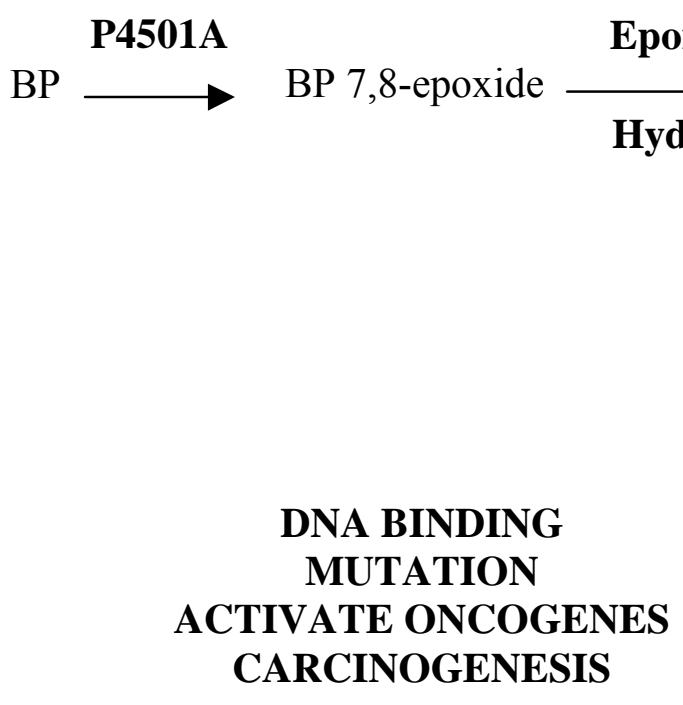

Figure: 3.1 Proposed Biotransformation scheme for Benzo(a)pyrene (BP) (Mohamadi A Sarkar, 1992. NCI grant \# CA-62369)

CYP enzymes also are involved in estrogen metabolism. These enzymes have an active role in endometrium especially where role of estrogen was predominantly seen. We propose the scheme of estrogen metabolism, which is likely to trigger carcinogenesis in uterus in the following diagram: 


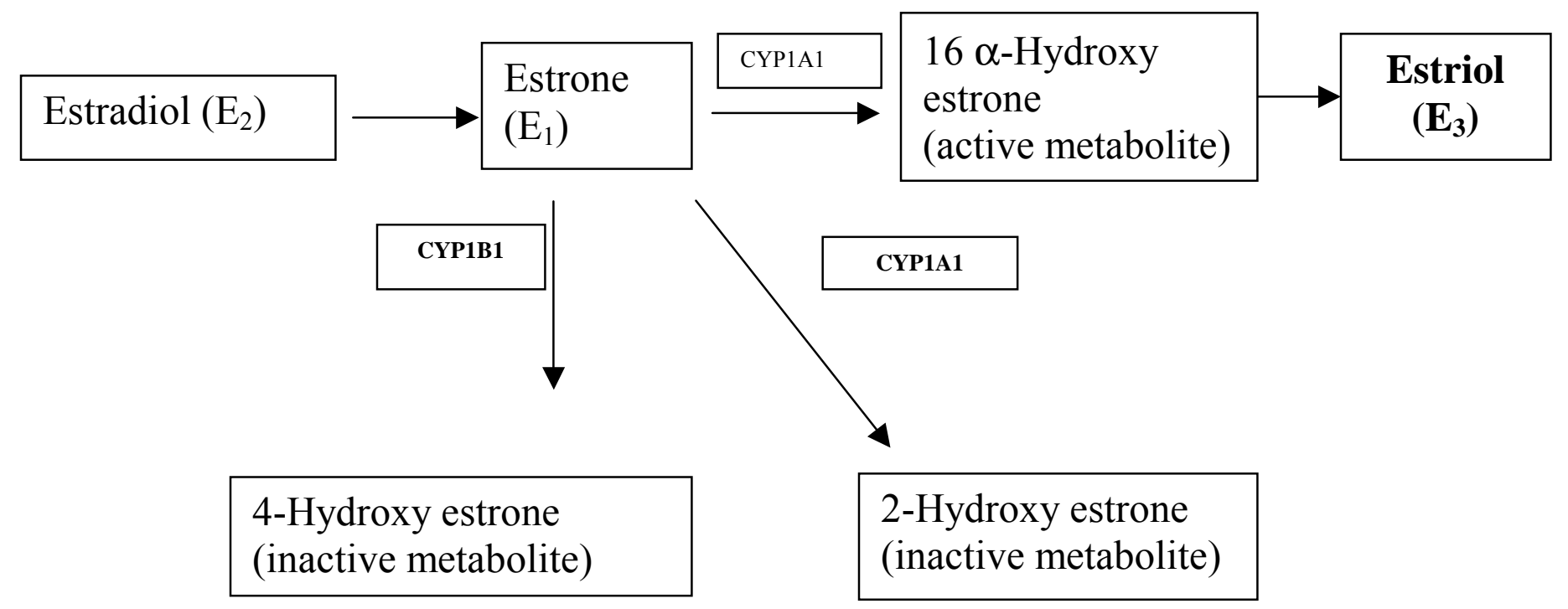

\section{Quinone intermediates}

Figure: 3.2 Proposed metabolic scheme for estrogens modified from Yager et al (1996)

The CYP enzymes like CYP1B1 and CYP3A group (especially CYP3A3/4 and CYP3A7) are actively involved in estrogen metabolism. These enzymes also indirectly influence the carcinogenicity through estrogen mediated pathway. The metabolites of CYP enzymes are hydrophilic which can conveniently form covalent structures with DNA if not excreted fully. The DNA is in active state of multiplication in uterus due to cyclic changes. This offers an immediate possibility to influence tumorigenesis. 
In heavy smokers the problem of over expression of CYP enzymes contribute to the formation of excessive reactive metabolites possibly due to excessive release of BP into tissues and accelerated CYP activity. There is ample evidence showing that free estrogens contribute to incidence of breast cancer. The cytochrome mediated metabolism of estrogens releases free catechol estrogens. Therefore sensitive tissues in uterus get exposed to these estrogens which are likely to contribute to neoplastic transformations.

\section{HYPOTHESIS:}

The levels of one or more of CYP enzymes were involved in the activation of benzo (a) pyrene which may be causing the increased risk for cervical or endometrial cancer. Smoking induces the activation of CYP1A1 and /or CYP1A2, which may be a major cause of cervical cancer. Induction of those isozymes might decrease the risk of endometrial cancer due to decreased estrogenic activity, which was known to be a risk factor in endometrial cancer.

\section{AIMS:}

1. To investigate and identify the Cytochrome P- 450 expression viz.: CYP1A1, CYP1B1, and CYP3A group in the endometrial, endocervical and/or squamous cell regions (exocervix) of human uterus.

2. To evaluate the intensity of expressions at mRNA level in various regions of the uterus.

3. To analyze the expression levels of CYP1A1, CYP1B1, CYP3A3/A4 and CYP3A7 in women at various phases of their menstrual cycle.

4. To assess the significance and differentiate expressions among smokers and nonsmokers. 


\section{CHAPTER 4}

MATERIALS AND METHODS 


\section{MATERIALS AND METHODS}

\section{Materials and Equipment used:}

The list of materials, equipment and buffers used are given in Appendix: D.

\section{Methods:}

The protocol involving collection of tissue samples from patients was approved by the West Virginia University Institutional Review Board. The uterine tissue samples were collected from women undergoing hysterectomy for various benign clinical conditions. Clinical history and other demographic details were obtained from clinical records. The format employed to collect data is presented in Appendix: E.

\section{Tissue Procurement}

Uterine tissue was obtained initially from six non-smoking pre-menopausal women undergoing hysterectomy for benign indications. The tissues were collected within 30 minutes of surgery, from three different regions of the organ, carefully sectioned to maintain sampling consistency. The endometrium was obtained by scrapping the posterior surface of the inner lining of the fundus of the uterus. A thin layer of tissue was excised from the cervical canal at 6'o clock position, to include the endocervix and squamocolumnar junction. The ectocervix or squamous (exocervix) region was sectioned from the anterior region of the cervical. The tissues were collected in separate containers and stored immediately at $-70^{\circ} \mathrm{C}$. The quantities of samples collected are shown in the Figure 4.1 
Size of tissue obtained after sampling from a typical uterus

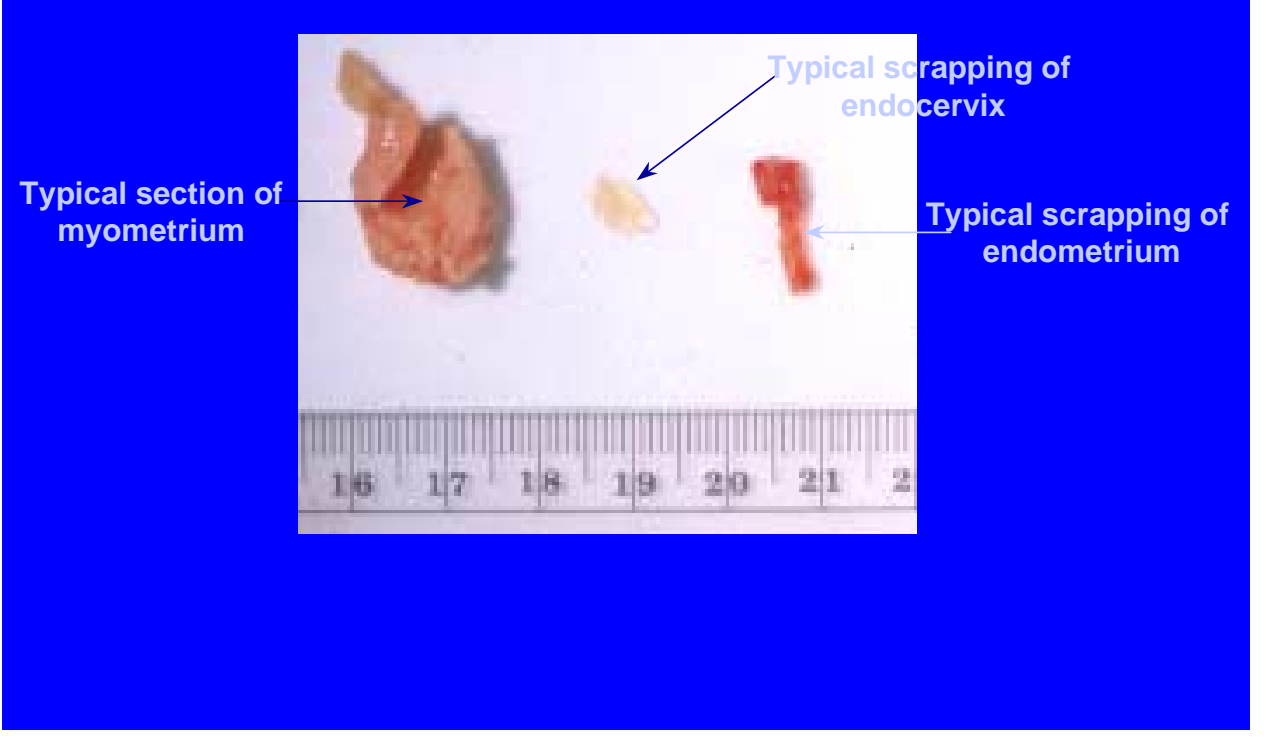

Figure: 4.1 Tissue sampling procedure

Initially the samples were collected from six patients and RNA extraction was done. Subsequent to analyzing these samples for the expression of CYP1A1 and CYP1B1 and optimizing the PCR protocols, tissue procurement continued for a total of 36 patients in a similar fashion over a period of 2 years. The limitation of obtaining tissue samples from clinical subjects was compounded due to competitive requirements of tissues for pathological studies, clinician's preferences and patient willingness.

\section{RNA Procedures}

\section{RNA extraction}

Total RNA was extracted from the tissues by homogenizing the tissue in liquid nitrogen and quickly transferring to $3 \mathrm{ml}$ of RNA STAT-60 (Tel-Test inc., Friendswood, TX) reagent. A 
standard extraction protocol involving RNA STAT-60 kit was used, yielding $50 \mu \mathrm{g}-100 \mu \mathrm{g}$ RNA from 50-300 mg of tissue.

\section{RNA quantification}

RNA concentrations were measured at $260 \mathrm{~nm}$ on a Beckman UV spectrophotometer and the Abs $260 / 280$ was $>1.5$ for all samples. The procedure to operate the UV spectrometer was as per the manual. The RNA concentrations were calculated after adjusting to the dilutions used in measuring the absorbance. The final concentrations of the samples are provided in Table in Appendix: F.

\section{RNA quality analysis}

The extracted RNA was run on $1.2 \%$ agarose formaldehyde denaturing gel electrophoresis to check the quality of RNA isolated. The quality of RNA was checked for DNA contamination, degradation due to RNases and also visual verification of $28 \mathrm{~S}$ and $18 \mathrm{~S}$ bands.

\section{Reverse - Transcription polymerase chain reaction (RT-PCR) of CYP mRNAs}

cDNA was synthesized in a total volume of $20 \mu \mathrm{l}$ of reaction mixture containing $2 \mu \mathrm{g}$ of total RNA in the reverse transcription reaction buffer (Gibco-BRL, Gaithersburg, MD), 10mM DTT, $25 \mu \mathrm{g} / \mathrm{ml}$ of oligo(dT), $0.5 \mathrm{mM}$ of each dNTP, $25 \mathrm{mM} \mathrm{MgCl}_{2}$ and 200 units of M-MLV reverse transcriptase (Gibco-BRL). Samples were incubated at $42^{\circ} \mathrm{C}$ for $50 \mathrm{~min}$ and the reaction was terminated by heating at $95^{\circ} \mathrm{C}$ for $5 \mathrm{~min}$., followed by quick chilling on ice. Target sequences were amplified in a $100 \mu \mathrm{l}$ reaction mixture containing $15 \mu \mathrm{M}$ of each primer, and 5 units of Taq polymerase (Promega Corporation). After addition of $100 \mu$ l of mineral oil in PCR tubes $(0.5 \mathrm{ml})$, preincubation for $5 \mathrm{~min}$ at $95^{\circ} \mathrm{C}$ was carried out followed by thirty cycles of amplification using a thermal cycle program consisting of $94^{0} \mathrm{C}$ for $30 \mathrm{sec}$ of denaturation, $62^{0} \mathrm{C}$ 
for $30 \mathrm{sec}$ annealing, and $72^{\circ} \mathrm{C}$ for $1 \mathrm{~min}$ of extension on Perkin Elmer - Thermal Cycler system 480. The PCR products $(15 \mu \mathrm{l})$ were directly separated through $2 \%$ agarose gel electrophoresis and visualized by ethidium bromide staining. Sizes of the PCR products were estimated from the migration of the DNA size markers (2000 kb ladder - BioRad) run concurrently.

\section{Semiquantitaive Analysis:}

Densitometric analysis was carried out on those gels where PCR products were resolved using an image analysis (Optimas) software. Care was taken to follow uniform conditions throughout and to observe the same settings on the threshold values, microscopic lens, gel thickeness, quantity of PCR product loaded and other parameters. The quantitative values were further corrected/adjusted with the actual amount of mRNA used initially in the reaction.

Control RNA (891-bp CAT derived) was included to verify the PCR reaction. The quality of RNAs was evaluated through the expression of $\beta$-actin gene. The primers for $\beta$-actin were obtained from Clonetech (Palo Alto, CA). $\quad \beta$-actin was positive for all tissue samples. Contamination with genomic DNA was ruled out from the negative results obtained when the RT-PCR was performed without the reverse transcriptase.

The quantity of the PCR product was measured as a ratio of its optical density with that

of house keeping gene $-\beta$ - actin from same RNA. $\beta$ - actin was amplified with same conditions and same amount of mRNA. The $\beta$ - actin expression was optimized before quantifying in a similar way to amplified CYP1A1 and CYP1B1 genes.

The sequences of primers used for the PCR reaction have been identified and used by other researchers, therefore no further confirmation of the PCR product was considered 
necessary initially. However in subsequent experiments the PCR products were confirmed by hybridizing with internal oligos of the PCR product.

\section{Primers}

Sequences utilized for the preparation of forward (FP), and reverse (RP) PCR primers were as follows:

*CYP1A1: $\quad$ FP: 1729-1749: 5'-TAG ACA CTG ATC TGG CTG CAG - 3'

RP: 1856-1875: $\quad$ 5'- GGG AAG GCT CCA TCA GCA TC - 3'

**CYP1B1: $\quad$ FP: +1758 - +1777 5' - AAC TGT CCA TCA GGT GAG GT - 3'

RP: +2227 - +2248 5' - TAA GGA AGT ATA CCA GAA GGC - 3'

* $\quad$ Shimada, T. et al. 1989

** Denissenko, M. F. et al. 1996.

\section{Endometrial dating - proliferative and secretory endometrium}

The endometrial dating was accomplished by a pathologist, using a light microscope, according to the technique of Hertig and classified as either proliferative or secretory.

\section{Patient Demographics:}

Patient ages ranged from 25-78 years and weight from 112-277 pounds (Tables 1 and 2). None of the patients were taking medications that could potentially induce CYP450 activity. Seven of the twenty-two patients had uterine leiomyomata (fibroid uterus) and 5 patients had endometriosis. Three patients had endometrial hyperplasia, one patient had adenocarcinoma of the endometrium and one patient had Stage I - Squamous carcinoma of the cervix. Additionally, 
one patient (ID \# 10) had previously been treated for CIN III with a cone resection. In the patient with cancer, an attempt was made to obtain tissues from non-neoplastic regions if the tumor area was visibly discernable.

\section{Titration Analysis to determine linearity for sample comparison:}

Serial dilution of cDNA was performed and the diluted cDNA was amplified by PCR.

The PCR products exhibited excellent linearity $\left(r^{2}=0.97\right)$ over a concentration range of $0.6-0.75$ $\mu \mathrm{g} / \mu \mathrm{l}$. The correlation was evaluated by comparing the optical density of the PCR product, using densitometric analysis, with relative amounts of mRNA determined from the serial dilution of cDNA.

\section{Probes:}

The probes used to confirm the PCR products were oligos identified from internal sequences of the amplified fragment. The sequences are $18 \mathrm{nt}$ and $17 \mathrm{nt}$ long from antisense strand in the coding region of CYP1A1 and CYP1B1, respectively.

\section{Probe for CYP1A1： 5' - TAG GGG CAG GCA GGA TCC-3' (1780-1798) \\ Probe for CYP1B1: 5 '- CTC CCA GAA GCT CCT GC - 3' (2509-2526)}

\section{Southern Blot analysis:}

PCR products were analyzed by electrophoresis with ethidium bromide staining on $2 \%$ agarose gel with TBE buffer. The DNA markers (Bio-rad) were loaded to assess the sizes of the fragments. After electrophoresis the gels were denatured and blotted to Zeta probe Nylon 
membrane (Bio-rad) with 10x SSC overnight. Other sets of blots (transfer membranes) were also prepared where transfer was done by alkaline transfer method using $0.4 \mathrm{~N}$ sodium hydroxide solution. Membranes, except those done by the alkaline transfer, were cross linked by a UV cross linker (Stratagene). Membranes were prehybridized for one hour at $42^{\circ} \mathrm{C}$ for CYP1A1 and $38^{0} \mathrm{C}$ for CYP1B1 probes. Hybridization was accomplished overnight at $42^{\circ} \mathrm{C}$ and $38^{0} \mathrm{C}$ for CYP1A1 and CYP1B1, respectively, in the presence of formamide $50 \%$, SDS 7\%, $1 \mathrm{M}$ of $\mathrm{Na}_{2} \mathrm{HPO} 425 \%$, $5 \mathrm{M} \mathrm{NaCl} 5 \%, 0.5 \mathrm{M}$ EDTA $0.2 \%$ and Salmon sperm DNA ( $1 \mathrm{mg} / \mathrm{ml}$ solution) $1 \%$ in final concentration. After hybridization, the membranes of CYP1A1 were washed twice with solutions containing $2 \mathrm{xSSC}, 0.1 \% \mathrm{SDS}$ at $36^{\circ} \mathrm{C}$ for 15 minutes. This step was followed by a low stringency wash with $0.1 \% \mathrm{SDS}, 25 \mathrm{mM} \mathrm{Na}_{2} \mathrm{HPO}_{4}$ and $1 \mathrm{mM}$ of EDTA at $29^{\circ} \mathrm{C}$ for 15 minutes twice and by high stringency wash once for 20 minutes at $42^{0} \mathrm{C}$. Whereas for membranes of CYP1B1 the washes were done at $30^{\circ} \mathrm{C}$ for 15 minutes twice with buffer containing $2 x S S C$, $0.1 \%$ SDS followed by one wash at room temperature for 15 minutes with $0.1 \%$ SDS, $25 \mathrm{mM}$ $\mathrm{Na}_{2} \mathrm{HPO}_{4}$ and $1 \mathrm{mM}$ of EDTA. The probes were found to hybridize with PCR fragments, which were detected by exposing the membranes in overnight Phosphor-imager screen.

\section{Expression of CYP3A group of isozymes:}

CYP3A isozymes have $60-80 \%$ homology among all the members of the group. As a result, for the individual CYP3A, false positives and cross reaction with primers could not be completely eliminated. Further, the specificity of the primers for single isozyme can not be established in view of the close homology between members of CYP3A and individual variation among patients is also random. To circumvent this difficulty in expressing the CYP3A isoforms we adopted an approach as suggested by Dr. Thomas A Kocarek, Institute of Chemical 
Toxicology, Wayne State University, MI. Accordingly, a set of common primers was designed using software and the CYP3A was amplified from the mRNA. These primers were common to all CYP3A family of isozymes and as a result any one or two isozymes were amplified if present. The amplified PCR products were transferred to Zeta probe Nylon membranes and tested with individual probes of CYP3A3/4, CYP3A7 isozymes. CYP3A3 and CYP3A4 have 90\% homology in human sequences and exhibited similar induction pattern. Hence we considered one probe for CYP3A3/4 isozyme. The sequence alignment and identification of the forward and reverse primers are given in the Figure 4.2.

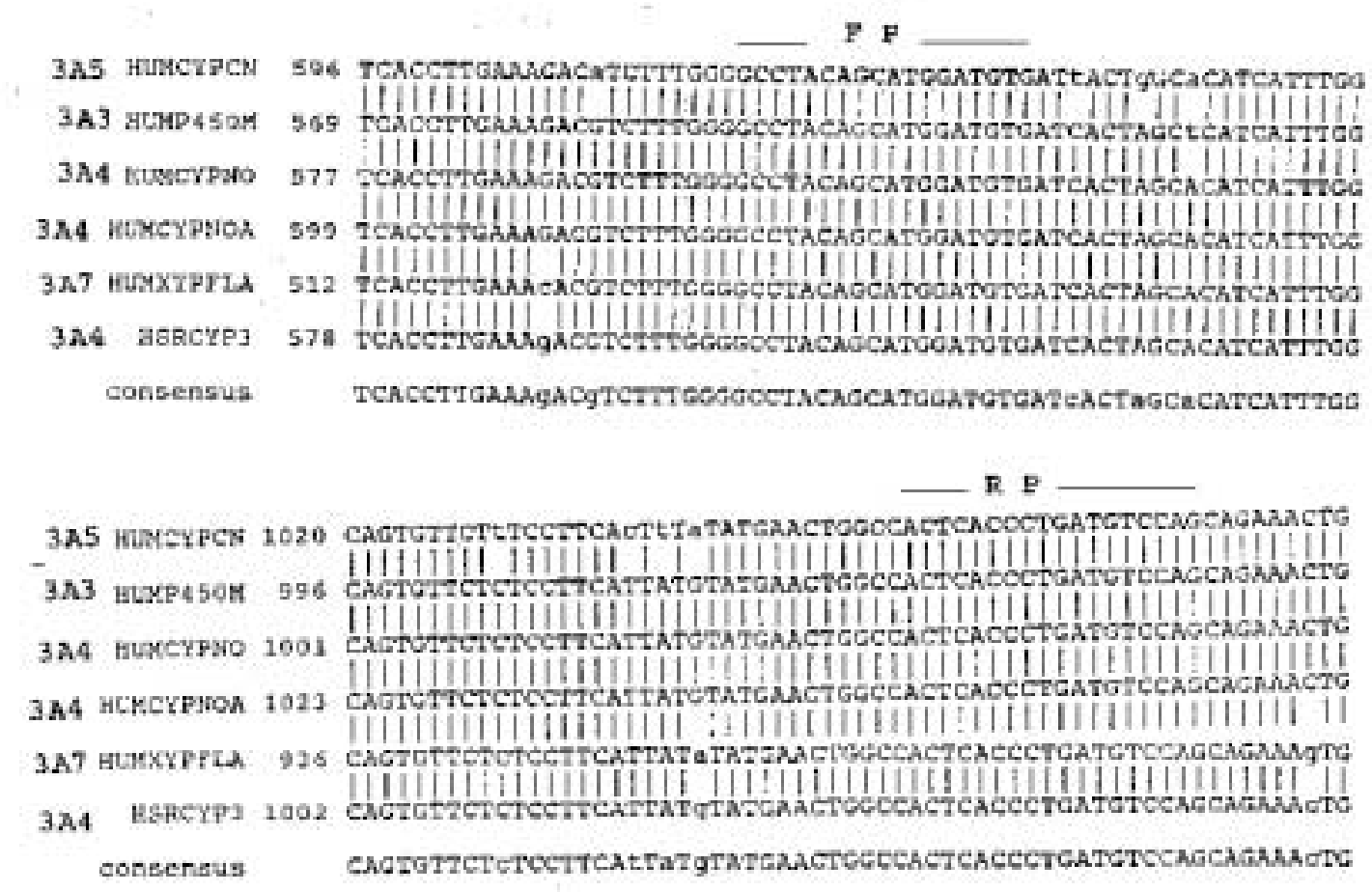

FP: Forward primer

RP: Reverse primer

Figure: 4.2 CYP 3A group sequences are aligned as obtained by using computer program.

Forward primer and Reverse primer locations are identified and marked as FP and RP. 


\section{Primer Design for CYP3A group of isozymes:}

As shown in Figure 4.2, sequences of all human CYP3A isozymes were aligned using a software and examined for common overlapping sequences.

The 619 to $636 \mathrm{nt}$ region and $1055-1072 \mathrm{nt}$ region among all the CYP3A sequences are common.

\section{Primers}

Sequences utilized for the preparation of forward (FP), and reverse (RP) PCR primers were as follows:

CYP3A

FP: 619-636: $\quad$ 5'- GCC TAC AGC ATG GAT GT - 3'

RP: 1055-1072: $\quad$ 5'- TGG ACA TCA GGG TGA GT - 3'

The specific probes for the CYP3A3/4 and CYP3A7 were identified from the sequences aligned.

\section{Probes}

The probes utilized for hybridization were as follows:

CYP3A4 :

759-779 5' - CTT AAA AAA TTT GTA ACT TC - 3'

CYP3A7 :

642-662 5' - CGA ATG GAT CTA ATG GAT TA - 3' 


\section{Reverse - Transcription polymerase chain reaction (RT-PCR) of CYP3A mRNAs}

The PCR reaction was carried out using the consensus primers for CYP3A in the region of $619 \mathrm{nt}$ to $1072 \mathrm{nt}$. The target complimentary DNA (cDNA) was synthesized from total RNA by RT-PCR reaction catalyzed by superscript II RNase H - reverse transcriptase (RT) enzyme(Gibco-BRL) carried out in a Perkin Elmer - Thermal Cycler system - 2400. First strand cDNA was synthesized in a total volume of $20 \mu \mathrm{l}$ of reaction mixture containing $2 \mu \mathrm{g}$ of total RNA in the reverse transcription reaction buffer (Gibco-BRL, Gaithersburg, MD), 10mM DTT, $25 \mu \mathrm{g} / \mathrm{ml}$ of oligo(dT), $0.5 \mathrm{mM}$ of each dNTP, $25 \mathrm{mM} \mathrm{MgCl}_{2}$ and 200 units of M-MLV reverse transcriptase (Gibco-BRL). Samples were incubated at $42^{\circ} \mathrm{C}$ for $50 \mathrm{~min}$ and the reaction was terminated by heating at $95^{0} \mathrm{C}$ for $5 \mathrm{~min}$., followed by quick chilling on ice. The reaction samples were further incubated with 100 units $/ \mathrm{ml}$ of RNase $\mathrm{H}$ for 20 minutes at $37^{0} \mathrm{C}$. Target sequences were amplified by hot start PCR at $94^{\circ} \mathrm{C}$ in a $20 \mu$ l reaction mixture containing $2 \mu \mathrm{M}$ of each primer and 1 unit of Taq polymerase (Promega). The sample tubes $(0.2 \mathrm{ml})$ were preincubated at $94^{0} \mathrm{C}$ for $1 \mathrm{~min}$ before the addition of Taq polymerase and followed by forty cycles of amplification using a thermal cycle program consisting of $94^{\circ} \mathrm{C}$ for $20 \mathrm{sec}$ of denaturation, $54^{0} \mathrm{C}$ for $20 \mathrm{sec}$ of annealing, and $72^{0} \mathrm{C}$ for $1 \mathrm{~min}$ of extension. The PCR reaction products $(10 \mu \mathrm{l})$ were separated through $2 \%$ agarose gel electrophoresis and visualized by ethidium bromide staining. Sizes of the PCR products were estimated from the migration of the DNA size markers (2000 kb ladder - BioRad) run concurrently.

Control RNA (891-bp CAT derived) was included to verify the PCR reaction. The quality of the RNA was examined by electrophoresis of $5 \mu \mathrm{g}$ RNA in $1.2 \%$ denaturing agarose gel (formaldehyde gel) and also evaluated through the expression of $\beta$-actin gene. The primers 
for $\beta$-actin were obtained from Clonetech (Palo Alto, CA). $\quad \beta$-actin was positive for all tissue samples. Contamination with genomic DNA was ruled out from the negative results obtained when RT-PCR was performed without the reverse transcriptase. Direct sequencing of PCR products did confirm the target sequences with $99 \%$ accuracy with a $1 \%$ base pair mismatch.

\section{Hybridization analysis:}

The method as given in current protocols (Frederick et al. 1987) was followed with some modifications. After electrophoresis the gels were denatured and blotted to Zeta probe Nylon membrane (Bio-rad), where transfer was done by alkaline transfer method using $0.4 \mathrm{~N}$ sodium hydroxide solution. Membranes were hybridized with the specific internal probes for CYP3A3/4 and CYP3A7.

The probes were obtained from Gibco-BRL and end labeled at the 5 ' end with $\gamma^{32-} \mathrm{P}$ dATP (Redivue - Amersham) using 5'-End labeling system (Promega). The probes were made with 10 pmoles of oligo incubated with $\gamma-{ }^{32} \mathrm{P}$ ATP and T4 polynucleotide kinase in $1 \mathrm{x}$ forward reaction buffer at $37^{\circ} \mathrm{C}$ for 30 minutes. The reaction containing the probes were purified by separating the unincorporated oligos with G-50 Sephadex columns (Boehringer Mannheim ). The specific activity obtained for the probes was $137000 \mathrm{cpm}$ to $156000 \mathrm{cpm}$ per 10 pmoles as measured in a scintillation counter.

The membranes were transferred to hybridization flasks without any air bubbles between the membranes and wall of the glass flasks. These membranes having the CYP3A products were initially prehybridized with hybridization buffer at $65^{\circ} \mathrm{C}$ for $2-4$ hours. Then the membranes were incubated overnight with probes $(25 \mu \mathrm{l}$ final volume) in $8 \mathrm{ml}$ of 
hybridization buffer. The hybridization and washes were undertaken in hybridization oven (Stovall).

Wash solutions included wash buffer containing $5 \mathrm{X}$ SSC, and 0.1\% SDS which was used for $15 \mathrm{~min}$ at $34^{0} \mathrm{C}$, followed by buffer II containing $\mathrm{NaHPO}_{4} 25 \mathrm{mM}$, EDTA $1 \mathrm{mM}$, SDS $0.1 \%$ at $29.5^{0} \mathrm{C}$ for $15 \mathrm{~min}$. A final wash was done with buffer II above at room temp for 15 minutes. The probes were found to hybridize with PCR fragments, which were measured after overnight exposure of the membranes on a Phosphor-imager screen.

\section{Reconfirmation of the probe specificity:}

The probes were stripped from the respective membranes by incubating in warm $\left(37^{0} \mathrm{C}\right)$ stripping solution containing $20 \% \mathrm{SSC}$ until the buffer attained room temperature. The membranes were then hybridized by interchanging the probes and evaluated as to the relative intensities of expression of $3 \mathrm{~A} 4$ and $3 \mathrm{~A} 7$ on the membranes. This process eliminated the possibility of any non-specific hybridization, and confirmed that the expression levels of $3 \mathrm{~A} 4$ and 3A7 remained similar after interchanging the probes on the same membranes to that of different membranes.

\section{ImageQuant Analysis:}

The relative abundance of hybridization was measured by using ImageQuant software under uniform parameters of equal area, pixels, color intensity values etc., after correcting for background intensity with relative areas at the same lane of fragment movement in respective gels. The values generated were analyzed using JMP software (SAS Institute, NC). 


\section{Data Analysis:}

Statistical analyses were carried out using JMP Software (SAS Institute, NC).

Comparisons were made using a multi-factor analysis of variance. The values of density of the probe as measured in a phosphor imager were adjusted to that of initial mRNA concentrations and then as a ratio of its density with that of housekeeping gene - $\beta$ - actin from the same RNA. $\beta$ - actin was amplified with the same conditions and same amount of mRNA. The differences in optical density of probes as obtained by computerized image analysis were evaluated between different regions of the uterus with respect to smoking status and menstrual phase. 


\section{CHAPTER 5}

RESULTS 


\section{RESULTS}

\section{Expression of CYP1A1 and CYP1B1 in nonsmokers:}

The patient demographics are shown in Table 1 for the first six patients used as a model to analyze the expression of CYP1A1 and CYP1B1 among nonsmokers. The findings have been published in Cancer Letters 122, (1998), pp $143-150$.

The age of the patients ranged from 37-48 years and weight ranged from 135-277 lbs. None of the patients were on any comedications that could potentially induce CYP450 activity. Four of the six patients had uterine leiomoyma and all except one patient were in the proliferative phase of their menstrual cycle.

The expression of CYP1A1 and CYP1B1 in different regions of the human uterine tissue is shown in Figures 5.1 and 5.2 respectively. The transcripts encoding CYP1B1 were uniform in the endometrial region for all the patients except one where it was significantly decreased $(\mathrm{p}<0.05)$. The endometrium in this patient was in the secretory phase, whereas all the other endometrial tissues were in the proliferative phase. The transcripts encoding for CYP1B1 were significant in only $2 / 6$ patients in the squamous region (exocervix) and minimal in the endocervix. The expression of CYP1A1 appeared to be increased in one patient (Pt. \#3) in all three regions, yet the patient history did not give any indications to suggest enzyme induction. The same patient also had induced levels of CYP1B1 mRNA in the squamous region (exocervix) and endocervix. A semi-quantitative analysis of the optical density of the RT-PCR products by densitometry yielded results as shown in Figure 5.3. The endometrium appeared to have the highest degree of transcripts encoding for CYP1B1 whereas the endocervix had the least expression of both the isoforms. 


\section{Expression of CYP1A1 and CYP1B1 in Nonsmokers and Smokers and with respect to Menstrual phase:}

Transcripts encoding for CYP1A1 and CYP1B1 mRNA were observed in different regions of the human uterus as shown in Figures 5.4 and 5.5 respectively. The demographics of all the 22 patients for this analysis is given in Table 2. The measured levels of CYP1A1 and CYP1B1 for all patients are given in Tables 3 and 4. There were no differences in $\beta$-actin mRNA levels for each sample (data not shown), confirming that equal quantities of mRNA were used in all analyses. CYP mRNAs detected in samples stored at $-70^{\circ} \mathrm{C}$ (stored for less than 3 months) were comparable to those extracted from fresh samples. Electrophoretic mobility of the PCR products was at the expected molecular weights in all samples, enabling comparison of relative expression of mRNAs in the different regions from each individual. The transcripts of these two CYPs in all the three regions of uterus among nonsmokers and smokers are shown in Figures 5.6 (endometrium), 5.7 (Cervix) and 5.8 (Squamous region). No difference for CYP1A1 mRNA expression could be observed in the three regions when compared to proliferative or secretory phases of menstrual cycle.

\section{CYP1A1 and CYP1B1 in the Endometrium:}

CYP1A1 (Figure 5.4) and CYP1B1 (Figure 5.5) were expressed in the endometrium of all patients except Pt. \#10 whose endometrium was hyperplastic. CYP1A1 was expressed in the endometrium of all except one patient but expression was minimal in other regions.

Expression of CYP1B1 was significantly higher in endometrium and extremely low in secretory stage of menstrual phase. Densitometric analysis of the CYP1B1 PCR product relative to $\beta$-actin 
mRNA indicated a 20-fold greater level of CYP1B1 expression (Figure 5.12) in proliferative endometrium compared to secretory endometrium which was statistically significant $(\mathrm{p}<0.05)$. Comparison of CYP1B1 expression in the endometrium from smokers and nonsmokers indicated an apparent reduction in the mRNA coding for CYP1B1 in smokers which was not statistically significant (Figure. 5.11). This difference could be confounded due to a preponderance of secretory endometrium in the smoker group (6/11). The apparent differences in CYP1B1 expression for proliferative endometrium remained significant, even after separating the smokers from the nonsmokers. On the other hand, no significant differences in mRNA for CYP1A1 $(p>0.05)$ were observed in the endometrium from smokers compared to nonsmokers (Figure 5.9) and when comparing the proliferative to the secretory endometrium (Figure 5.10).

\section{CYP1A1 and CYP1B1 in the Cervix:}

The mRNA levels for CYP1A1 and CYP1B1 were variable in both smokers and nonsmokers (Figures 5.4, 5.5 and 5.7). While 3/11 nonsmokers did not have measurable levels of CYP1A1 mRNA, detectable levels were observed in every smoker. An apparent 12-fold induction in the CYP1A1 mRNA levels was observed in the smokers compared to nonsmokers (Figure 5.9), and one of the smokers had the highest level of mRNA of all the patients. Overall the levels of CYP1B1 mRNA were lower in the cervix, with none being detected in 11/22 patients, 5 of which were smokers and 6 nonsmokers (Figure 5.11). No differences could be observed in the expression of the two isoforms in the cervical tissue obtained from patients with secretory and proliferative endometrium (Figure 5.12). 


\section{CYP1A1 and CYP1B1 in the Squamous (exocervix) Region:}

CYP1B1 mRNA was not detectable in the squamous (exocervix) region of smokers (Figure 5.8) and only 2/11 nonsmokers had measurable levels, albeit Pt.\#3 had significant expression (Figure 5.5).

CYP1B1 expression appeared to be lower in smokers by 3-fold. Poor expression of CYP1A1 was also seen in the nonsmokers compared to smokers. Approximately a 2-fold induction of the CYP1A1 mRNA was apparent in smokers compared to nonsmokers (Figure 5.9). Patient \#3 had significant expression of both CYP1B1 and CYP1A1 in this region, however her history was not suggestive of enzyme induction.

\section{Expression of CYP3A3/A4 and CYP3A7 in Endometrium and Cervix:}

The patient demographics are shown in Table 5. The measured levels of CYP3A3/A4 and CYP3A7 as ratios with respect to $\beta$ actin levels are given in Table 6 . The age of the patients ranged from 25-48 years and weight ranged from 112-277 pounds. None of the patients were on any comedications that could potentially affect CYP450 levels, specifically the patient charts were evaluated for any drugs that could likely induce CYP3A isoforms e.g. rifampin or rifabutin. The endometrial tissue was classified as either in the secretory or luteal phase $(n=15)$ and proliferative or follicular phase $(\mathrm{n}=19)$. Two patients not included in the table did not have any measurable CYP3A consensus primer RT-PCR product and therefore could not be processed for hybridization.

Initial probing evaluation with the consensus CYP3A primers illustrated measurable CYP3A expression in the cervix as well as the endometrium (Figure 5.13), however the intensity 
was visibly lower in the endometrium (Figure 5.14) compared to the cervix (Figure 5.15). The expression of CYP3A4 and CYP3A7 in different regions of the same representative human uterine tissue is shown in Figures 5.14 and 5.15, respectively. The transcripts encoding for CYP3A7 appear to be higher in endometrium obtained from patients in the proliferative phase (Figure 5.16) of the menstrual cycle compared to secretory phase (Figure 5.17). The CYP3A4 mRNA appeared to be comparable between the two phases. A semi-quantitative analysis of the autoradiography by the ImageQuant software yielded relative intensities, which were compared.

The expression of CYP3A4 and CYP3A7, as measured by the relative abundance of hybridization, were much higher in the endometrium compared to the cervix (Figures 5.18 and 5.19). No difference in expression of CYP3A3/3A4 was observed in different stages of endometrium. The endometrium from the patients in proliferative phase had the maximum CYP3A7 expression levels (Figure 5.18), which was significantly greater than the secretory phase $(\mathrm{p}<0.05)$. The relative intensity of hybridization for CYP3A4 in the endometrium appeared to be similar between the phases of the menstrual cycle (Figure 5.18).

\section{Expression of CYP3A3/A4 and CYP3A7 in Nonsmokers and Smokers:}

A 30fold decrease of CYP3A3/3A4 was observed among smokers than nonsmokers in secretory phase of endometrium. Expression of CYP3A7 was increased 17-fold in proliferative stage than in secretory phase in endometrium. A 40-fold and 20-fold higher expression of CYP3A7 and CYP3A3/3A4 were observed in proliferative to secretory phase endometrium in smokers (Figure 5.21b). No significant difference was noticed for either isoforms in different menstrual phases among overall comparison of smokers and nonsmokers. 
There is no significant difference ( $>0.5$ ) among smokers and nonsmokers in the expression of CYP3A3/A4 in endometrium (Figure 5.20). In endometrium the expression of CYP3A7 is also not significantly different ( $>$ > 0.08) in smokers and nonsmokers (Figure 5.21). In cervical region (Figures 5.22 and 5.23) also the expression of these isozymes is not significantly different between smokers and nonsmokers ( $p>0.4$ for CYP3A3/A4 and $p>0.3$ for CYP3A7). The expression of CYP3A3/A4 and CYP3A7 in endometrium and cervix for nonsmokers and smokers is given in Figures 5.24 and 5.25, respectively. The results of CYP3A3/A4 and CYP3A7 were analyzed statistically with interactions and without interactions (Appendices D.2 to D.5). Models were analyzed between CYP3A3/A4 and CYP3A7 with the differences from that of relative expression between smokers and nonsmokers (Appendices D. 6 to D.7), from same patients with different regions, endometrium and cervix (Appendices D. 8 to D.9). The master data table as modified is given in Appendix: G.1. According to this two way analysis, there is no significant difference between endometrium and cervix in smokers in either for CYP3A3/A4 or CYP3A7 enzymes, whereas, there is a significant difference between endometrium and cervix in both isozymes among nonsmokers. Between the two regions, endometrium and cervix among smokers, there is significant difference in expression of CYP3A7 over CYP3A3/A4 and similar significance was observed in nonsmokers in cervix region where CYP3A3/A4 is more than CYP3A7. 
FIGURES 


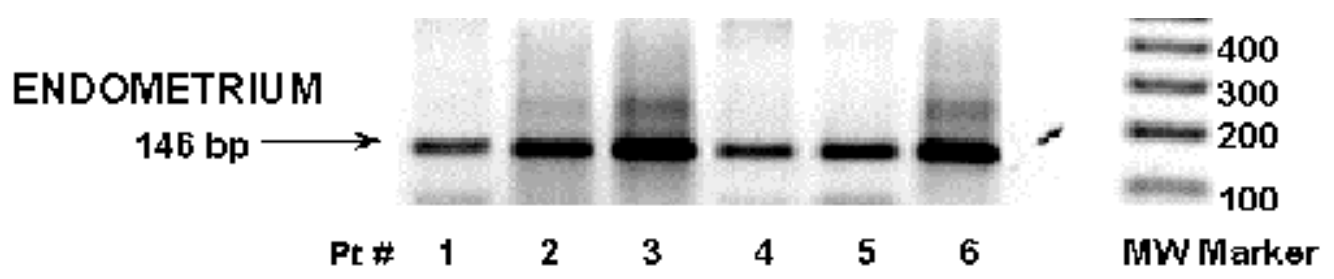

SQUAMOUS

REGION

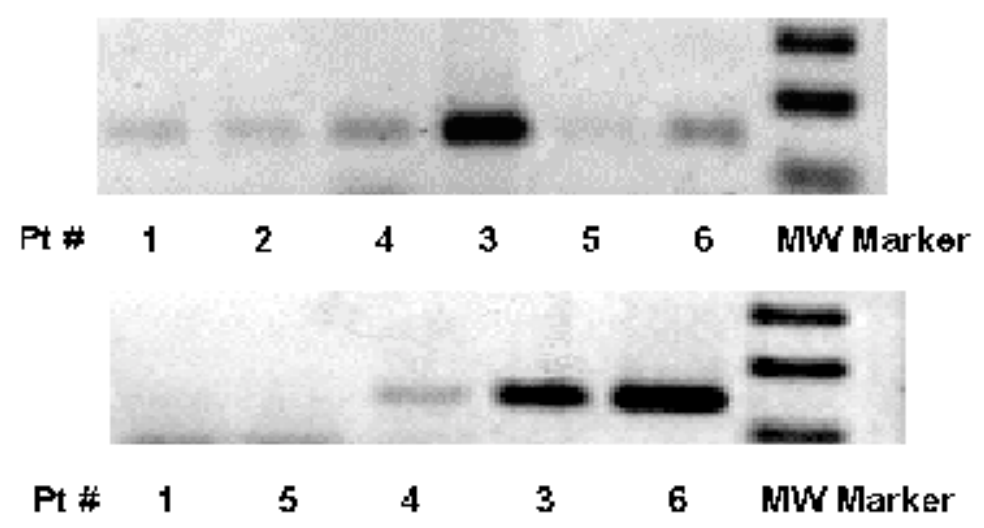

Figure: 5.1 Expression of CYP1A1 mRNA in Nonsmokers in three regions of uterus 

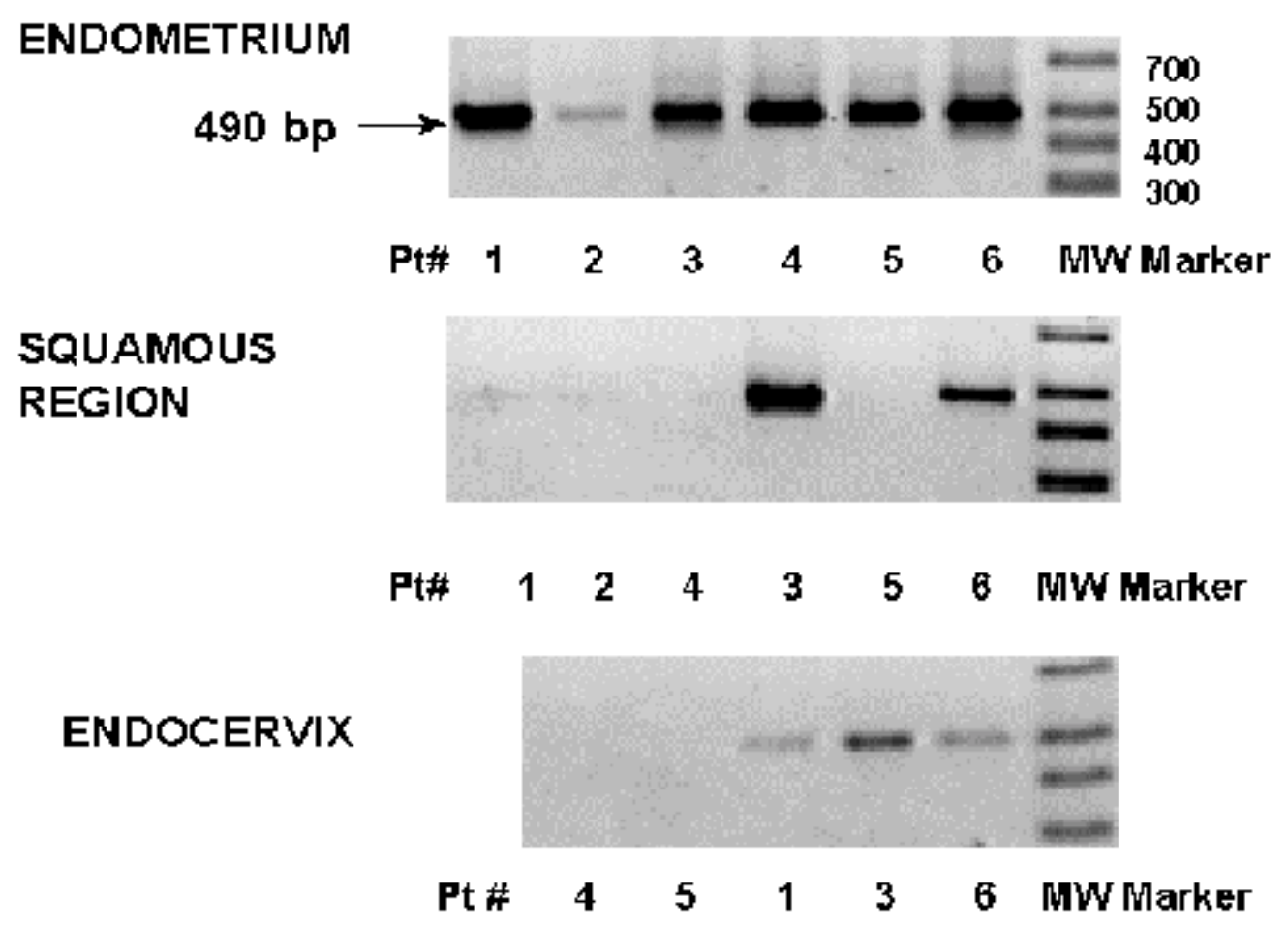

Figure: 5.2 Expression of CYP1B1 mRNA in Nonsmokers in three regions of uterus 


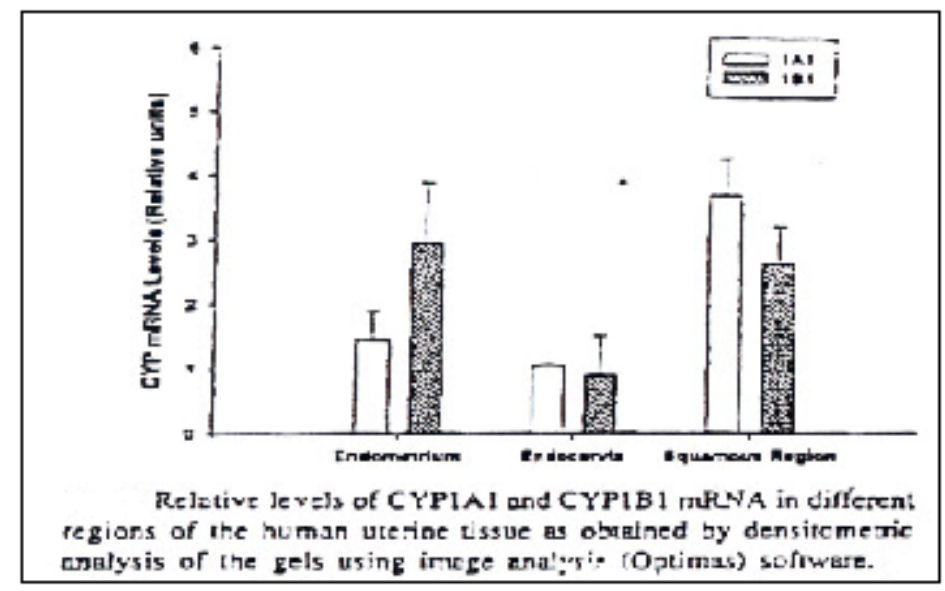

Figure 5.3: CYP1A1 and CYP1B1 expression in uterus 


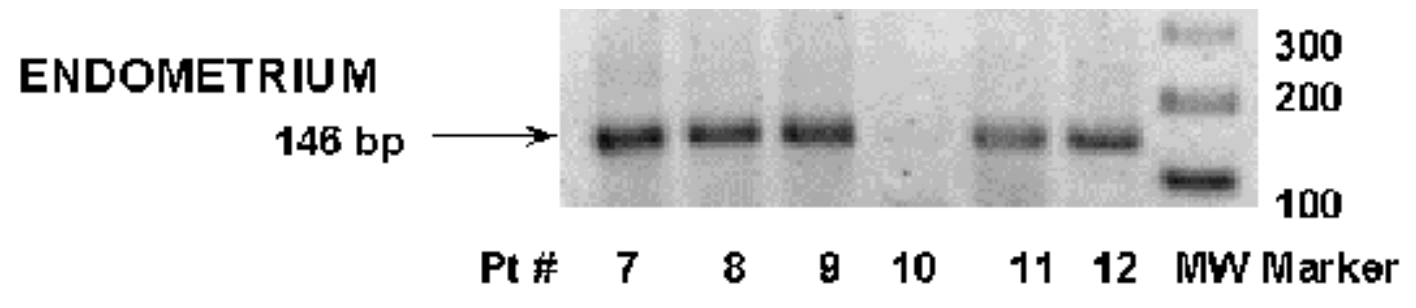

SQUAMOUS

REGION

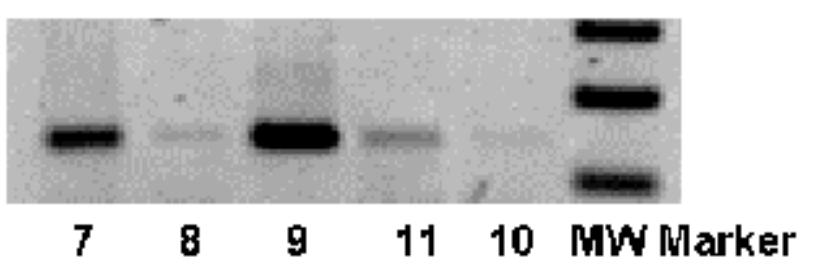

\section{ENDOCERVIX}

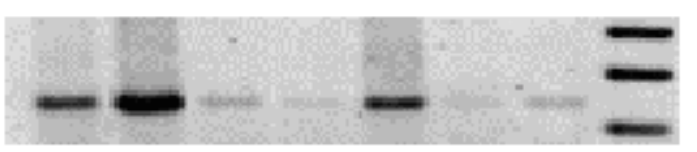

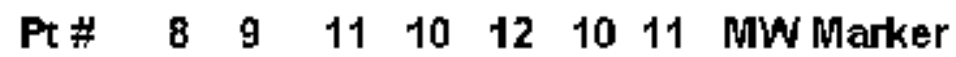

Figure: 5.4 Expression of CYP1A1 mRNA in Smokers in three regions of uterus 


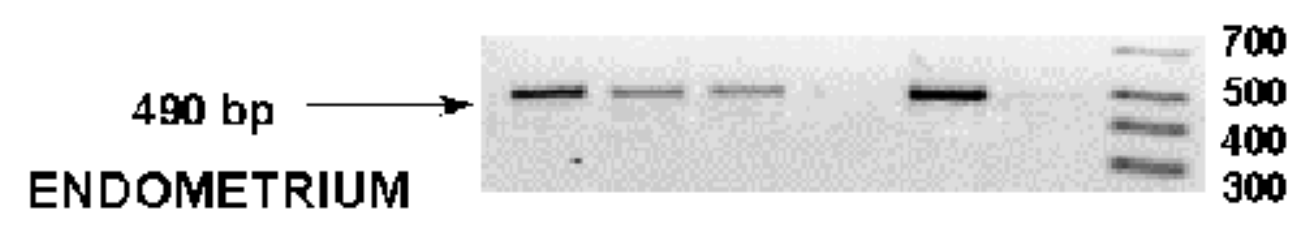

$\begin{array}{llllllll}\text { Pt \# } & 7 & 8 & 9 & 10 & 11 & 12 & \text { MW Marker }\end{array}$

\author{
SQUAMOUS \\ REGION
}
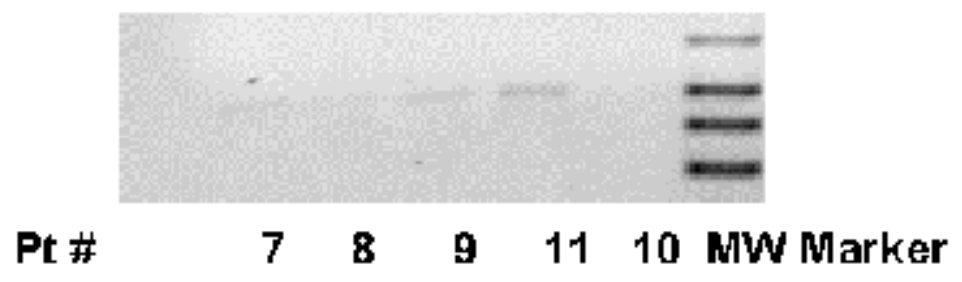

\title{
ENDOCERVIX
}

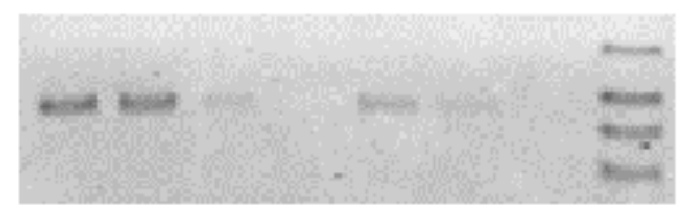

Pt \# $\quad 8 \quad 9 \quad 11 \quad 10 \quad 12 \quad 10 \quad 11$ MW Marker

Figure: 5.5 Expression of CYP1B1 mRNA in Smokers in three regions of uterus 


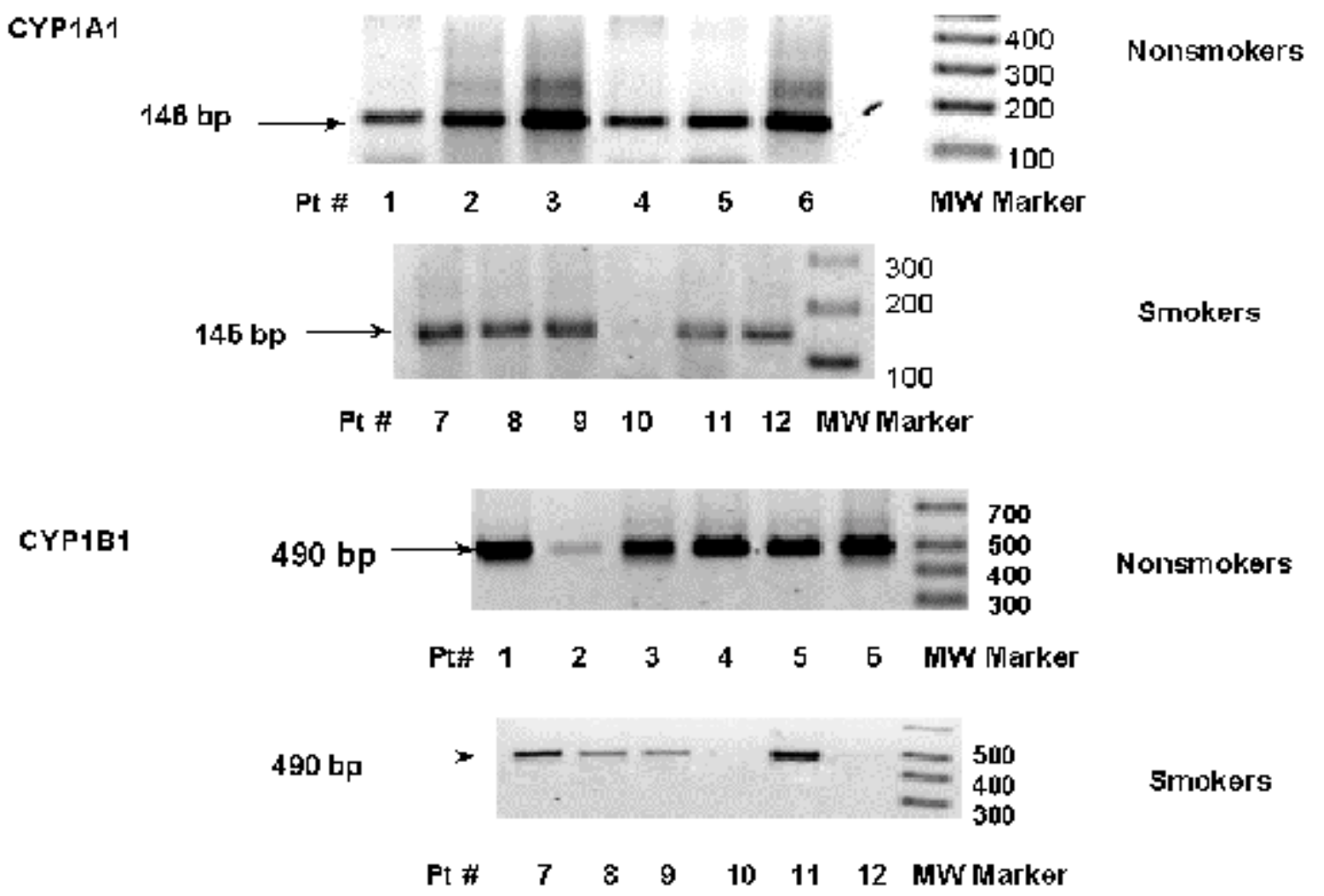

Figure: 5.6 Expression of CYP1A1 and CYP1B1 in Endometrium comparison between nonsmokers and smokers 


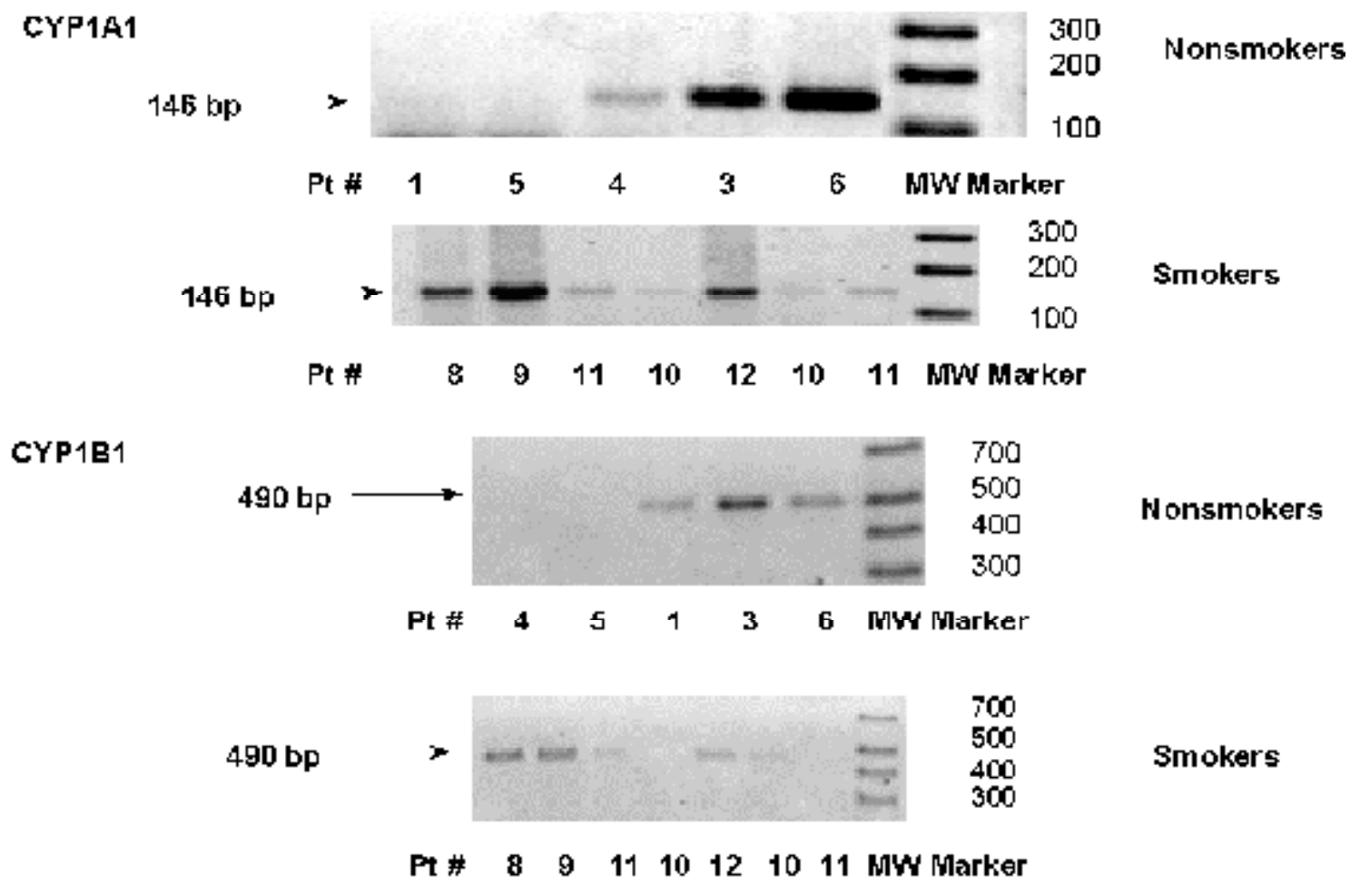

Figure: 5.7 Expression of CYP 1A1 and CYP 1B1 in CERVIX comparison between nonsmokers and smokers 


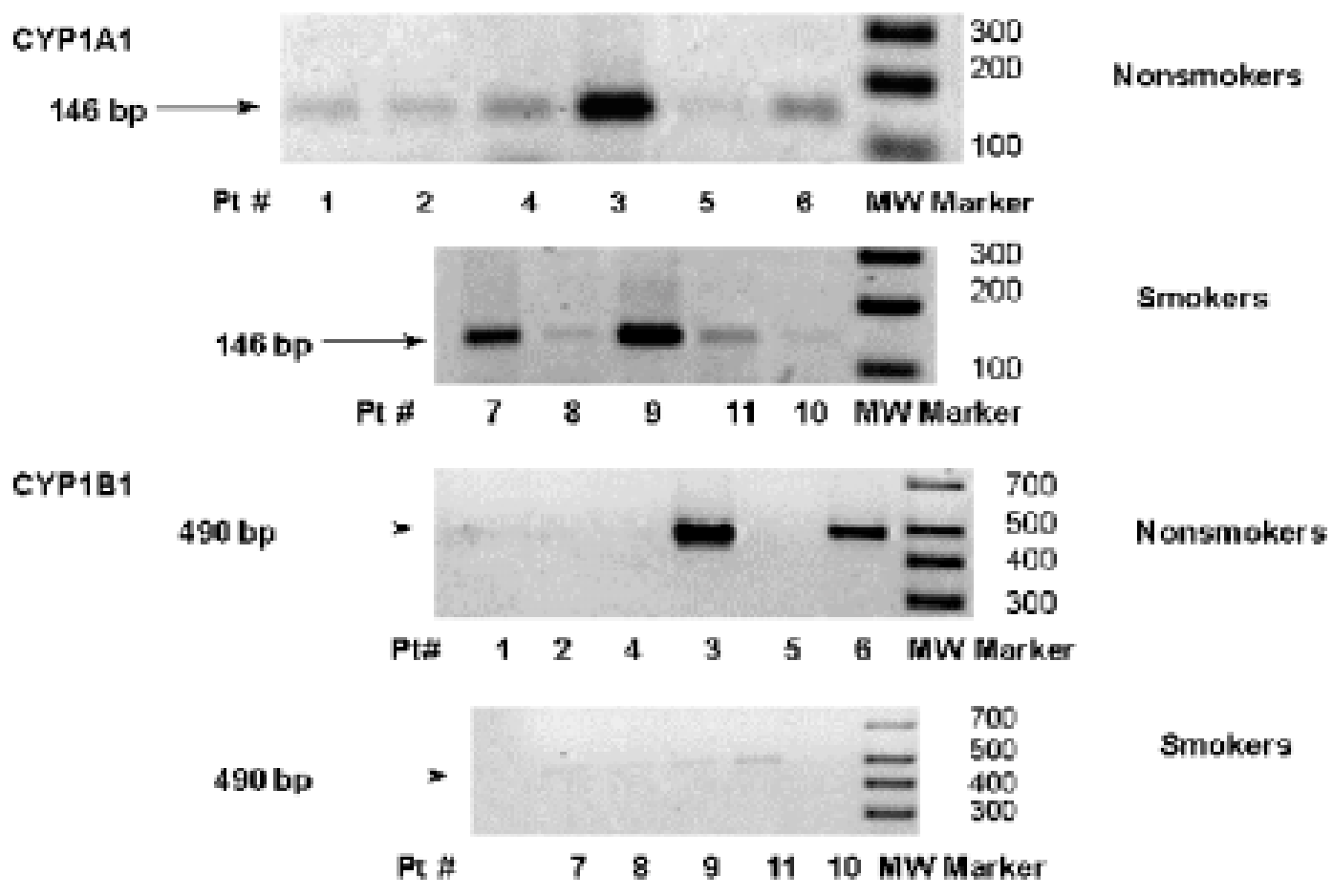

Fig: 5.8 Expression of CYP 1A1 and CYP 1B1 in SQUAMOUS REGION - comparison between nonsmokers and smokers 


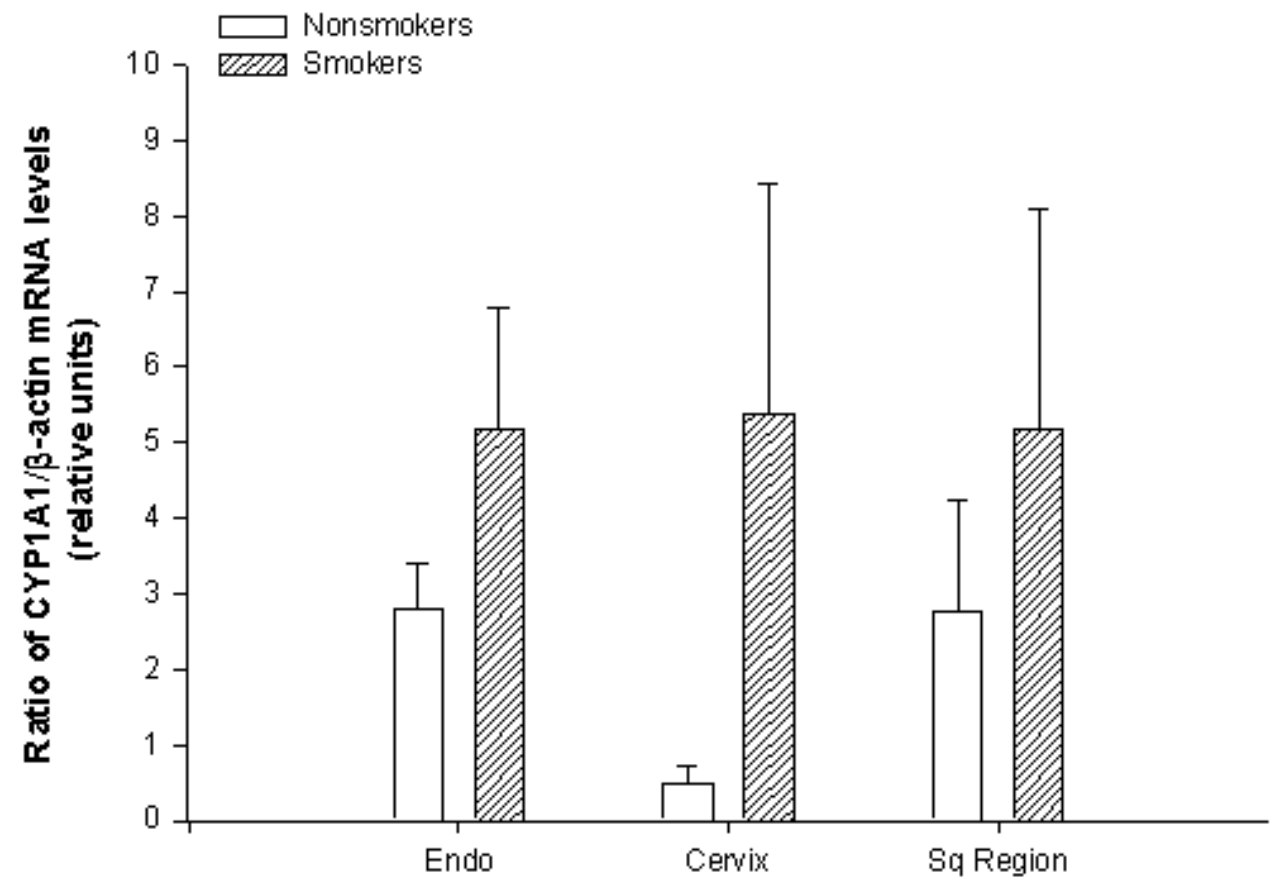

Figure: 5.9 Ratio of CYP1A1/ $\beta$-actin mRNA levels among nonsmokers and smokers 


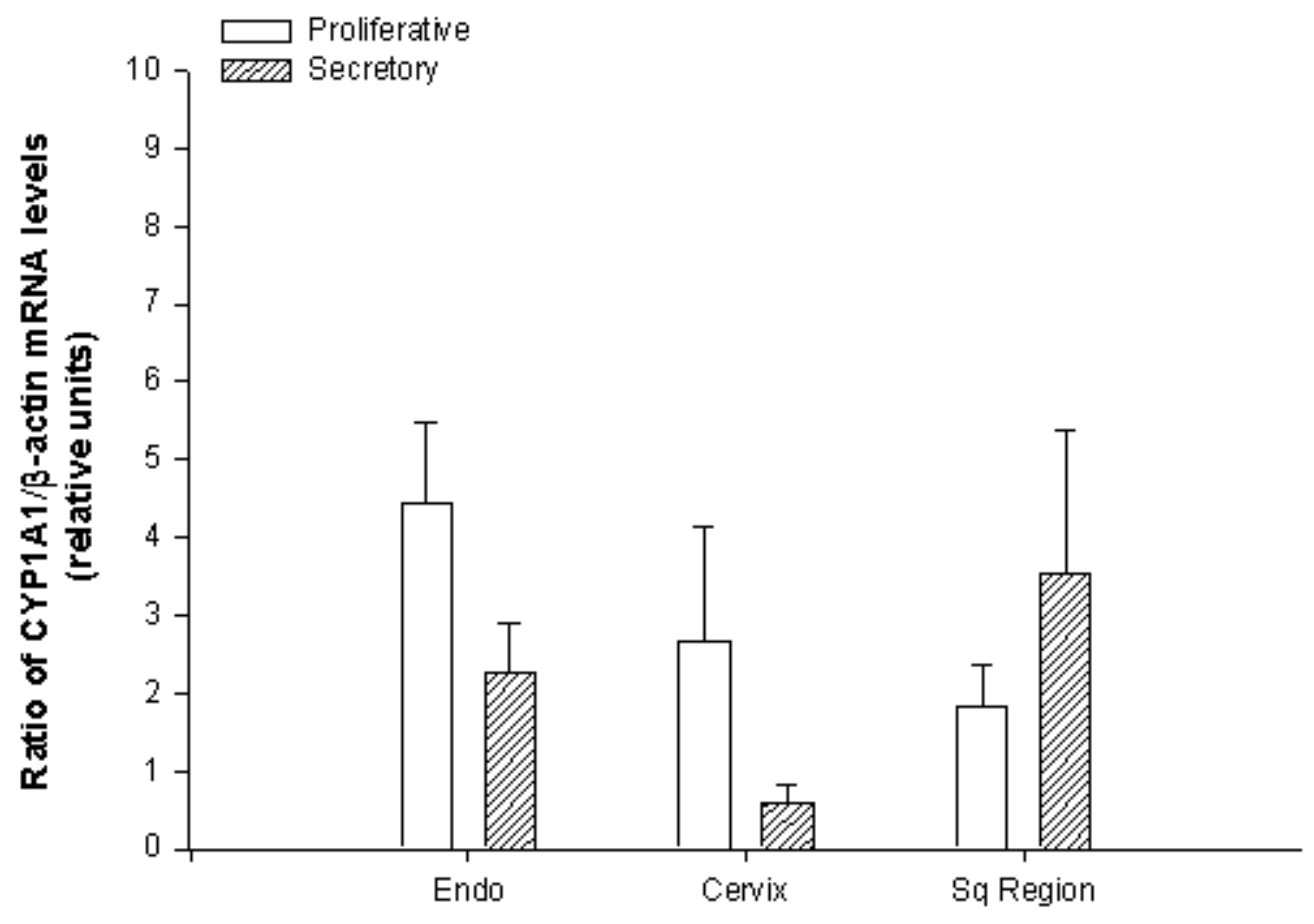

Figure: 5.10 Ratio of CYP1A1/ $\beta$-actin mRNA levels among proliferative and secretory phases 


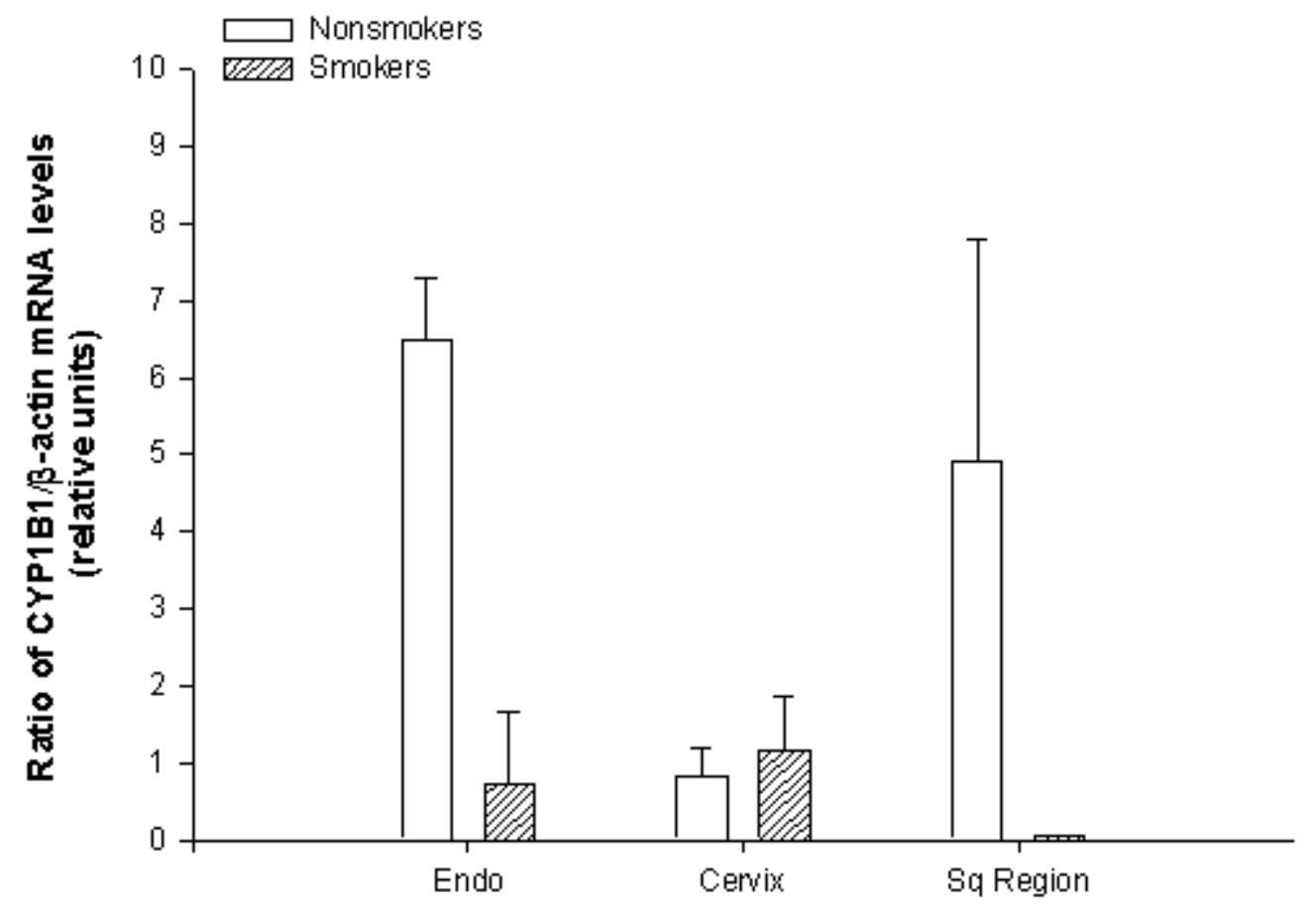

Figure: 5.11 Ratio of CYP1B1/ $\beta$-actin mRNA levels among nonsmokers and smokers 


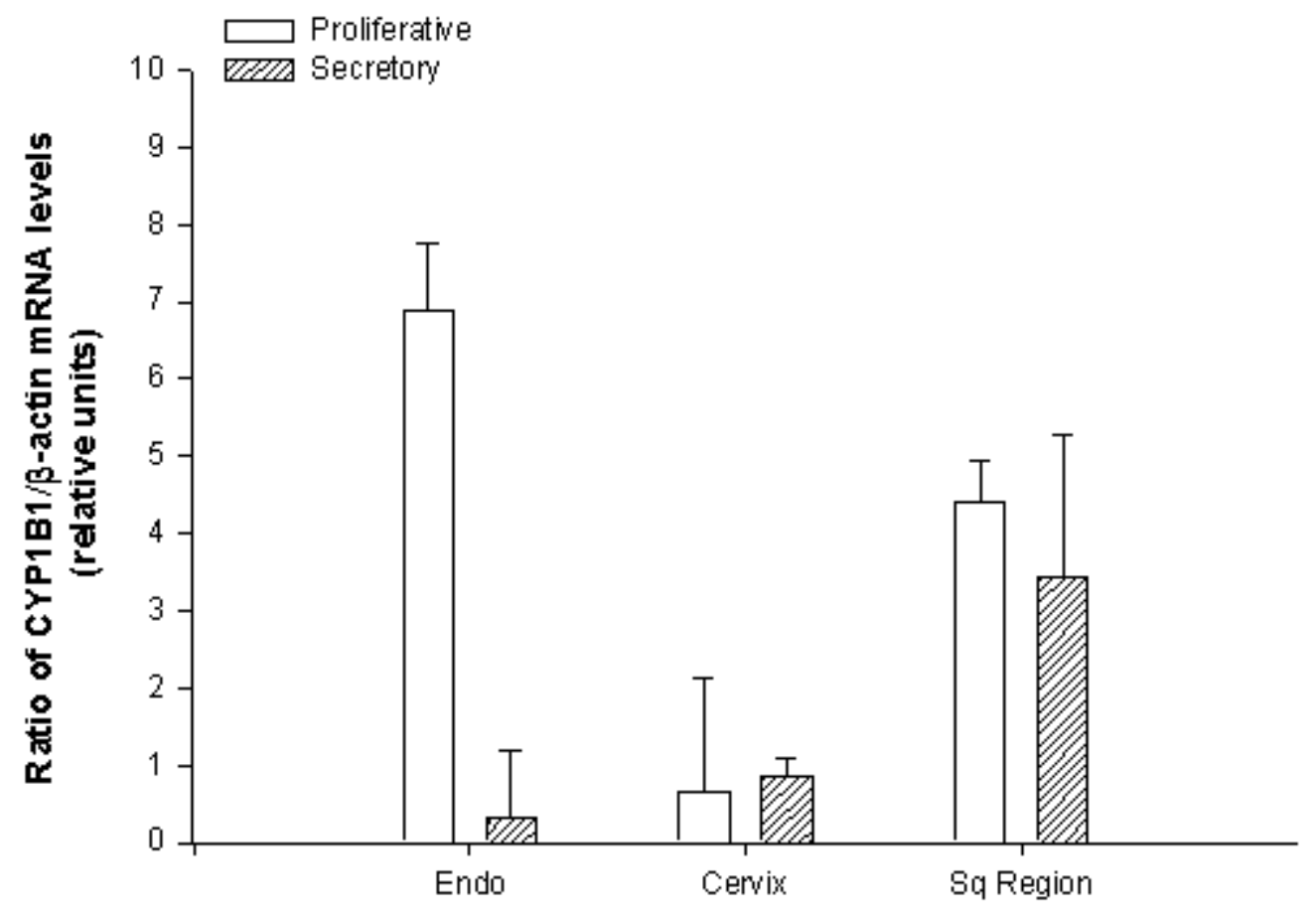

Figure: 5.12 Ratio of CYP1B1/ $\beta$-actin mRNA levels among proliferative and secretory phases 


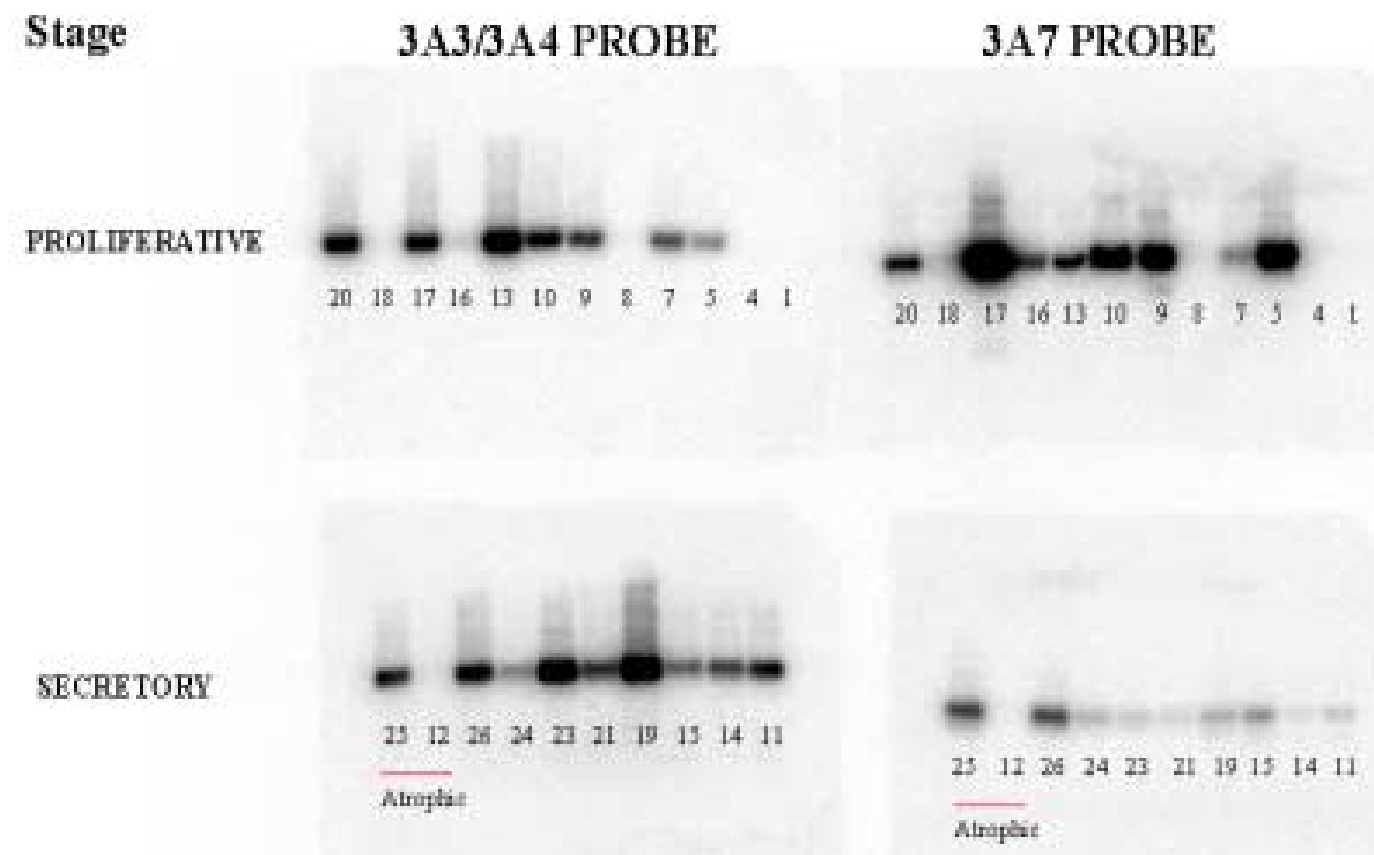

Figure: 5.13 CYP3A Expression in ENDOMETRIUM with PROBES 


\section{GEL PICTURE}

453 bp

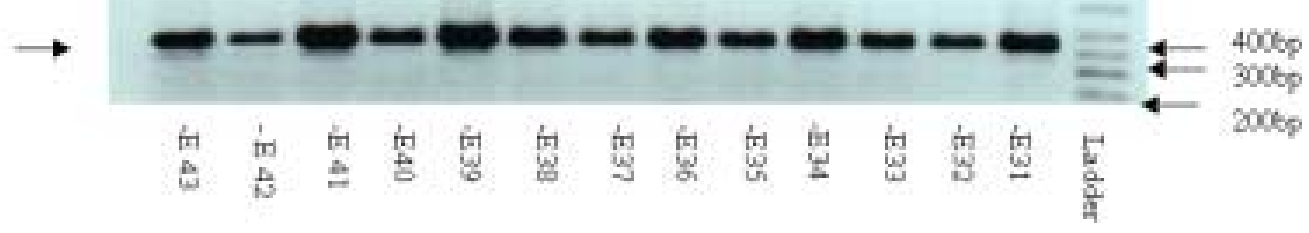

CYP $3 \mathrm{~A} 3 / 4$

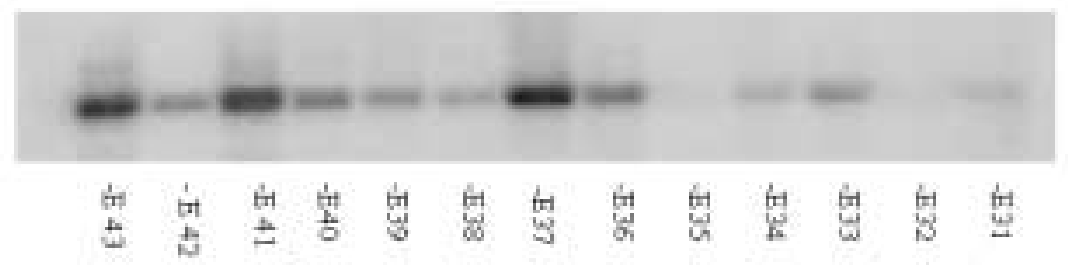

CYP 3A7

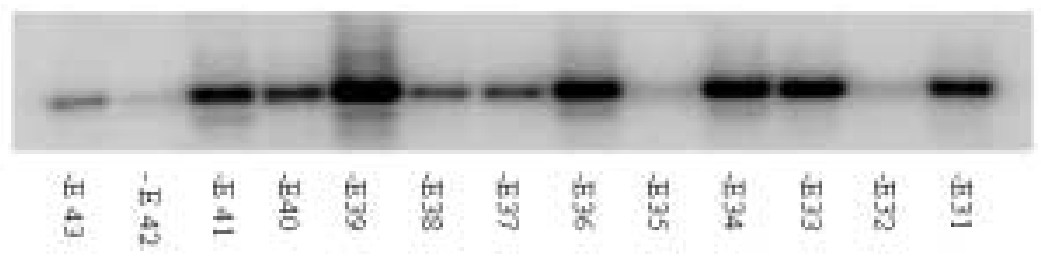

Figure: 5.14

CYP3A3/4 and CYP3A7 Expression in ENDOMETRIUM 


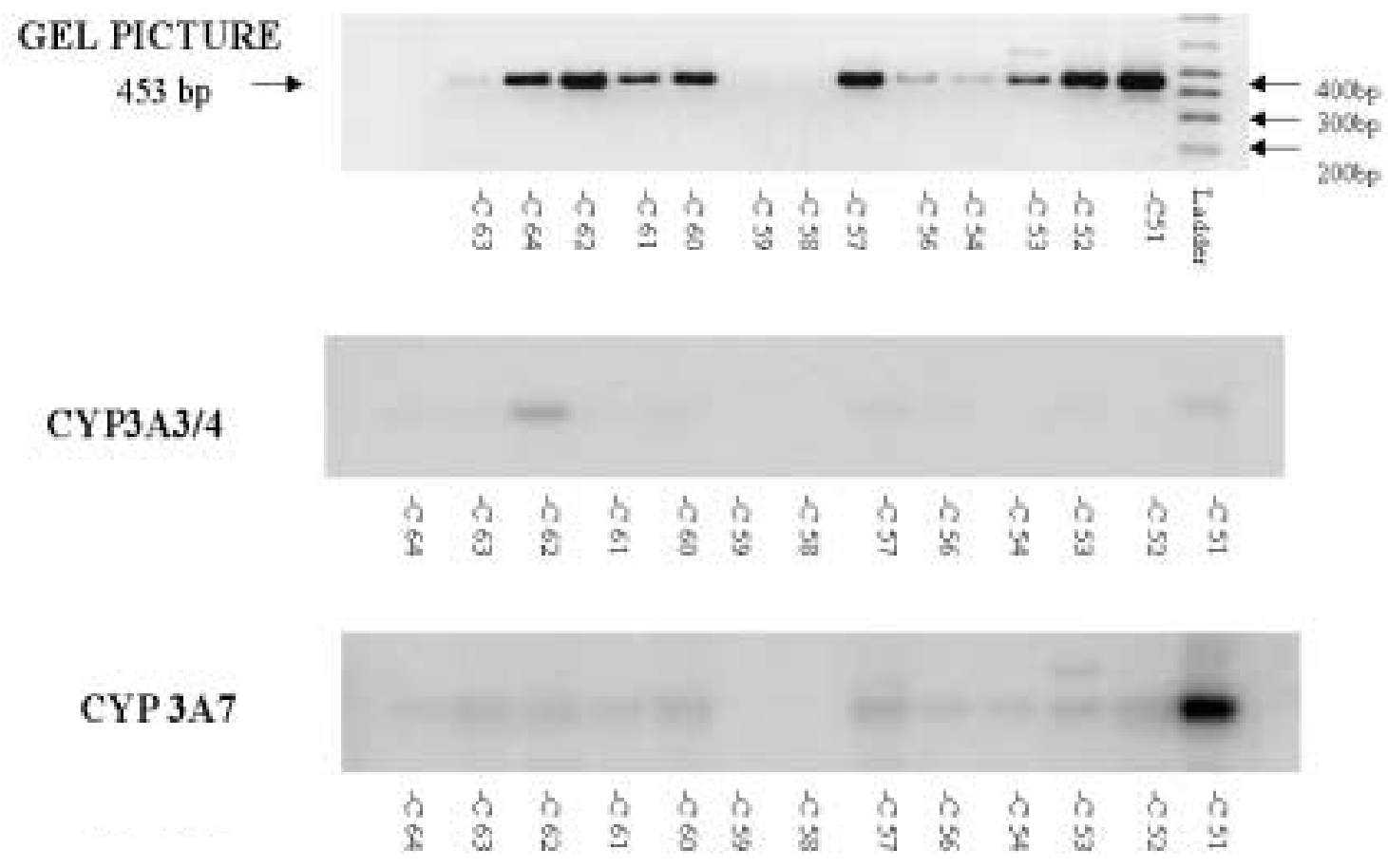

Figure: 5.15 CYP3A3/A4 AND CYP3A7 Expression in CERVIX 


\section{GEL PICTURE}

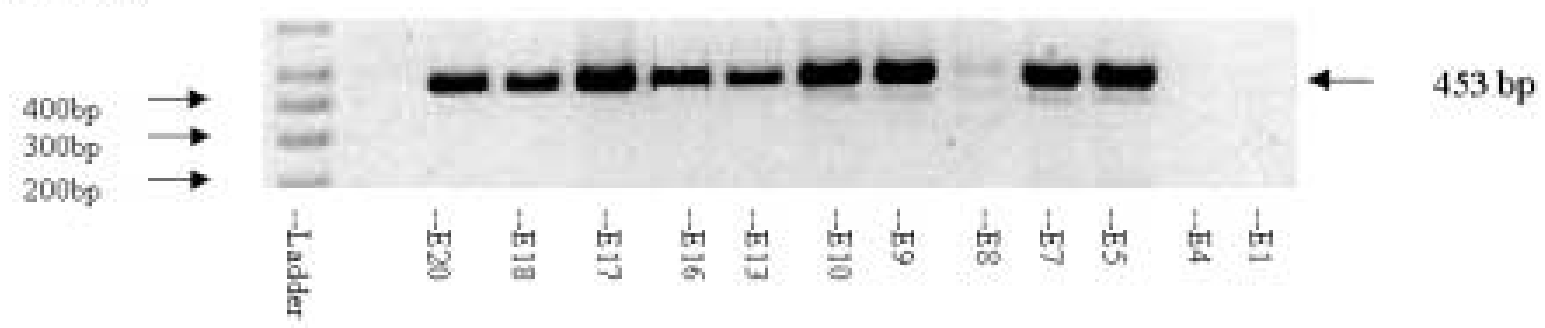

CYP3A3/4

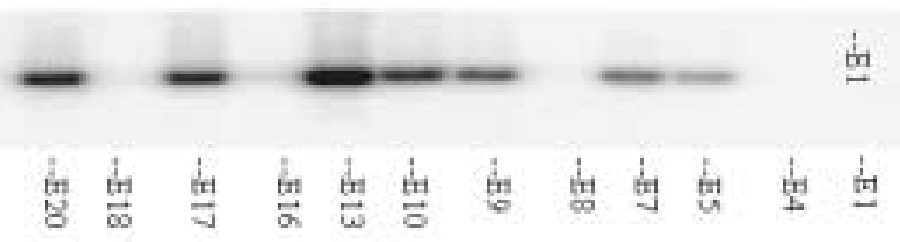

CYP 3A7

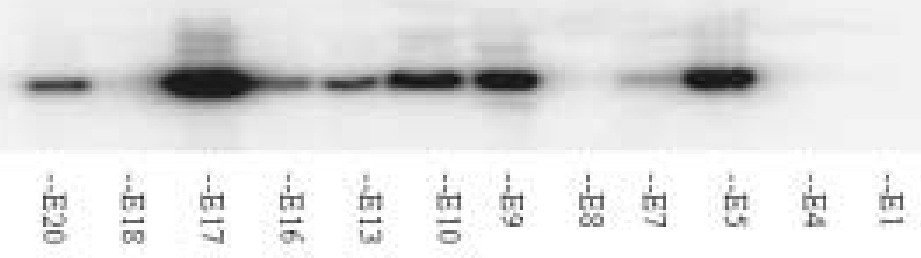

Figure: 5.16 Expression of CYP3A3/4 and CYP3A7 - PROLIFERATIVE ENDOMETRIUM 


\section{GEL PICTURE}

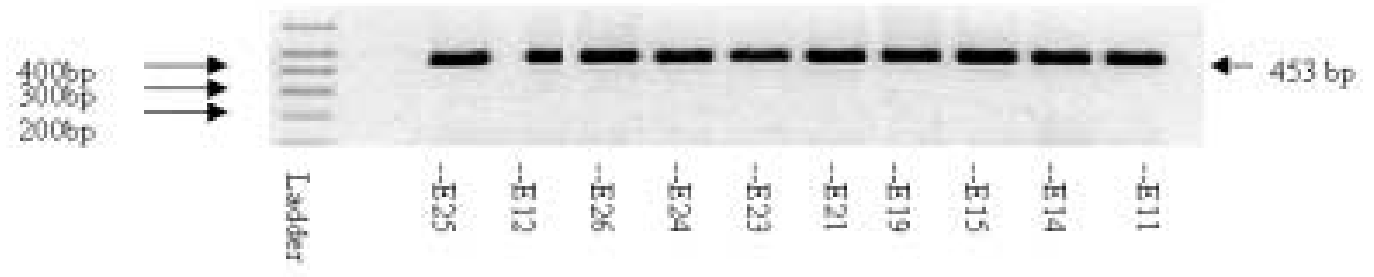

CYP3A3/4

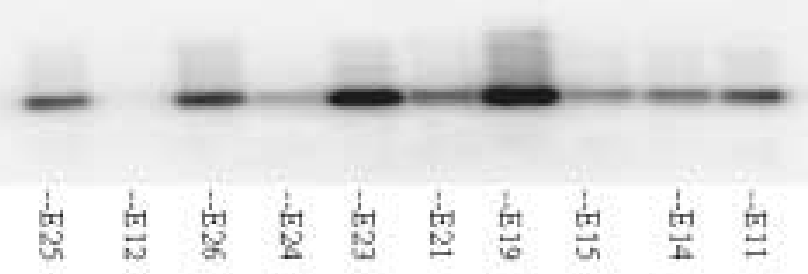

CYP 3A7

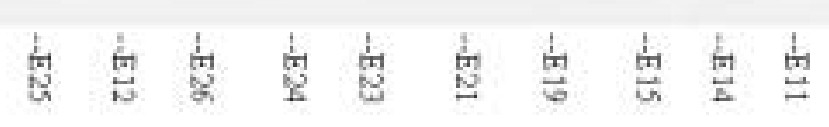

Figure: 5.17 Expression of CYP3A3/4 AND CYP3A7 SECRETORY ENDOMETRIUM 


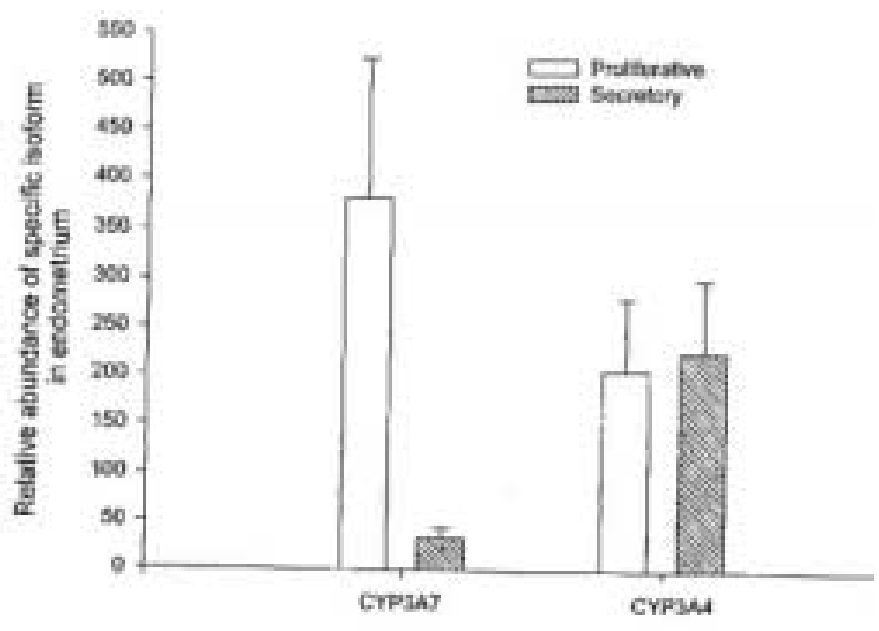

Figure: 5.18 CYP3A expression in ENDOMETRIUM 


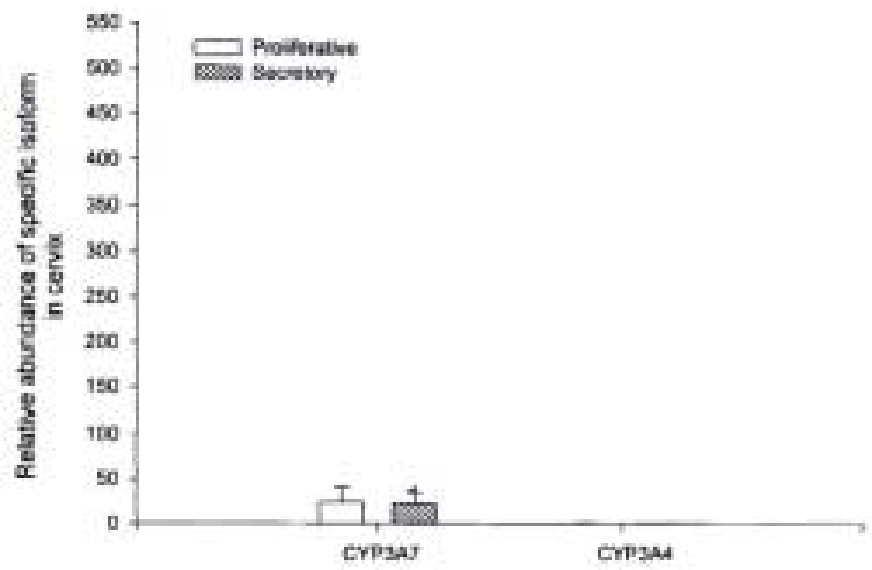

Figure: 5.19 CYP3A levels in CERVIX 


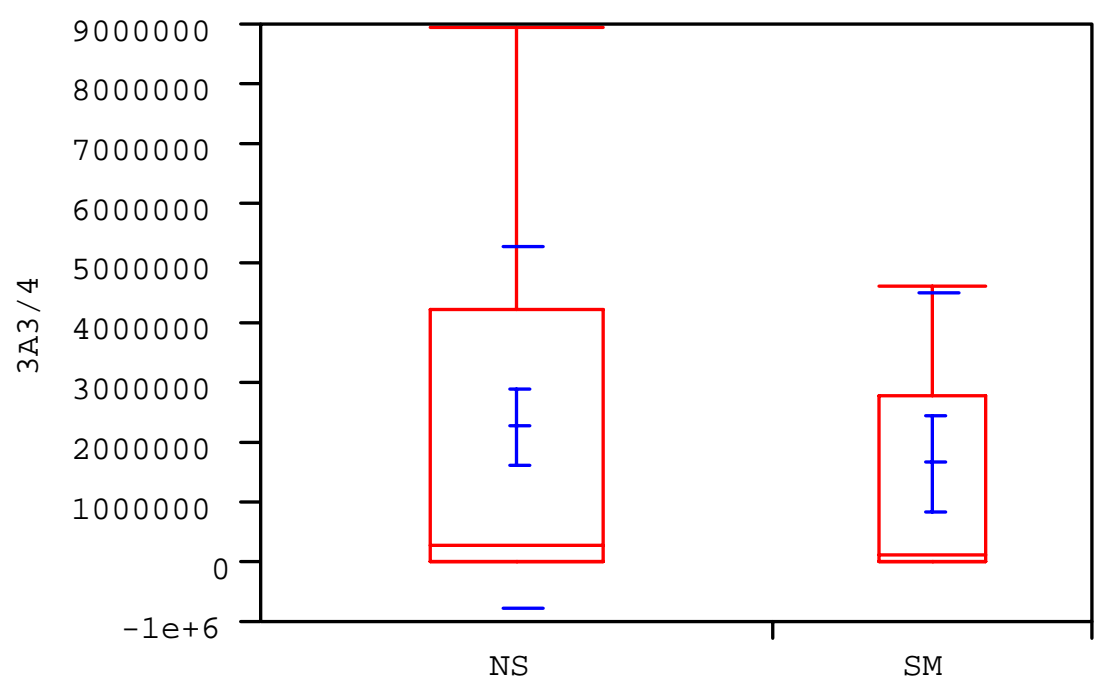

SM/NS

SM: Smokers

NS: Nonsmokes

Figure : 5.20 Levels of CYP3A3/A4 by nonsmokers and smokers in ENDOMETRIUM 


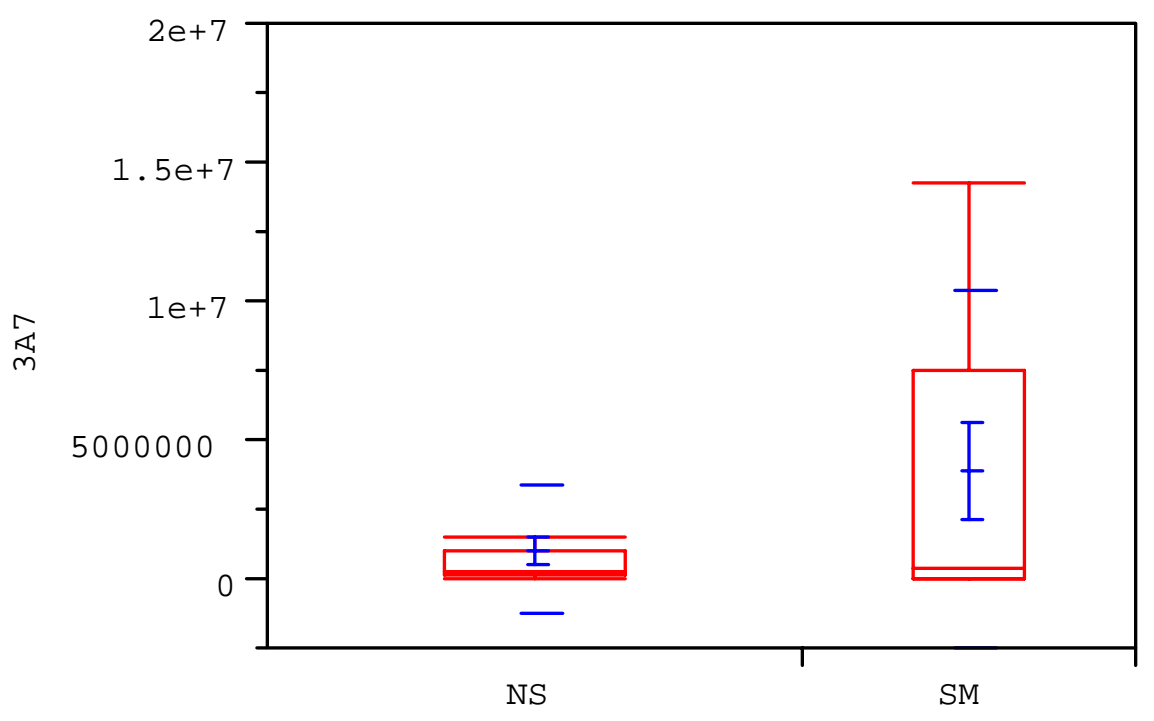

$\mathrm{SM} / \mathrm{NS}$

SM: Smokers

NS: Nonsmokers

Figure: 5.21 Levels of CYP3A7 by nonsmokers and smokers in ENDOMETRIUM 


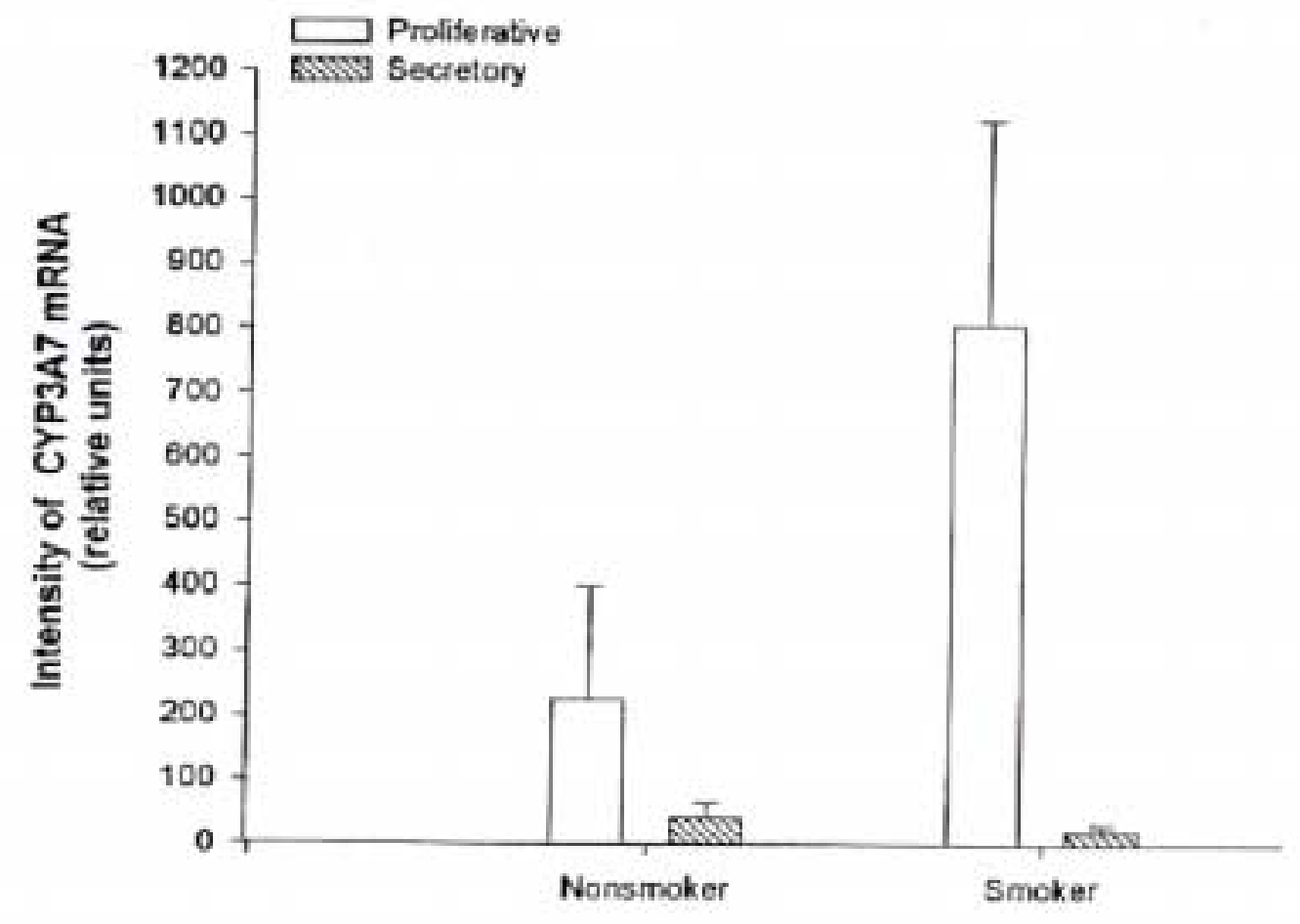

Figure: 5.21b Levels of CYP3A7 levels in PROL and SECR ENDOMETRIUM in nonsmokers and smokers 


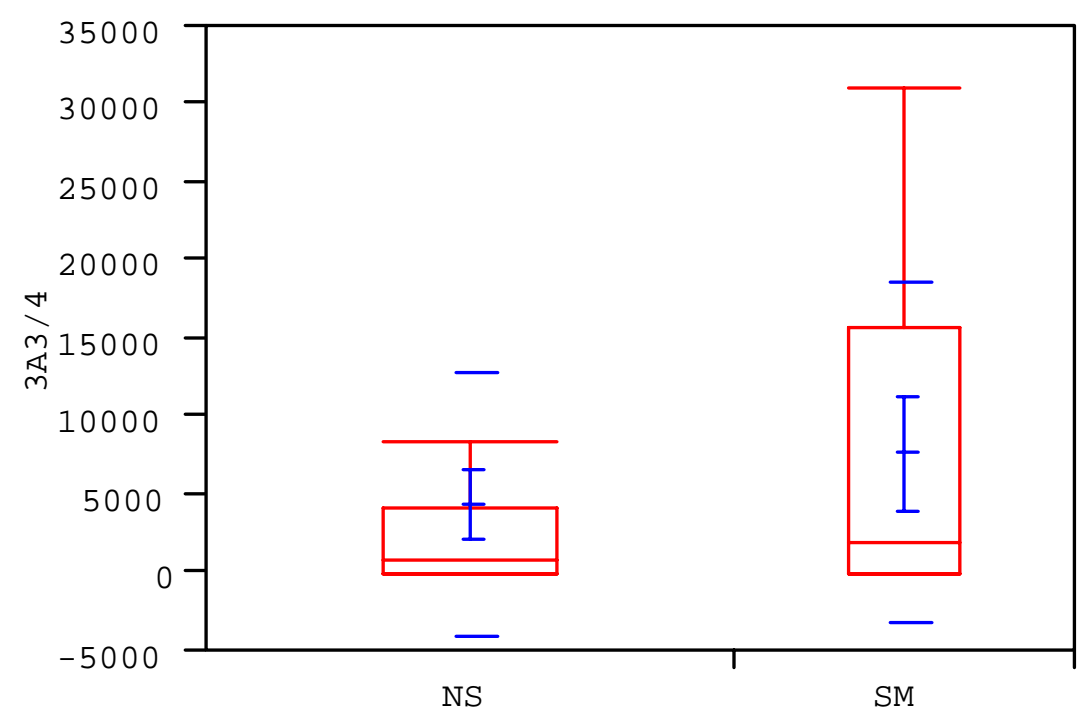

$\mathrm{SM} / \mathrm{NS}$

SM: Smokers

NS: Nonsmokers

Figure: 5.22 Levels of CYP3A3/A4 by nonsmokers and smokers in cervix 


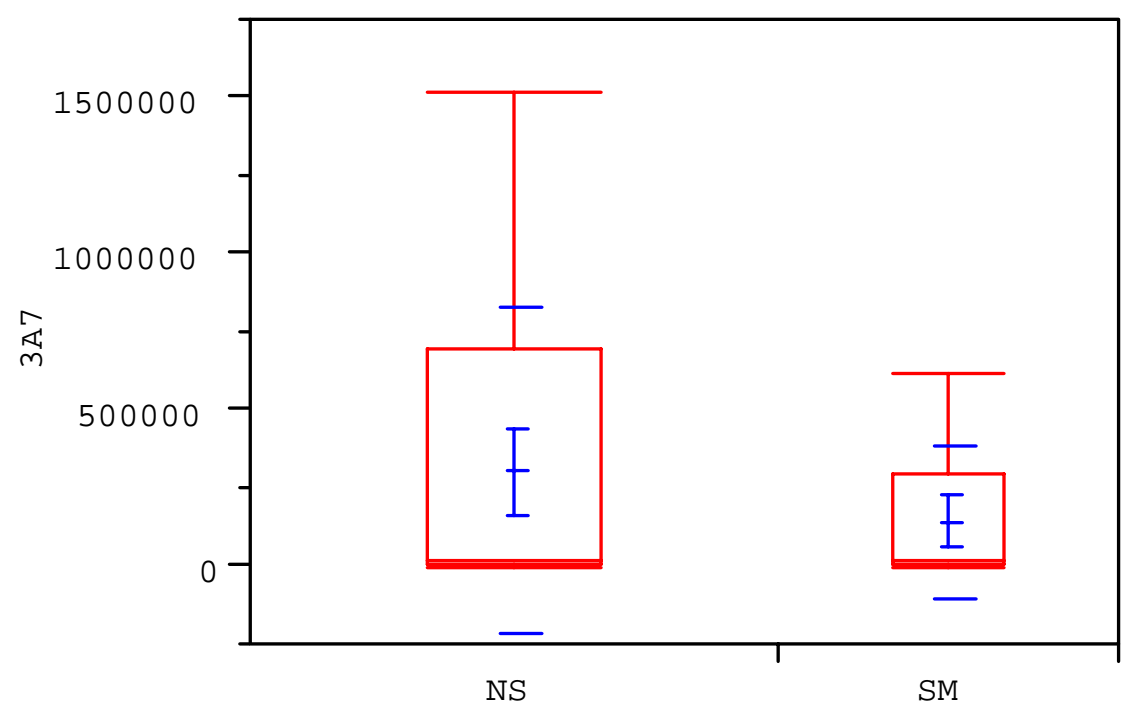

$\mathrm{SM} / \mathrm{NS}$

SM: Smokers

NS: Nonsmokers

Figure: 5.23 Levels of CYP3A7 by nonsmokers and smokers in cervix 


\section{GEL PICTURE}

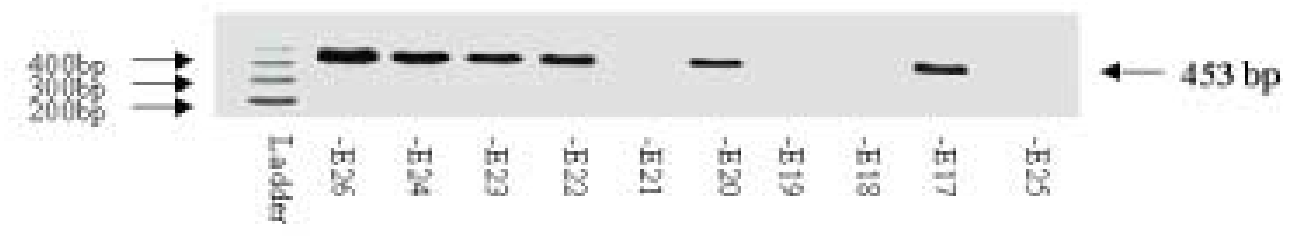

CYP3A3/4

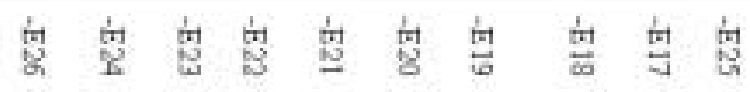

CYP 3A7

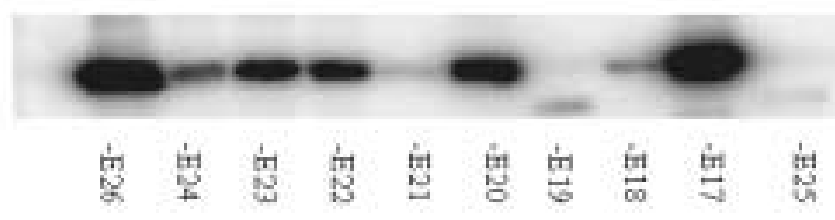

Note: E17, E18, E19, E20, E21 are smokers

E22, E23, E24, E25, E26 are nonsmokers

Figure: 5.24 Expression of CYP3A3/4 AND CYP3A7 in ENDOMETRIUM in nonsmokers and smokers 


\section{GEL PICTURE}

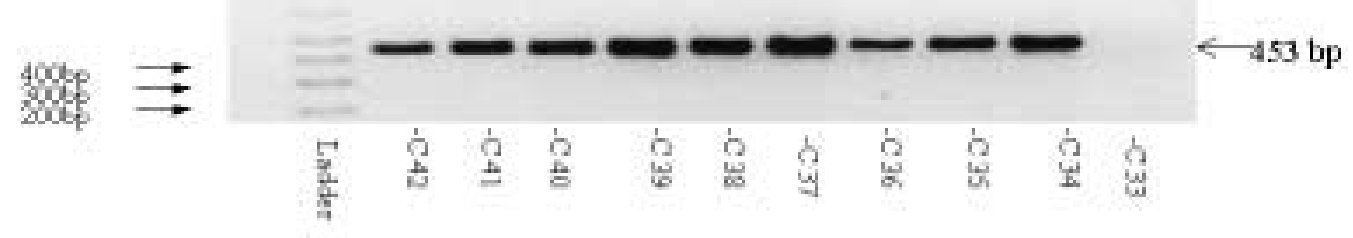

CYP3A3/4

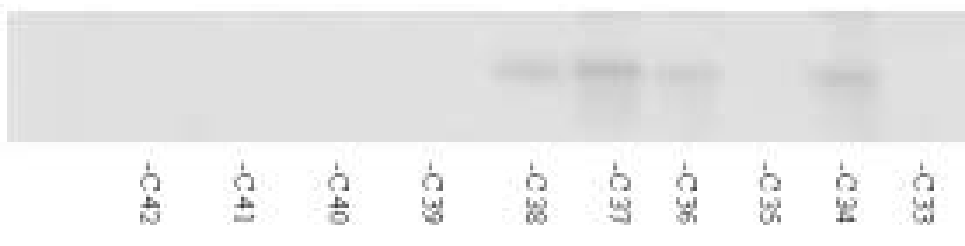

CYP 3A7

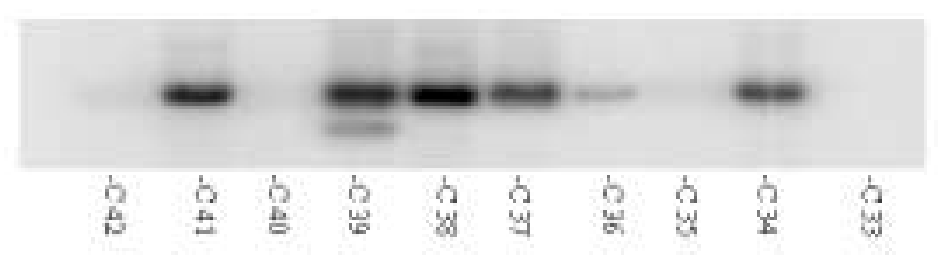

Note: C33, C34, C35, C36, C37 are smokers

$\mathrm{C} 38, \mathrm{C} 39, \mathrm{C} 40, \mathrm{C} 41, \mathrm{C} 42$ are nonsmokers.

Figure: 5.25 Expression of CYP3A3/4 AND CYP3A7 in CERVIX in nonsmokers and smokers 
TABLES 
Table:1 Demographics of Patients

\begin{tabular}{|c|c|c|c|c|c|}
\hline $\begin{array}{l}\text { Pt ID } \\
\#\end{array}$ & WT & AGE & SM/NS & COMEDICATION & DIAGNOSIS \\
\hline 1 & 154 & 48 & NS & SINEGUAM, DIAZIDE & $\begin{array}{l}\text { FIBROID UTERUS } \\
\text { FOCAL MILD } \\
\text { CHRONIC } \\
\text { CERVICITIS AND } \\
\text { SQUAMOUS } \\
\text { METAPLASIA }\end{array}$ \\
\hline 2 & 277 & 38 & NS & $\begin{array}{l}\text { SYNTHROID, } \\
\text { PROLISEC }\end{array}$ & $\begin{array}{l}\text { SYMPTOMATIC } \\
\text { PELVIC } \\
\text { RELAXATION }\end{array}$ \\
\hline 3 & 135 & 44 & NS & $\begin{array}{l}\text { DEMORAL, } \\
\text { PHENORGAN, } \\
\text { VALIUM }\end{array}$ & $\begin{array}{l}\text { FIBROID UTERUS, } \\
\text { SQUAMOUS } \\
\text { METAPLASIA OF } \\
\text { ENDOCERVIX }\end{array}$ \\
\hline 4 & 202.5 & 41 & NS & $\begin{array}{l}\text { KEFZOL, PROVRA, } \\
\text { VIBROMYCIN }\end{array}$ & $\begin{array}{l}\text { DYSMENORRHEA } \\
\text {,DYSPLASIAAND } \\
\text { ENDOMETRIOSIS }\end{array}$ \\
\hline 5 & 142 & 48 & NS & $\begin{array}{l}\text { DRIXORAL, ATIVAN, } \\
\text { BC PILLS }\end{array}$ & $\begin{array}{l}\text { FIBROID UTERUS, } \\
\text { CHRONIC CYSTIC } \\
\text { CERVICITIS, and } \\
\text { ENDOCERVICAL } \\
\text { SQUAMOUS } \\
\text { METAPLASIA }\end{array}$ \\
\hline 6 & 186.1 & 37 & NS & $\begin{array}{l}\text { IMITREX, ANAPROX, } \\
\text { LODINE }\end{array}$ & $\begin{array}{l}\text { CHRONIC PELVIC } \\
\text { PAIN, } \\
\text { LEIOMYOMAS, } \\
\text { MULTIPLE } \\
\text { FOLLICLE CYSTS }\end{array}$ \\
\hline
\end{tabular}


TABLE: 2 Demographics of all Patients analyzed for CYP1A1 and CYP1B1 during various stages of menstrual cycle and smoking status

\begin{tabular}{|c|c|c|c|c|c|c|}
\hline $\begin{array}{l}\text { PT } \\
\#\end{array}$ & STAGE & WT & AGE & SM/NS & COMEDICATION & DIAGNOSIS \\
\hline 1 & prol & 154 & 48 & ns & $\begin{array}{l}\text { sineguam, } \\
\text { diazide }\end{array}$ & $\begin{array}{l}\text { Fibroid uterus focal } \\
\text { mild chronic cervicitis } \\
\text { and squamous } \\
\text { metaplasia }\end{array}$ \\
\hline 2 & secr & 277 & 38 & ns & $\begin{array}{l}\text { synthroid, } \\
\text { prolisec }\end{array}$ & $\begin{array}{l}\text { Symptomatic pelvic } \\
\text { relaxation }\end{array}$ \\
\hline 3 & secr & 202.5 & 41 & ns & $\begin{array}{l}\text { kefzol, provra, } \\
\text { vibromycin }\end{array}$ & $\begin{array}{l}\text { Dysmenorrhea,dysplasi } \\
\text { aand endometriosis }\end{array}$ \\
\hline 4 & prol & 135 & 44 & ns & $\begin{array}{c}\text { demoral, } \\
\text { phenorgan, } \\
\text { valium }\end{array}$ & $\begin{array}{l}\text { Fibroid uterus, } \\
\text { squamous metaplasia } \\
\text { of endocervix }\end{array}$ \\
\hline 5 & prol & 142 & 48 & ns & $\begin{array}{c}\text { drixoral, ativan, } \\
\text { bc pills }\end{array}$ & $\begin{array}{l}\text { Fibroid uterus, Chronic } \\
\text { cystic cervicitis, and } \\
\text { endocervical squamous } \\
\text { metaplasia }\end{array}$ \\
\hline 6 & prol & $\begin{array}{r}186.1 \\
2 \\
\end{array}$ & 37 & ns & $\begin{array}{c}\text { imitrex, } \\
\text { anaprox, lodine }\end{array}$ & $\begin{array}{l}\text { Chronic pelvic pain, } \\
\text { leiomyomas, multiple } \\
\text { follicle cysts }\end{array}$ \\
\hline 7 & prol & 230 & 38 & $\mathrm{sm}$ & $\begin{array}{l}\text { diet pills, } \\
\text { morphine }\end{array}$ & $\begin{array}{l}\text { Menorrahagia, } \\
\text { enlarged uterus }\end{array}$ \\
\hline 8 & prol & 165 & 29 & $\mathrm{sm}$ & prozac & $\begin{array}{l}\text { Severe endometriosis, } \\
\text { pelvic pain, } \\
\text { dysporunia, } \\
\text { menorrhagia, } \\
\text { dysmenorrhea }\end{array}$ \\
\hline 9 & secr & 124 & 41 & $\mathrm{sm}$ & $\begin{array}{l}\text { hydrochloro } \\
\text { thiazide }\end{array}$ & $\begin{array}{c}\text { Fibroid uterus, } \\
\text { Menorrhagia }\end{array}$ \\
\hline 10 & prol & 112 & 25 & $\mathrm{sm}$ & augmentin & $\begin{array}{l}\text { Pelvic pain with } \\
\text { endometriosis }\end{array}$ \\
\hline 11 & secr & 205 & 38 & $\mathrm{sm}$ & morphine & $\begin{array}{l}\text { Fibroid uterus, } \\
\text { dysfunctional uterine } \\
\text { bleeding, } \\
\text { dysmenorrhea }\end{array}$ \\
\hline
\end{tabular}

Contd.. 
Contd..

\begin{tabular}{|c|c|c|c|c|c|c|}
\hline 12 & secr & 195 & 35 & ns & progestrone. & $\begin{array}{l}\text { Vaginal bleeding, } \\
\text { Endometrial atrophy on } \\
\text { progestrone use, Endo } \\
\text { hyperplasia, Chronic } \\
\text { cervicitis, Nabothian cysts } \\
\text { of cervix, Focal } \\
\text { parakeratosis of exocervical } \\
\text { epithelium }\end{array}$ \\
\hline 13 & secr & 266 & 56 & $\mathrm{~ns}$ & no & $\begin{array}{l}\text { Endometrial cancer, } \\
\text { rectocele, genuine stress, } \\
\text { urinary incontinence, post } \\
\text { menopausal bleeding }\end{array}$ \\
\hline 14 & secr & 215 & 49 & ns & provra & $\begin{array}{l}\text { Uterine discensus, } \\
\text { cystocele, } \\
\text { rectocele,endometrial } \\
\text { hyperplasia, with atypia, } \\
\text { cervix showing nabothian } \\
\text { cysts and focal chronic } \\
\text { inflammaton. }\end{array}$ \\
\hline 15 & secr & 120 & 78 & ns & morphine & $\begin{array}{l}\text { Uterine diseensus, } \\
\text { cystocele, rectocele, fibroid } \\
\text { uterus }\end{array}$ \\
\hline 16 & secr & 132 & 47 & ns & provra & $\begin{array}{l}\text { fibroid dysfunctional } \\
\text { uterus,endometrial } \\
\text { hyperplasia }\end{array}$ \\
\hline 17 & secr & 181 & 48 & $\mathrm{sm}$ & $\begin{array}{l}\text { sudafed, } \\
\text { ibuprofen }\end{array}$ & $\begin{array}{l}\text { Heavy pain ful periods, } \\
\text { pelvic relaxation, urinary } \\
\text { incontinence }\end{array}$ \\
\hline 18 & prol & 148 & 38 & $\mathrm{sm}$ & no & Pelvic pain, endometriosis \\
\hline 19 & atrophic & 200 & 62 & $\mathrm{sm}$ & ultram & Severe Cervical dysplasia \\
\hline 20 & prol & 186 & 39 & $\mathrm{sm}$ & $\begin{array}{l}\text { progestrone, } \\
\text { aegestin, drug } \\
\text { sensitivity for } \\
\text { provra }\end{array}$ & $\begin{array}{l}\text { Pelvic endometriosis, } \\
\text { persistent pelvic pain, and } \\
\text { tenderness, possible } \\
\text { adenomyosis, menorrhagia. }\end{array}$ \\
\hline 21 & hyperplasia & 213 & 41 & $\mathrm{sm}$ & $\begin{array}{l}\text { depo-provra, } \\
\text { tolazamide }\end{array}$ & Intractable uterine bleeding \\
\hline 22 & prol & 112 & 37 & $\mathrm{sm}$ & no & $\begin{array}{l}\text { Stage I and A-2 squamous } \\
\text { carcinoma of cervix }\end{array}$ \\
\hline
\end{tabular}




\section{Table: 3 CYP1A1 expression levels in various regions as ratio with $\beta-\operatorname{actin}$}

$\begin{array}{cccccc}\text { PT id \# } & \text { Squamous } & \text { Endometr } & \text { Cervix } & \text { SM/NS } & \text { STAGE } \\ 1 & 0.12595 & 0.40555 & 0 & \text { NS } & \text { PROL } \\ 2 & 3.96598 & 0.74032 & 0 & \text { NS } & \text { SECR } \\ 3 & 3.35676 & 2.12341 & 1.13086 & \text { NS } & \text { SECR } \\ 4 & 4.46956 & 0.54298 & 0.19036 & \text { NS } & \text { PROL } \\ 5 & 3.0548 & 3.02123 & 0 & \text { NS } & \text { PROL } \\ 6 & 1.75032 & 2.17854 & 0.96513 & \text { NS } & \text { PROL } \\ 7 & 9.23558 & 2.96866 & 0 & \text { SM } & \text { SECR } \\ 8 & 1.8216 & 6.8105 & 1.84731 & \text { SM } & \text { PROL } \\ 9 & 15.7428 & 8.73288 & 16.561 & \text { SM } & \text { ATROPHIC } \\ 10 & 1.10473 & 0 & 0 & \text { SM } & \text { HYPERPLASIA } \\ 11 & 13.5322 & 2.25665 & 0.74667 & \text { SM } & \text { PROL } \\ 12 & 0 & 12.3142 & 13.6697 & \text { SM } & \text { PROL } \\ 13 & 1.13222 & 1.16218 & 0.86855 & \text { SM } & \text { PROL } \\ 14 & 0.68485 & 0.05979 & 1.18839 & \text { SM } & \text { PROL } \\ 15 & 1.64991 & 0.79901 & 1.47769 & \text { SM } & \text { SECR } \\ 16 & 2.22665 & 1.49169 & 0.27886 & \text { SM } & \text { PROL } \\ 17 & 0.7496 & 0.63925 & 0.02866 & \text { SM } & \text { SECR } \\ 18 & 0.17768 & 0 & 0.10993 & \text { NS } & \text { SECR } \\ 19 & 0.90688 & 0.18558 & 0.33963 & \text { NS } & \text { SECR } \\ 20 & 0.1738 & 0.87274 & 0.19131 & \text { NS } & \text { SECR } \\ 21 & 0.48839 & 1.2258 & 0.09724 & \text { NS } & \text { SECR } \\ 22 & 0.37408 & 0.81056 & 0.15431 & \text { NS } & \text { SECR }\end{array}$

PROL: Proliferative stage

SECR: Secretory stage

SM: Smokers

NS: Nonsmokers 
Table: 4 CYP1B1 expression levels in various regions as ratio with $\beta$-actin

$\begin{array}{cccccc}\text { PT id \# } & \text { Squamous } & \text { Endometrium } & \text { Cervix } & \text { SM/NS } & \text { STAGE } \\ 1 & 0 & 2.48632 & 0.26048 & \text { NS } & \text { PROL } \\ 2 & 0 & 0.07734 & & \text { NS } & \text { SECR } \\ 3 & 2.08222 & 2.15973 & 1.72426 & \text { NS } & \text { SECR } \\ 4 & 0 & 2.84938 & 0 & \text { NS } & \text { PROL } \\ 5 & 0 & 7.03089 & 0 & \text { NS } & \text { PROL } \\ 6 & 3.19936 & 3.07206 & 0.27266 & \text { NS } & \text { PROL } \\ 7 & 0 & 1.55331 & 0 & \text { SM } & \text { SECR } \\ 8 & 0 & 1.51628 & 0 & \text { SM } & \text { PROL } \\ 9 & 0 & 0.91298 & 1.86394 & \text { SM } & \text { ATROPHIC } \\ 10 & 0 & 0 & 0.365 & \text { SM } & \text { HYPERPLASIA } \\ 11 & 0 & 4.53018 & 0 & \text { SM } & \text { PROL } \\ 12 & & 0 & 0.32087 & \text { SM } & \text { PROL } \\ 13 & 0 & 0 & 0.07821 & \text { SM } & \text { PROL } \\ 14 & 0 & 0.03325 & 0 & \text { SM } & \text { PROL } \\ 15 & 0 & 0 & 0 & \text { SM } & \text { SECR } \\ 16 & 0 & 0.05333 & 0 & \text { SM } & \text { PROL } \\ 17 & 0.06335 & 0.03706 & 0 & \text { SM } & \text { SECR } \\ 18 & 0 & 0.02099 & 0.27864 & \text { NS } & \text { SECR } \\ 19 & 0.08079 & 0 & 0.12023 & \text { NS } & \text { SECR } \\ 20 & 0 & 0.04947 & 0 & \text { NS } & \text { SECR } \\ 21 & 0 & 0 & 0 & \text { NS } & \text { SECR } \\ 22 & 0 & 0.53777 & 0.05757 & \text { NS } & \text { SECR }\end{array}$

PROL: Proliferative

SECR: Secretory

SM: Smokers

NS: Nonsmokers 
Table: 5 Demographics of patients used for CYP3A expression

\begin{tabular}{|c|c|c|c|c|c|c|c|}
\hline $\begin{array}{l}\text { Endo } \\
\#\end{array}$ & $\begin{array}{l}\text { Cerv } \\
\#\end{array}$ & Stage & wt & Age & SM/NS & Comedication & diagnosis \\
\hline E31 & $\mathrm{C} 51$ & inactive & 217 & 49 & NS & Prednisone & $\begin{array}{l}\text { Pelvic } \\
\text { pain, } \\
\text { Prolapse }\end{array}$ \\
\hline E32 & $\mathrm{C} 52$ & secr & 148 & 36 & $\mathrm{SM}^{*}$ & Naproxin & $\begin{array}{l}\text { Chronic } \\
\text { pelvic } \\
\text { pain }\end{array}$ \\
\hline E33 & $\mathrm{C} 53$ & prol & 237 & 34 & NS & $\begin{array}{l}\text { Glucotrol, } \\
\text { Lotrel, } \\
\text { Percocet, } \\
\text { Colace }\end{array}$ & $\begin{array}{l}\text { Recurrent } \\
\text { uterine } \\
\text { bleeding, } \\
\text { Persistent } \\
\text { complex } \\
\text { hyperplas } \\
\text { ia }\end{array}$ \\
\hline E34 & C54 & $\mathrm{prol} / \mathrm{ca}$ & 225 & 46 & NS & $\begin{array}{l}\text { Synthroid, } \\
\text { Provera, } \\
\text { Pravachol }\end{array}$ & $\begin{array}{l}\text { Fibroid } \\
\text { uterus, } \\
\text { Bleeding, } \\
\text { Polyps }\end{array}$ \\
\hline E35 & C56 & secr & 120 & 35 & NS & Nil & $\begin{array}{l}\text { Pelvic } \\
\text { lymphede } \\
\text { ctomy, } \\
\text { Cervical } \\
\text { cancer? }\end{array}$ \\
\hline E36 & C57 & secr & 185 & 38 & SM & Nil & $\begin{array}{l}\text { Fibroid } \\
\text { uterus, } \\
\text { multiple } \\
\text { myomas }\end{array}$ \\
\hline E37 & $\mathrm{C} 58$ & secr & 119 & 41 & NS & Naprosyn & $\begin{array}{l}\text { Pelvic } \\
\text { pain, } \\
\text { Pelvic } \\
\text { mass } \\
\end{array}$ \\
\hline E38 & C59 & prol & 105 & 42 & NS & $\begin{array}{l}\text { Droperidol,kef } \\
\text { zol, Cefazolin }\end{array}$ & $\begin{array}{l}\text { Fibroid } \\
\text { uterus }\end{array}$ \\
\hline E39 & C60 & inactive & 140 & 74 & NS & $\begin{array}{l}\text { Synthroid, } \\
\text { Cipro, Asprin, } \\
\text { vit e, captocil }\end{array}$ & $\begin{array}{l}\text { Pelvic } \\
\text { pain }\end{array}$ \\
\hline
\end{tabular}

Contd.. 
Contd..

\begin{tabular}{|l|l|l|l|l|l|l|l|}
\hline E40 & C61 & prol & 270 & 47 & SM** & Cipro & $\begin{array}{l}\text { Hernia, } \\
\text { menomet } \\
\text { rorrhagea }\end{array}$ \\
\hline E41 & C62 & secr & 134 & 31 & NS & $\begin{array}{l}\text { Serzone, } \\
\text { Trazodone, } \\
\text { Ventolin } \\
\text { inhaler, } \\
\text { Proventil, } \\
\text { prednisone etc. }\end{array}$ & $\begin{array}{l}\text { Fibroid } \\
\text { uterus, } \\
\text { ovarian } \\
\text { cysts, } \\
\text { chronic } \\
\text { pelvic } \\
\text { pain }\end{array}$ \\
\hline E42 & C63 & prol & 149 & 44 & NS & $\begin{array}{l}\text { Premarin, } \\
\text { colace, tylenol }\end{array}$ & $\begin{array}{l}\text { Uterine } \\
\text { fibroids }\end{array}$ \\
\hline E43 & C64 & secr & 168 & 40 & SM & $\begin{array}{l}\text { Anaprox, } \\
\text { lorezapam, } \\
\text { pyroxicam }\end{array}$ & $\begin{array}{l}\text { Endometr } \\
\text { iosis }\end{array}$ \\
\hline
\end{tabular}

*only one patient is black.

** One patient is smoker for 12 years but quit smoking in 1973 
Table: 6 Levels of CYP3A3/A4 and CYP3A7 as ratios with respective $\beta$ actin levels

$\begin{array}{ccccc}\text { ID\# } & \text { STAGE } & \text { SM / NS } & \text { 3A3 /A4 } & \text { 3A7 } \\ \text { E1 } & \text { PROL } & \text { SM } & 0 & 0 \\ \text { E4 } & \text { PROL } & \text { NS } & 0 & 0 \\ \text { E5 } & \text { PROL } & \text { SM } & 950517 & 14223601 \\ \text { E7 } & \text { PROL } & \text { NS } & 2152962 & 91058 \\ \text { E8 } & \text { PROL } & \text { NS } & 0 & 0 \\ \text { E9 } & \text { PROL } & \text { NS } & 3128568 & 10664064 \\ \text { E10 } & \text { PROL } & \text { SM } & 4619279 & 9430575 \\ \text { E13 } & \text { PROL } & \text { NS } & 8971099 & 2659004 \\ \text { E16 } & \text { PROL } & \text { NS } & 0 & 127022 \\ \text { E17 } & \text { PROL } & \text { SM } & 6976845 & 19244217 \\ \text { E18 } & \text { PROL } & \text { SM } & 0 & 0 \\ \text { E20 } & \text { PROL } & \text { SM } & 7769961 & 5457450 \\ \text { E11 } & \text { SECR } & \text { NS } & 4243992 & 95210 \\ \text { E14 } & \text { SECR } & \text { NS } & 2403039 & 10567 \\ \text { E15 } & \text { SECR } & \text { SM } & 26821 & 390583 \\ \text { E19 } & \text { SECR } & \text { SM } & 432695 & 154682 \\ \text { E21 } & \text { SECR } & \text { SM } & 42844 & 34066 \\ \text { E23 } & \text { SECR } & \text { NS } & 6938609 & 81577 \\ \text { E24 } & \text { SECR } & \text { NS } & 8473469 & 114550 \\ \text { E25 } & \text { SECR } & \text { NS } & 4252467 & 1146260 \\ \text { E26 } & \text { SECR } & \text { NS } & 5853757 & 1053534 \\ \text { E22 } & \text { SECR } & \text { NS } & 0 & 904271 \\ \text { E31 } & \text { INACTIVE } & \text { NS } & 16144.86 & 593082 \\ \text { E32 } & \text { SECR } & \text { SM* } & 5188.64 & 59660.02 \\ \text { E33 } & \text { PROL } & \text { NS } & 56258.25 & 1014889 \\ \text { E34 } & \text { PROL/CA } & \text { NS } & 22997.22 & 1032549 \\ \text { E35 } & \text { SECR } & \text { NS } & 5060.3 & 61469.89 \\ \text { E36 } & \text { SECR } & \text { SM } & 109528.2 & 899699.7 \\ \text { E37 } & \text { SECR } & \text { NS } & 374089.3 & 295883.6 \\ \text { E38 } & \text { PROL } & \text { NS } & 33689.78 & 256547.4 \\ \text { E39 } & \text { INACTIVE } & \text { NS } & 53867.4 & 1521953 \\ \text { E40 } & \text { PROL } & \text { SM** } & 96553.12 & 428051.7 \\ \text { E41 } & \text { SECR } & \text { NS } & 274711.9 & 574076.6 \\ \text { E42 } & \text { PROL } & \text { NS } & 68775.67 & 29237.53 \\ \text { E43 } & \text { SECR } & \text { SM } & 279421.2 & 101713.1 \\ & & & & \\ & & & & \text { Contd... }\end{array}$


Contd..

\section{A3/3A4 and 3A7 DATA ON CERVIX}

$\begin{array}{lcccc} & & & \mathbf{3 A 3} \mathbf{3 A 4} & \mathbf{3 A 7} \\ \text { C33 } & \text { PROL } & \text { SM } & 0 & 0 \\ \text { C34 } & \text { PROL } & \text { SM } & 18427 & 533427 \\ \text { C35 } & \text { SECR } & \text { SM } & 0 & 0 \\ \text { C36 } & \text { PROL } & \text { SM } & 12748 & 59205 \\ \text { C37 } & \text { SECR } & \text { SM } & 30978 & 615701 \\ \text { C38 } & \text { SECR } & \text { NS } & 15755 & 1522111 \\ \text { C39 } & \text { SECR } & \text { NS } & 0 & 922991 \\ \text { C40 } & \text { SECR } & \text { NS } & 0 & 0 \\ \text { C41 } & \text { SECR } & \text { NS } & 0 & 1111309 \\ \text { C42 } & \text { SECR } & \text { NS } & 0 & 0 \\ \text { C51 } & \text { INACTIVE } & \text { NS } & 8260.72 & 619157.8 \\ \text { C52 } & \text { SECR } & \text { SM* } & 0 & 35017.32 \\ \text { C53 } & \text { PROL } & \text { NS } & 1754.84 & 18999.14 \\ \text { C54 } & \text { PROL/CA } & \text { NS } & 0 & 9095.2 \\ \text { C56 } & \text { SECR } & \text { NS } & 1411.7 & 10089.04 \\ \text { C57 } & \text { SECR } & \text { SM } & 3002.82 & 19757.01 \\ \text { C58 } & \text { SECR } & \text { NS } & 0 & -205.07 \\ \text { C59 } & \text { PROL } & \text { NS } & 0 & 536.31 \\ \text { C60 } & \text { INACTIVE } & \text { NS } & 2636.4 & 14631.52 \\ \text { C61 } & \text { PROL } & \text { SM** } & 1422.36 & 8284.52 \\ \text { C62 } & \text { SECR } & \text { NS } & 29144.06 & 9226.17 \\ \text { C63 } & \text { PROL } & \text { NS } & 2312.09 & 14586.55 \\ \text { C64 } & \text { SECR } & \text { SM } & 1941.52 & 7218.67\end{array}$

* This is the only case who is black.

**Smoker for 12 years but quit smoking in 1973. 


\section{CHAPTER 6}

\section{DISCUSSION}




\section{DISCUSSION}

The CYP1A1 and CYP1B1 isoforms are key enzymes in the formation of reactive metabolites from procarcinogens (Juchau et al.1982; Kawajiri et al. 1991; Kociba et al. 1978) and therefore play an important role in determining the carcinogenic outcome. Variability in the expression of these enzymes in barrier extrahepatic tissues e.g. lung (Liehr et al. 1986) may provide an explanation for differential susceptibility to neoplasia in some individuals. To date, no reports exist regarding evaluation of the constituent expression of CYP1A1 and CYP1B1 in human uterine tissue. While CYP1A1 is generally believed to be predominantly an extrahepatic enzyme (Liehr et al. 1996), CYP1B1 is also expressed constitutively in extrahepatic organs such as breast, prostate and lung (Liehr et al. 1995). Moreover, recent findings suggest that CYP1B1 is a key enzyme in estradiol hydroxylation (Hayes et al. 1996). The catechol estrogens lead to inactivation of estrogenic activity, however, they are toxicologically active and appear to play a role in toxicity and tumorigenesis (Liehr et al. 1990; Lucier et al. 1991). The mechanism for these toxic effects appears to involve free radicals, generated from the reductive-oxidative cycling of the catechol estrogens with their corresponding semiquinone and quinone forms, which cause cellular damage (McManus et al. 1990; Nutter et al. 1994; Shimada, et al. 1989). Therefore, alterations in the expression of these two isoforms may help us better understand the role of procarcinogen activation in human tumors of extrahepatic origin.

In our study we have shown that CYP1A1 and CYP1B1 are constitutively expressed in the endometrial tissue of the human uterus which does not seem to vary significantly in nonsmoking women without malignant indications. Although we observed a significantly lower 
expression of CYP1B1 in a patient with secretory endometrium, further investigation is indicated to determine if the menstrual phase could account for this observation. It can be speculated that the variations in hormonal levels during the menstrual cycle may impact the expression of CYP1B1, particularly in regard to the endocrine regulatory role of this enzyme. Interestingly, even though CYP1A1 is predominantly an extrahepatic enzyme, expression of this isoform was minimal in the cervix and squamous region (except for patient \#3). Probably due to proliferative nature of the endometrial glands and the sensitive responsiveness of this tissue to hormonal influences, the CYP1 family isoforms are constitutively expressed in the endometrium. Metabolism of estrogens is primarily hepatic, nevertheless some metabolism has been observed in physiologically relevant extrahepatic tissues e.g. breast (Shimada et al. 1992), uterus (Hakkola et al. 1996) and placenta (Sutter et al. 1994). It is likely that the constitutive expression of CYP1A1 and CYP1B1 in human endometrium plays a critical role in the localized metabolism of estrogens. Differential expression of these isoforms may have an impact on the extent of localized inactivation of the estrogens and hence may determine the physiologic and toxicologic outcome.

The study included 22 patients in whom expression of CYP1A1 and CYP1B1 in three different regions with respect to smoking and nonsmoking status and also different stages of menstrual cycle have been considered. In particular, mRNA encoding for CYP1B1 was completely absent from the squamous (exocervix) region and was not expressed in cervix of more than half of the patients. Moreover, significant expression of CYP1B1 was observed in the endometrium, which appeared to vary with the menstrual phase. Transcripts coding for CYP1A1 appeared to be significantly induced in the cervix of smokers compared to nonsmokers, but 
differences in phases of menstrual cycle had no apparent effect on the expression of that isozyme. Such variable expression of CYP1A1 and CYP1B1, in different regions of the uterus of smokers and nonsmokers, could explain the differential susceptibility of smokers and nonsmokers to cervical and endometrial cancer.

Variability in the expression of these enzymes in barrier and extrahepatic tissues such as lung (Shimada et al. 1992) and uterus may provide an explanation for differential susceptibility to neoplasia in some individuals. Similar to CYP1A1, which is generally believed to be predominantly an extrahepatic enzyme (Masters et al. 1987), CYP1B1 is also expressed constitutively in extrahepatic tissues such as breast, prostate and lung (Brake et al. 1995). These data confirm a recent report of CYP1B1 expression in endometrium (Murray et al. 1997). Moreover, recent findings suggest that CYP1B1 is a key enzyme in estradiol hydroxylation (Hayes et al. 1996). Catechol estrogens lead to inactivation of estrogenic activity, however, they are toxicologically active and appear to play a role in tumorigenesis (Ikawa et al. 1995; Murray et.al.1997). The mechanism by which these toxic effects occur involves formation of free radicals, generated by the reductive-oxidative cycling of the catechol estrogens with their corresponding semiquinone and quinone forms, causing cellular damage (Liehr et al. 1990, Dwivedy et al. 1992; Nutter et. al 1994). Therefore, while CYP1A1 is a key enzyme involved in activation of procarcinogens from cigarette smoke and other environmental pollutants, CYP1B1 plays an equally important role in promoting estrogen induced cancers.

The patient demographic data (Tables 1,2 and 3) do not indicate prolonged enzyme releasing therapy. However, some individual response for specific CYP enzymes can not be ruled out. That kind of analysis is outside the purview of this study. So, based on the overview 
of medication, length of use of drugs and disease conditions, it is reasonable to assume that expression of CYPs is modulated by factors other than drugs and disease of the patients.

The CYP1A1 mRNA is significantly induced in smokers whereas the CYP1B1 mRNA appears to be down regulated. Although, each isoform is thought to be induced via the nuclear ligand/Ah receptor complexes, mediated atypical induction (Eugster et al. 1993; Nebert et al. 1994), profiles for these isoforms have been observed in other extrahepatic tissues. For example, in the glomerular mesangial cell (Bowes et al.1996) as well as the liver, lung and thymus (Vogel et al. 1997), TCDD induces CYP1B1 more effectively than CYP1A1. Whereas the pattern of induction is reversed with benzo(a)pyrene (Bowes et al. 1996), CYP1A1 is induced predominantly, without much effect on CYP1B1. It seems likely that such a differential induction of CYP1A1 and CYP1B1 mRNA is occurring in the uterine tissue of smokers. Not only are there differences between the two isoforms, but regiospecific induction of CYP1A1 occurs in the uterus. A 12-fold increase in CYP1A1 mRNA was seen in the cervix, whereas only a 2-fold induction of CYP1A1 mRNA was observed in the endometrium and squamous (exocervix) region. It is well established that PAHs influence the accumulation of the CYP1A mRNAs by both transcriptional and post-transcriptional mechanisms (Pasco et al. 1988). It has also been shown that induction of CYP1A mRNA is followed by a proportional increase in catalytic activity (Pasanen et al. 1988). Since CYP1A1 is the key enzyme involved in the conversion of benzo(a)pyrene to highly reactive epoxides (Miller et.al. 1990), increased enzyme levels would generate greater amounts of reactive metabolites. This increased CYP1A1 activity and expression might explain the increased risk of cervical cancer in some smokers. Further evidence of carcinogenicity of PAHs from cigarette smoke in the cervix is provided by the 
appearance of elevated levels of DNA adducts in cervical epithelium (Otsuki et al.1994). Interestingly, the patient previously treated for CIN III had no detectable CYP1A1 mRNA, probably because the atypical tissue at the squamous-columnar epithelial junction had been completely removed during the previous surgical procedure.

A significantly lower expression of CYP1B1 $(\mathrm{p}<0.05)$ in patients with secretory endometrium and absence of detectable mRNA in the postmenopausal women (patients \# 15 and \#19) suggest that CYP1B1 regulation is altered during the menstrual cycle. The endometrium responds to ovarian steroid hormones in a series of clearly distinct phases which characterize the menstrual cycle. Estrogen dependent proliferation and progesterone dependent differentiation of the endometrium are well documented. Cyclic expression of other genes during the menstrual cycle has been previously reported (Loza et al. 1991). It can be speculated that hormonal variation during the menstrual cycle may have some impact on the expression of CYP1B1, particularly due to the endocrine regulatory role of this enzyme. It is possible that the constitutive expression of CYP1A1 and CYP1B1 in the human endometrium plays a critical role in the localized metabolism of estrogens. This is particularly relevant since some estrogen metabolism has been observed in the uterus (Sholl et. al 1983; Rock et al. 1994). The significance of variation in expression of CYP1B1 in the menstrual cycle is borne out by the observation that endometrial cancer most commonly occurs in women who do not ovulate regularly. Such cases commonly show a persistence of proliferative endometrium along with absence of secretory endometrium. Based on our results, it can be speculated that in some women a differential expression of the CYP1B1 isoforms may exist, thereby increasing 
susceptibility to exposure from catechol estrogens resulting from localized estrogen metabolism in the endometrium.

It has been demonstrated that human endometrium, as well as cervix from women undergoing hysterectomy for benign conditions, express CYP3A4 and CYP3A7. This observation supports the previous finding of CYP3A7 mRNA in endometrium from 5 pregnant women (Schuetz et al. 1993). The appearance of the CYP3A isoform was documented by RT-PCR, and southern blot hybridization techniques. Based on the results, it appears that human cervix minimally expresses CYP3A isoforms, however significant expression is seen in the endometrium that is highly variable, possibly due to cyclic expression. Particularly, the CYP3A7 mRNA appeared to be much higher in the proliferative phase compared to the secretory phase. The expression of CYP3A4 and CYP3A7 mRNA in human endometrium suggests that it might be an important site for intermediary steroid metabolism. The CYP3A family is known to be inducible, for example the CYP3A mRNA increases in response to the administration of synthetic and natural glucocorticoids (Molowa et al. 1986; Scheutz et al. 1984), macrolide antiobiotics (Watkins et al. 1986), rifampin and rifabutin (Oesch et al. 1996), environmental agents such as polychlorinated biphenyls (PCBs) and organochlorine pesticides (Scheutz et al. 1986). We observed an increase in the CYP3A7 mRNA in endometrium associated with the menstrual phase. The possibility of enzyme induction cannot be ruled out, particularly by exposure to PCBs, dichlorodiphenyltrichlorethane and other persistent lipophilic environmental agents that are virtually ubiquitous in the general US population (Stehr-Green et al. 1986). However, the increase in CYP3A7 mRNA occurred consistently in the proliferative phase in most patients, suggesting that the changes in the amounts of endogenous substrates and 
hormones can affect CYP3A expression in the endometrium. The reported 3 to 4 -fold increase in endometrial tissue concentrations of DHEA-s, a known substrate for CYP3A7 (Kitada et.al. 1987), during the secretory phase in premenopausal women (Bonney et al. 1984) coincides with the decreased levels of CYP3A7 seen in our study. Transcription for the rat liver CYP3A isoform, CYP3A1, is controlled by a nonclassical glucocorticoid receptor mediated process (Burger et al. 1992.). Moreover, the synthetic glucocorticoid agonist, dexamethasone, induces CYP3A7 mRNA in the human hepatoblastoma HEPG2 (Beach et al. 1992) through transcriptional activation of CYP3A7. These observations suggest that steroid hormones and their receptors play a role in the regulation of CYP3A7. The 11 beta-hydroxysteroid dehyrogenase type II enzyme, a potent inactivator of glucocorticoids, is significantly lower during the proliferative phase compared to the secretory phase of the menstrual cycle (Smith et.al.1997), probably resulting in higher tissue levels of glucocorticoids. Moreover, the endometrial mRNA levels of coritocosteroid binding globulin (CBG) which binds steroid hormones and plays a role in their transportation, were significantly higher in the secretory phase compared to the proliferative phase (Misao et.al. 1994). These findings suggest that high tissue specific levels of CBG, in the endometrium would result in increased binding of glucocorticoids thereby reducing the exposure of endometrium to free glucocorticoids. This decreased tissue specific exposure to glucocorticoids might account for the relative downregulation of CYP3A7 in secretory phase, since this isoform is susceptible to glucocorticoid induction. Further investigations are necessary to clearly elucidate whether the increased mRNA levels of CYP3A7 in the proliferative phase are due to upregulation, or lower mRNA levels in the secretory phase are due to downregulation. 
Panel: A

\begin{tabular}{|c|c|c|}
\hline \multicolumn{2}{|r|}{ 3A3/A4 } & $3 \mathrm{~A} 7$ \\
\hline & E $\quad C$ & E $\quad C$ \\
\hline & $\downarrow$ & 1 \\
\hline SM & not significant & not significant \\
\hline NS & $\begin{array}{l}\text { significant } \\
(\mathrm{E}>\mathrm{C})\end{array}$ & $\begin{array}{l}\text { Significant } \\
(E>C)\end{array}$ \\
\hline
\end{tabular}

Panel: B

\begin{tabular}{|ccc|}
\hline & ENDO & CERV \\
& 3A3---3A7 & 3A3---3A7 \\
& & \\
SM & significant & not significant \\
& $(3 \mathrm{~A} 3<3 \mathrm{~A} 7)$ & \\
& & \\
NS & not significant & Significant \\
& & $(3 \mathrm{~A} 3<3 \mathrm{~A} 7)$ \\
& & \\
& & \\
\hline
\end{tabular}

Figure: 6.1. The comparative analysis of CYP3A expressions in endometrium and cervix

Both enzymes CYP3A3/A4 and CYP3A7 have exhibited a possible interdependent relationship in their induction in uterine tissue in smokers and nonsmokers. Only nonsmokers exhibited significant expression of these enzymes in endometrium, which is due to higher estrogen stimulus present in this tissue. Further, the endometrial tissue is in a state of continuous growth and DNA also is in continuous and regular replication, which explains the enhanced induction and expression of their mRNA. Whereas in smokers, absence of this phenomenon explains that constitutive presence of smoking related procarcinogens alter the induction levels of these CYPs in the both regions of cervix and endometrium. Inactivation of procarcinogens like BP is catalyzed by these CYPs, which are also involved in estrogen metabolism. Therefore levels of CYP3A7 and CYP3A3/A4 enzymes were elevated among smokers (Figure 6.1-A). The 
differential expression of these two isozymes in the same tissue within the group of smokers and nonsmokers reveals similar findings and agrees with the hypothesis of CYP mediated BP catalysis in uterine tissue. The smokers exhibited elevated levels of CYP3A3/A4 more than CYP3A7 in endometrium. Similar significance was evident in nonsmokers in cervix region. This explains the relative importance of CYP3A3/A4. BP induces CYP3A3/A4, which participates in estrogen metabolism. Thus, there is the least chance of overexposure of estrogen in endometrial tissues among smokers. This explains the phenomenon of smokers exhibiting reduced incidence of endometrial cancer. In nonsmokers CYP3A7 is significantly higher in cervix which possibly offers protective mechanism against estrogen exposure (Figure 6.1-B). Both of these enzymes have shown a balanced expression in nonsmokers endometrium and smokers cervix. The absence of statistical significance may not disprove the relative roles of these enzymes, however the differences in the expression of both isoforms could be clinically significant. The location of enhanced activity for CYP3A7 in cervix seemed to translocate to endometrium region among smokers possibly due to some intracellular mechanism or through higher levels of BP like procarcinogens present in cigarette smoking. 
CHAPTER 7

CONCLUSIONS 


\section{CONCLUSIONS}

1. Evaluation of cytochrome P450 expression in uterine tissue revealed that CYP1A1 CYP1B1 and CYP3A3/A4 and CYP3A7 isoforms are constitutively expressed in endometrium, endocervix and squamous (exocervix) regions. The expression levels are variable in the tissues depending on the cyclic changes and nature of the tissue, which are also dependent on other metabolic stimulii.

2. Smoking induced the expression of CYP1A1, CYP3A3/A4 and CYP3A7 in differential manner depending on the stages of endometrium.

3. Differential expression of these isoforms was indicative of CYP involvement in smoking related carcinogenesis.

4. Expression of CYP1B1 was significantly higher in endometrium and extremely low in secretory stage of menstrual phase whereas expression of CYP1A1 was significantly higher in squamous region. A 20-fold increase in CYP1B1 was observed in endometrium of proliferative phase. CYP1B1 was expressed in only 2 out of 6 patients in squamous (exocervix) region, and 3 out of 5 patients in cervix. CYP1A1 was expressed in the endometrium of all except one patient. No difference for CYP1A1 mRNA expression could be observed in the three regions when compared to proliferative or secretory phases of menstrual cycle

5. CYP1B1 expression appeared to be lower in smokers by 3-fold and no measurable expression was seen in squamous (exocervix) region. A 12-fold increase in expression of CYP1A1 was evident in cervix of smokers compared to nonsmokers.

6. CYP3A isoforms are expressed in human endometrium. Cyclic variability of CYP3A3/4 and CYP3A7 during the proliferative and secretory phase might be due to the variations in hormonal 
levels in the uterus. Differential expression of the CYP3A isoforms suggests possible physiological function of these enzymes in the uterus.

7. Differential expression of CYP3A isoforms in the menstrual phase between smokers and nonsmokers suggests that these enzymes might play a role in the toxicological outcome in the uterus. No difference in expression of CYP3A3/3A4 was observed in different stages of endometrium.

8. Significant decrease of CYP3A3/3A4 was observed among smokers by 30 -fold than nonsmokers in secretory phase. Expression of CYP3A7 increased 17-fold in proliferative stage than in secretory phase in endometrium.

9. A 40-fold and 20-fold higher expression, respectively of CYP3A7 and CYP3A3/3A4 were observed in proliferative and secretory phases in smokers.

10. No significant difference was noticed for either of isoforms in different menstrual phases among overall comparison of smokers and nonsmokers. 


\section{CHAPTER 8}

FUTURE RESEARCH DIRECTIONS 


\section{FUTURE RESEARCH DIRECTIONS}

The identifiction of cytochromes and their characterization significantly improves our understanding of drug metabolism. The related genotoxic studies help to identify the susceptability to various xenobiotics in different individuals. However, investigations should be aimed at the identification of cytochrome P450s in a non-invasive, rapid and accurate manner sothat, bench mark susceptibility levels could be determined. Genetic predisposition studies could be directed to the detection of active cytochrome gene expression and to use them as biomarkers.

CYP genes appear to be primarily regulated at the transcriptional level. Some reports implicate post transcriptional and post translational regulation in rabbits (Costas 1996). It would seem therefore, the post translational investigation of CYP3A will give more information on how CYP3A is able to contribute to carcinogenesis.

Possible small nuclear proteins associated with cytochromes may be implicated in activating the CYP enzymes which could be investigated or identified to substantiate the signal transduction process of bulky DNA adduct formation. The targetting of drugs could be investigated with respect to their ability to induce various CYPs.

Following populations could be studied to gain additional insight on cancer.

a) Populations suffering with cancer due to environmental estrogens or potentially exposed to PAH in smoke or cigarette smoking.

b) Populations, those are demographically matched with smoking and nonsmoking status but are not suffering from cancer. 
The expression levels of cytochrome $\mathrm{P} 450$ s relating to various races or geographic localization would throw light on susceptibility to carcinogenicity due to CYP inductions in those populations. Further studies to assess the high risk populations of uterine cancer by measuring genetic expressions of CYP enzymes and the associated polymorphisms will help in addressing the preventive and environmental scanning measures.

Mutation in DNA repair proteins, which are likely to contribute to excessive proliferation of endometrial tissue can be investigated. This would validate that proliferation alone is the contributory engine for carcinogenesis. Some of the oncogene activation and disturbance in apoptotic response due to CYP activation could be studied in uterine cancer where investigations on tumor suppressor genes and oncogenes in uterine cancer are likely to be the future areas of interest. It is also possible that other CYP families may be involved in endometrial and cervical cancer development, which can be investigated further. CYP activation is of major interest to drug industry for its role in predicting cytotoxicity. It still needs to be confirmed that CYP induction is the predisposing factor. 


\section{BIBLIOGRAPHY}




\section{BIBLIOGRAPHY}

1. Akiba,S. and Hirayama,T. (1990) Cigarette smoking and cancer mortality risk in Japanese men and women--results from reanalysis of the six-prefecture cohort study data. Environ.Health Perspect., 87, 19-26.

2. American Cancer Society, Atlanta. Cancer facts and figures. 1998. Ref Type: Pamphlet

3. Anttila,S., Hietanen,E., Vainio,H., Camus,A.M., Gelboin,H.V., Park,S.S., Heikkila,L., Karjalainen,A., and Bartsch,H. (1991) Smoking and peripheral type of cancer are related to high levels of pulmonary cytochrome P450IA in lung cancer patients. Int.J.Cancer, 47, 681-685.

4. Aoyama,T., Korzekwa,K., Nagata,K., Gillette,J., Gelboin,H.V., and Gonzalez,F.J. (1990) Estradiol metabolism by complementary deoxyribonucleic acid-expressed human cytochrome P450s. Endocrinology, 126, 3101-3106.

5. Austin,H., Drews,C., and Partridge,E.E. (1993) A case-control study of endometrial cancer in relation to cigarette smoking, serum estrogen levels, and alcohol use. Am.J.Obstet.Gynecol., 169, 1086-1091.

6. Bailar,J.C. (1963) The incidence of independent tumors among uterine cancer patients. Cancer, 16, 842-853.

7. Barber,H.R.K. (1989) Cancer of endometrium. Gynecol.Oncol.,232.

8. Baron,J.A., Byers,T., Greenberg,E.R., Cummings,K.M., and Swanson,M. (1986) Cigarette smoking in women with cancers of the breast and reproductive organs. J.Natl.Cancer Inst., 77, 677-680.

9. Beach,D.L., Schuetz,J.D., and Guzelian,P. (1992) Regulation of expression of cytochrome p450 HFLA by dexamethasone in the human hepatoblastoma HEP G2. FASEB (Fed.Am.Soc.Exp.Biol.) J., 6, 1951.

10. Berliner DL and Salhanick HA. (1956) The presence of 6- $\beta$-hydroxylase in human placenta. Clin.Endocrinol.Metab, 16, 903-904. 
11. Berne, H. A. Diethylstilbestrol (DES) Syndrome: Present status of animal and human studies. 1992.

Ref Type: Report

12. Bibbo,M., Dytch,H.E., Alenghat,E., Bartels,P.H., and Wied,G.L. (1989) DNA ploidy profiles as prognostic indicators in CIN lesions. Am.J.Clin.Pathol., 92, 261-265.

13. Bonney,R.C., Scanlon,M.J., Jones,D.L., Reed,M.J., and James, V.H. (1984) Adrenal androgen concentrations in endometrium and plasma during the menstrual cycle. J.Endocrinol., 101, 181-188.

14. Bowes,R.C., III, Parrish,A.R., Steinberg,M.A., Willett,K.L., Zhao,W., Savas,U., Jefcoate,C.R., Safe,S.H., and Ramos,K.S. (1996) Atypical cytochrome P450 induction profiles in glomerular mesangial cells at the mRNA and enzyme level. Evidence for CYP1A1 and CYP1B1 expression and their involvement in benzo[a]pyrene metabolism. Biochem.Pharmacol., 52, 587-595.

15. Brake,P.B., Chirstou,M., Savas,U., Bhattacharya,K.K., Alexander,D.L., Larsen,M., and Jefocate,C.R. (1995) Selective expression and hormonal regulation of Cytochrome p 450 1B1 in mammary cells. Proc.Am.Assoc.Cancer Res., 36, 257.

16. Brian,W.R., Sari,M.A., Iwasaki,M., Shimada,T., Kaminsky,L.S., and Guengerich,F.P. (1990) Catalytic activities of human liver cytochrome P-450 IIIA4 expressed in Saccharomyces cerevisiae. Biochemistry, 29, 11280-11292.

17. Brinton,L.A., Schairer,C., Haenszel,W., Stolley,P., Lehman,H.F., Levine,R., and Savitz,D.A. (1986) Cigarette smoking and invasive cervical cancer. JAMA, 255, 3265-3269.

18. Brinton,L.A., Barrett,R.J., Berman,M.L., Mortel,R., Twiggs,L.B., and Wilbanks,G.D. (1993) Cigarette smoking and the risk of endometrial cancer. Am.J.Epidemiol., 137, 281-291.

19. Brisson,J., Morin,C., Fortier,M., Roy,M., Bouchard,C., Leclerc,J., Christen,A., Guimont,C., Penault,F., and Meisels,A. (1994) Risk factors for cervical intraepithelial neoplasia: differences between low- and high-grade lesions. Am.J.Epidemiol., 140, 700-710.

20. Brookes,P. and Duncan,M.E. (1971) Carcinogenic hydrocarbons and human cells in culture. Nature, 234, 40-43. 
21. Burger,H.J., Schuetz,J.D., Schuetz,E.G., and Guzelian,P.S. (1992) Paradoxical transcriptional activation of rat liver cytochrome P-450 3A1 by dexamethasone and the antiglucocorticoid pregnenolone 16 alpha-carbonitrile: analysis by transient transfection into primary monolayer cultures of adult rat hepatocytes. Proc.Natl.Acad.Sci.U.S.A, 89, 2145-2149.

22. Butler,M.A., Iwasaki,M., Guengerich,F.P., and Kadlubar,F.F. (1989) Human cytochrome P-450PA (P-450IA2), the phenacetin O-deethylase, is primarily responsible for the hepatic 3-demethylation of caffeine and $\mathrm{N}$-oxidation of carcinogenic arylamines. Proc.Natl.Acad.Sci.U.S.A, 86, 7696-7700.

23. Conney,A.H. (1982) Induction of microsomal enzymes by foreign chemicals and carcinogenesis by polycyclic aromatic hydrocarbons: G. H. A. Clowes Memorial Lecture. Cancer Res., 42, 4875-4917.

24. Costas Ioannides. (1996) Cytochromes P450. CRC Press, London.

25. Daniell,H.W. (1978) Smoking, obesity, and the menopause [letter]. Lancet, 2, 373.

26. Dannan,G.A., Porubek,D.J., Nelson,S.D., Waxman,D.J., and Guengerich,F.P. (1986) 17 beta-estradiol 2-and 4-hydroxylationcatalyzed by rat hepatic cytochrome $\mathrm{p} 450$ : Roles of individual forms inductive effects, developmental patterns and alterations by gonadectomy and hormone replacement. Endocrinology, 118, 1952-1960.

27. Denissenko,M.F., Pao,A., Tang,M., and Pfeifer,G.P. (1996) Preferential formation of benzo[a]pyrene adducts at lung cancer mutational hotspots in P53. Science, 274, 430-432.

28. Dorman,B.H., Genta,V.M., Mass,M.J., and Kaufman,D.G. (1981) Benzo(a)pyrene binding to DNA in organ cultures of human endometrium. Cancer Res., 41, 2718-2722.

29. Durst,M., Gissmann,L., Ikenberg,H., and zur,H.H. (1983) A papillomavirus DNA from a cervical carcinoma and its prevalence in cancer biopsy samples from different geographic regions. Proc.Natl.Acad.Sci.U.S.A, 80, 3812-3815.

30. Dwivedy,I., Devanesan,P., Cremonesi,P., Rogan,E., and Cavalieri,E. (1992) Synthesis and characterization of estrogen 2,3- and 3,4-quinones. Comparison of DNA adducts formed by the quinones versus horseradish peroxidase-activated catechol estrogens. Chem.Res.Toxicol., 5, 828-833. 
31. el Bayoumy,K. (1992) Environmental carcinogens that may be involved in human breast cancer etiology. Chem.Res.Toxicol., 5, 585-590.

32. Eshleman,J.R. and Markowitz,S.D. (1995) Microsatellite instability in inherited and sporadic neoplasms. Curr.Opin.Oncol., 7, 83-89.

33. Ethier,S.P. (1995) Growth factor synthesis and human breast cancer progression [see comments]. J.Natl.Cancer Inst., 87, 964-973.

34. Eugster,H.P., Probst,M., Wurgler,F.E., and Sengstag,C. (1993) Caffeine, estradiol, and progesterone interact with human CYP1A1 and CYP1A2. Evidence from cDNAdirected expression in Saccharomyces cerevisiae. Drug Metab Dispos., 21, 43-49.

35. Falck,F., Jr., Ricci,A., Jr., Wolff,M.S., Godbold,J., and Deckers,P. (1992) Pesticides and polychlorinated biphenyl residues in human breast lipids and their relation to breast cancer. Arch.Environ.Health, 47, 143-146.

36. Fishman,J. (1976) The catechol estrogens. Neuroendocrinology, 22, 363-374.

37. Fishman,J., Schneider,J., Hershcope,R.J., and Bradlow,H.L. (1984) Increased estrogen-16 alpha-hydroxylase activity in women with breast and endometrial cancer. J.Steroid Biochem., 20, 1077-1081.

38. Fornander,T., Rutqvist,L.E., Cedermark,B., Glas,U., Mattsson,A., Silfversward,C., Skoog,L., Somell,A., Theve,T., and Wilking,N. (1989) Adjuvant tamoxifen in early breast cancer: occurrence of new primary cancers. Lancet, 1, 117-120.

39. Frederick M.Ausubel, Roger Brent, Robert E.Kingston, David D.Moore, J.G.Seidman, John A.Smith, and Kevin Struhl (1987) Current protocols in molecular biology. John Wiley \& Sons, Inc..

40. Fujii-Kuriyama,Y., Mizukami,Y., Kawajiri,K., Sogawa,K., and Muramatsu,M. (1982) Primary structure of a cytochrome P-450: coding nucleotide sequence of phenobarbital-inducible cytochrome P-450 cDNA from rat liver. Proc.Natl.Acad.Sci.U.S.A, 79, 2793-2797.

41. Gelboin,H.V. (1980) Benzo[alpha]pyrene metabolism, activation and carcinogenesis: role and regulation of mixed-function oxidases and related enzymes. Physiol Rev., 60, 1107-1166. 
42. Geneste,O., Camus,A.M., Castegnaro,M., Petruzzelli,S., Macchiarini,P., Angeletti,C.A., Giuntini,C., and Bartsch,H. (1991) Comparison of pulmonary DNA adduct levels, measured by 32P-postlabelling and aryl hydrocarbon hydroxylase activity in lung parenchyma of smokers and ex-smokers. Carcinogenesis, 12, 1301-1305.

43. Goshman,L.M. and Heidelberger,C. (1967) Binding of tritium-labeled polycyclic hydrocarbons to DNA of mouse skin. Cancer Res., 27, 1678-1688.

44. Guengerich F.P. (1987) Enzymology of rat liver cytochrome P-450. In Mammalian Cytochrome P-450. In Guengerich F.P.(ed.) (ed.) CRC Press Inc., Boca Raton, FL., Vol I, pp 1-54.

45. Guengerich F.P., Shimada,T., Johnson,W.W., and Yueng,Y.F. (1996) Activation of carcinogens by human cytochrome p450 1B1 and inactivation by glutathione Stransferases. Proc.Am.Assoc.Cancer Res., 37, 664.

46. Guengerich,F.P. (1988) Oxidation of 17 alpha-ethynylestradiol by human liver cytochrome P-450. Mol.Pharmacol., 33, 500-508.

47. Hakkola,J., Raunio,H., Purkunen,R., Pelkonen,O., Saarikoski,S., Cresteil,T., and Pasanen,M. (1996) Detection of cytochrome P450 gene expression in human placenta in first trimester of pregnancy. Biochem.Pharmacol., 52, 379-383.

48. Hakkola,J., Pasanen,M., Hukkanen,J., Pelkonen,O., Maenpaa,J., Edwards,R.J., Boobis,A.R., and Raunio,H. (1996) Expression of xenobiotic-metabolizing cytochrome P450 forms in human full-term placenta. Biochem.Pharmacol., 51, 403-411.

49. Hakkola,J., Pasanen,M., Pelkonen,O., Hukkanen,J., Evisalmi,S., Anttila,S., Rane,A., Mantyla,M., Purkunen,R., Saarikoski,S., Tooming,M., and Raunio,H. (1997) Expression of CYP1B1 in human adult and fetal tissues and differential inducibility of CYP1B1 and CYP1A1 by Ah receptor ligands in human placenta and cultured cells. Carcinogenesis, 18, 391-397.

50. Hayes,C.L., Spink,D.C., Spink,B.C., Cao,J.Q., Walker,N.J., and Sutter,T.R. (1996) 17 betaestradiol hydroxylation catalyzed by human cytochrome P450 1B1. Proc.Natl.Acad.Sci.U.S.A, 93, 9776-9781.

51. Hecht,S.S. and Hoffmann,D. (1988) Tobacco-specific nitrosamines, an important group of carcinogens in tobacco and tobacco smoke. Carcinogenesis, 9, 875-884. 
52. Hellberg,D., Valentin,J., and Nilsson,S. (1986) Smoking and cervical intraepithelial neoplasia. An association independent of sexual and other risk factors? Acta Obstet.Gynecol.Scand., 65, 625-631.

53. Hellberg,D., Nilsson,S., Haley,N.J., Hoffman,D., and Wynder,E. (1988) Smoking and cervical intraepithelial neoplasia: nicotine and cotinine in serum and cervical mucus in smokers and nonsmokers. Am.J.Obstet.Gynecol., 158, 910-913.

54. Henderson,B.E., Ross,R., and Bernstein,L. (1988) Estrogens as a cause of human cancer: the Richard and Hinda Rosenthal Foundation award lecture. Cancer Res., 48, 246253.

55. Herrington,D.M., Gordon,G.B., Achuff,S.C., Trejo,J.F., Weisman,H.F., Kwiterovich,P.O., Jr., and Pearson,T.A. (1990) Plasma dehydroepiandrosterone and dehydroepiandrosterone sulfate in patients undergoing diagnostic coronary angiography. J.Am.Coll.Cardiol., 16, 862-870.

56. Hirose,K., Tajima,K., Hamajima,N., Takezaki,T., Inoue,M., Kuroishi,T., Kuzuya,K., Nakamura,S., and Tokudome,S. (1996) Subsite (cervix/endometrium)-specific risk and protective factors in uterus cancer. Jpn.J.Cancer Res., 87, 1001-1009.

57. Hoffmann,D. and Wynder,E.L. (1976) Smoking and occupational cancers. Prev.Med., 5, 245-261.

58. Holinka,C.F. (1994) Aspects of hormone replacement therapy. Ann.N.Y.Acad.Sci., 734, 271-284.

59. Holly,E.A., Petrakis,N.L., Friend,N.F., Sarles,D.L., Lee,R.E., and Flander,L.B. (1986) Mutagenic mucus in the cervix of smokers. J.Natl.Cancer Inst., 76, 983-986.

60. Homesley,H.D. and Zaino,R. (1994) Endometrial cancer: prognostic factors. Semin.Oncol., 21, 71-78.

61. Hukkanen,J., Mantyla,M., Kangas,L., Wirta,P., Hakkola,J., Paakki,P., Evisalmi,S., Pelkonen,O., and Raunio,H. (1998) Expression of cytochrome P450 genes encoding enzymes active in the metabolism of tamoxifen in human uterine endometrium. Pharmacol.Toxicol., 82, 93-97.

62. Ikawa,S., Uematsu,F., Watanabe,K., Kimpara,T., Osada,M., Hossain,A., Sagami,I., Kikuchi,H., and Watanabe,M. (1995) Assessment of cancer susceptibility in 
humans by use of genetic polymorphisms in carcinogen metabolism.

Pharmacogenetics, 5 Spec No, S154-S160.

63. Juchau,M.R., Namkung,J., and Chao,S.T. (1982) Mono-oxygenase induction in the human placenta. Interrelationships among position-specific hydroxylations of 17 betaestradiol and benzo[a]pyrene. Drug Metab Dispos., 10, 220-224.

64. Kaderlik,K.R. and Kadlubar,F.F. (1995) Metabolic polymorphisms and carcinogen-DNA adduct formation in human populations. Pharmacogenetics, 5 Spec No, S108-S117.

65. Kapitulnik,J., Poppers,P.J., Buening,M.K., Fortner,J.G., and Conney,A.H. (1977a) Activation of monooxygenases in human liver by 7,8-benzoflavone. Clin.Pharmacol.Ther., 22 , 475-484.

66. Kapitulnik,J., Popper,P.J., and Conney,A.H. (1977b) Comparative metabolism of benzo[a]pyrene and drugs in human liver. Clin.Pharmacol.Ther., 21, 166-176.

67. Kaufman,D.G., Adamec,T.A., Walton,L.A., Carney,C.N., Melin,S.A., Genta,V.M., Mass,M.J., Dorman,B.H., Rodgers,N.T., Photopulos,G.J., Powell,J., and Grisham,J.W. (1980) Studies of human endometrium in organ culture. Methods Cell Biol., 21B, 1-27.

68. Kawajiri,K., Gotoh,O., Sogawa,K., Tagashira,Y., Muramatsu,M., and Fujii-Kuriyama,Y. (1984) Coding nucleotide sequence of 3-methylcholanthrene-inducible cytochrome P-450d cDNA from rat liver. Proc.Natl.Acad.Sci.U.S.A, 81, 1649-1653.

69. Kawajiri,K., Nakachi,K., Imai,K., Yoshii,A., Shinoda,N., and Watanabe,J. (1990) Identification of genetically high risk individuals to lung cancer by DNA polymorphisms of the cytochrome P450IA1 gene. FEBS Lett., 263, 131-133.

70. Kawajiri,K. and Fujii-Kuriyama,Y. (1991) P450 and human cancer. Jpn.J.Cancer Res., 82, 1325-1335.

71. Kelce,W.R., Stone,C.R., Laws,S.C., Gray,L.E., Kemppainen,J.A., and Wilson,E.M. (1995) Persistent DDT metabolite p,p'-DDE is a potent androgen receptor antagonist [see comments]. Nature, 375, 581-585.

72. Key,T.J. and Pike,M.C. (1988) The dose-effect relationship between 'unopposed' oestrogens and endometrial mitotic rate: its central role in explaining and predicting endometrial cancer risk. Br.J.Cancer, 57, 205-212. 
73. Khaw,K.T., Tazuke,S., and Barrett-Connor,E. (1988) Cigarette smoking and levels of adrenal androgens in postmenopausal women. N.Engl.J.Med., 318, 1705-1709.

74. Kimura,J., Kato,Y., Hirose,T., and Okada,H. (1986) Growth promotion of human endometrial adenocarcinoma cell line HHUA by prolactin. Nippon Sanka Fujinka Gakkai Zasshi, 38, 1779-1780.

75. King,R.J.B. and Whitehead,M.I. (1983) Estrogen and Progestin effects on epithelium and stroma from pre-postmenopausal endometria: application to clinical studies of the climacteric syndrome. Progress Cancer Res.Ther., 25, 105.

76. King,R.J.B. and d'Arcangues,C. (1992) Steroid hormone effects on uterine blood vessels. In Alexander,N.J. and d'Arcangues,C. (eds.) Steroid Hormones and uterine bleeding. AAAS press, $\mathrm{p} 15$.

77. Kitada,M., Kamataki,T., Itahashi,K., Rikihisa,T., and Kanakubo,Y. (1987) P-450 HFLa, a form of cytochrome P-450 purified from human fetal livers, is the 16 alphahydroxylase of dehydroepiandrosterone 3-sulfate. J.Biol.Chem., 262, 13534-13537.

78. Kociba,R.J., Keyes,D.G., Beyer,J.E., Carreon,R.M., Wade,C.E., Dittenber,D.A., Kalnins,R.P., Frauson,L.E., Park,C.N., Barnard,S.D., Hummel,R.A., and Humiston,C.G. (1978) Results of a two-year chronic toxicity and oncogenicity study of 2,3,7,8-tetrachlorodibenzo-p-dioxin in rats. Toxicol.Appl.Pharmacol., 46, 279-303.

79. Koide,A., Fuwa,K., Furukawa,F., Hirose,M., Nishikawa,A., and Mori,Y. (1999) Effect of cigarette smoke on the mutagenic activation of environmental carcinogens by rodent liver. Mutat.Res., 428, 165-176.

80. LaVoie,E.J., Prokopczyk,G., Rigotty,J., Czech,A., Rivenson,A., and Adams,J.D. (1987) Tumorigenic activity of the tobacco-specific nitrosamines 4-(methylnitrosamino)-1(3-pyridyl)-1-butanone (NNK), 4-(methylnitrosamino)-4-(3-pyridyl)-1-butanol (isoNNAL) and N'-nitrosonornicotine (NNN) on topical application to Sencar mice. Cancer Lett., 37, 277-283.

81. Li,Y., Trush,M.A., and Yager,J.D. (1994) DNA damage caused by reactive oxygen species originating from a copper-dependent oxidation of the 2-hydroxy catechol of estradiol. Carcinogenesis, 15, 1421-1427.

82. Liehr,J.G., Fang,W.F., Sirbasku,D.A., and Ari-Ulubelen,A. (1986) Carcinogenicity of catechol estrogens in Syrian hamsters. J.Steroid Biochem., 24, 353-356. 
83. Liehr,J.G. and Roy,D. (1990) Free radical generation by redox cycling of estrogens. Free Radic.Biol.Med., 8, 415-423.

84. Liehr,J.G. (1994) Mecahanism of metabolic activation and inactivation of catecholestrogens: a basis of genotoxicity. Polycyclic Aromatic Compounds., 6, 229-239.

85. Liehr,J.G., Ricci,M.J., Jefcoate,C.R., Hannigan,E.V., Hokanson,J.A., and Zhu,B.T. (1995) 4-Hydroxylation of estradiol by human uterine myometrium and myoma microsomes: implications for the mechanism of uterine tumorigenesis. Proc.Natl.Acad.Sci.U.S.A, 92, 9220-9224.

86. Liehr,J.G. and Ricci,M.J. (1996) 4-Hydroxylation of estrogens as marker of human mammary tumors. Proc.Natl.Acad.Sci.U.S.A, 93, 3294-3296.

87. Lipman MM, Katz FJ, and Jailer JW. (1962) An alternate pathway for cortisol metabolism: $6-\beta$ hydroxycortisol production by human tissue slices. J.Clin.Endocrinol.Metab., 22, 268-272.

88. Loeb,L.A. (1994) Microsatellite instability: marker of a mutator phenotype in cancer. Cancer Res., 54, 5059-5063.

89. Loza,M.C. and Hicks,J.J. (1991) Uterine estrogen sulfatase activity at the time of blastocyst implantation in the rat. J.Steroid Biochem.Mol.Biol., 39, 45-49.

90. Lucier,G.W., Tritscher,A., Goldsworthy,T., Foley,J., Clark,G., Goldstein,J., and Maronpot,R. (1991) Ovarian hormones enhance 2,3,7,8-tetrachlorodibenzo-pdioxin-mediated increases in cell proliferation and preneoplastic foci in a two-stage model for rat hepatocarcinogenesis. Cancer Res., 51, 1391-1397.

91. MacMahon,B., Trichopoulos,D., Cole,P., and Brown,J. (1982) Cigarette smoking and urinary estrogens. N.Engl.J.Med., 307, 1062-1065.

92. MacMahon,B. (1994) Pesticide residues and breast cancer? [editorial; comment]. J.Natl.Cancer Inst., 86, 572-573.

93. Mass,M.J., Rodgers,N.T., and Kaufman,D.G. (1981) Benzo[a]pyrene metabolism in organ cultures of human endometrium. Chem.Biol.Interact., 33, 195-205. 
94. Masters,B.S.S., Muerfhoff,A.S., and Okita,R.T. (1987) Enzymology of extrahepatic cytochromes p-450. In F.P.Guengerich (ed.) Mammalian Cytochromes p-450. CRC press, pp 107-31.

95. McManus,M.E., Burgess,W.M., Veronese,M.E., Huggett,A., Quattrochi,L.C., and Tukey,R.H. (1990) Metabolism of 2-acetylaminofluorene and benzo(a)pyrene and activation of food-derived heterocyclic amine mutagens by human cytochromes P450. Cancer Res., 50, 3367-3376.

96. Merriam,J.C., Easterday,C.L., McKay,D.G., and and Hertig,A.T. (1960) Experimental production of endometrial carcinoma in the rabbit. Journal of Obst.Gyn., 16, 253262.

97. Michnovicz,J.J., Hershcopf,R.J., Naganuma,H., Bradlow,H.L., and Fishman,J. (1986) Increased 2-hydroxylation of estradiol as a possible mechanism for the antiestrogenic effect of cigarette smoking. N.Engl.J.Med., 315, 1305-1309.

98. Miller,W.R. (1990) Endocrine treatment for breast cancers: biological rationale and current progress. J.Steroid Biochem.Mol.Biol., 37, 467-480.

99. Misao,R., Hori,M., Ichigo,S., Fujimoto,J., and Tamaya,T. (1994) Corticosteroid-binding globulin mRNA levels in human uterine endometrium. Steroids, 59, 603-607.

100. Mohan,P.F. and Cleary,M.P. (1989) Dehydroepiandrosterone and related steroids inhibit mitochondrial respiration in vitro. Int.J.Biochem., 21, 1103-1107.

101. Molowa,D.T., Schuetz,E.G., Wrighton,S.A., Watkins,P.B., Kremers,P., Mendez-Picon,G., Parker,G.A., and Guzelian,P.S. (1986) Complete cDNA sequence of a cytochrome P-450 inducible by glucocorticoids in human liver. Proc.Natl.Acad.Sci.U.S.A, 83, 5311-5315.

102. Moolgavkar,S.H. and Stevens,R.G. (1981) Smoking and cancers of bladder and pancreas: risks and temporal trends. J.Natl.Cancer Inst., 67, 15-23.

103. Murray,G.I., Taylor,M.C., McFadyen,M.C., McKay,J.A., Greenlee,W.F., Burke,M.D., and Melvin,W.T. (1997) Tumor-specific expression of cytochrome P450 CYP1B1. Cancer Res., 57, 3026-3031.

104. Nakayama,J., Yuspa,S.H., and Poirier,M.C. (1984) Benzo(a)pyrene-DNA adduct formation and removal in mouse epidermis in vivo and in vitro: relationship of DNA binding to initiation of skin carcinogenesis. Cancer Res., 44, 4087-4095. 
105. Nandi,S., Guzman,R.C., and Yang,J. (1995) Hormones and mammary carcinogenesis in mice, rats, and humans: a unifying hypothesis. Proc.Natl.Acad.Sci.U.S.A, 92, 36503657.

106. Nebert,D.W. and Gonzalez,F.J. (1987) P450 genes: structure, evolution, and regulation. Annu.Rev.Biochem., 56, 945-993.

107. Nebert,D.W. (1989) The Ah locus: genetic differences in toxicity, cancer, mutation, and birth defects. Crit Rev.Toxicol., 20, 153-174.

108. Nebert,D.W. and McKinnon,R.A. (1994) Cytochrome P450: evolution and functional diversity. Prog.Liver Dis., 12, 63-97.

109. Nebert,D.W., McKinnon,R.A., and Puga,A. (1996) Human drug-metabolizing enzyme polymorphisms: effects on risk of toxicity and cancer. DNA Cell Biol., 15, 273-280.

110. Nesnow,S., Ross,J.A., Stoner,G.D., and Mass,M.J. (1995) Mechanistic linkage between DNA adducts, mutations in oncogenes and tumorigenesis of carcinogenic environmental polycyclic aromatic hydrocarbons in strain A/J mice. Toxicology, 105, 403-413.

111. Newell,G.R., Rawlings,W., Krementz,E.T., and Roberts,J.D. (1974) Multiple primary neoplasms in blacks compared to whites. 3. Initial cancers of the female breast and uterus. J.Natl.Cancer Inst., 53, 369-373.

112. Newell,G.R., Krementz,E.T., and Roberts,J.D. (1975) Excess occurrence of cancer of the oral cavity, lung, and bladder following cancer of the cervix. Cancer, 36, 21552158.

113. Nischan,P., Ebeling,K., and Schindler,C. (1988) Smoking and invasive cervical cancer risk. Results from a case-control study. Am.J.Epidemiol., 128, 74-77.

114. Nutter,L.M., Wu,Y.Y., Ngo,E.O., Sierra,E.E., Gutierrez,P.L., and Abul-Hajj,Y.J. (1994) An o-quinone form of estrogen produces free radicals in human breast cancer cells: correlation with DNA damage. Chem.Res.Toxicol., 7, 23-28.

115. Oesch,F., Arand,M., Benedetti,M.S., Castelli,M.G., and Dostert,P. (1996) Inducing properties of rifampicin and rifabutin for selected enzyme activities of the cytochrome P-450 and UDP-glucuronosyltransferase superfamilies in female rat liver. J.Antimicrob.Chemother., 37, 1111-1119. 
116. Otsuki,Y., Misaki,O., Sugimoto,O., Ito,Y., Tsujimoto,Y., and Akao,Y. (1994) Cyclic bcl-2 gene expression in human uterine endometrium during menstrual cycle. Lancet, 344, 28-29.

117. Pasanen,M., Stacey,S., Lykkesfeldt,A., Briand,P., Hines,R., and Autrup,H. (1988) Induction of cytochrome P-450IA1 gene expression in human breast tumour cell lines. Chem.Biol.Interact., 66, 223-232.

118. Pasco,D.S., Boyum,K.W., Merchant,S.N., Chalberg,S.C., and Fagan,J.B. (1988) Transcriptional and post-transcriptional regulation of the genes encoding cytochromes P-450c and P-450d in vivo and in primary hepatocyte cultures. J.Biol.Chem., 263, 8671-8676.

119. Peldonen,O. (1975) Developmental change in the apparent kinetic properties of drugoxidizing enzymes in the human liver. Res.Commun.Chem.Pathol.Pharmacol., 10, 293-302.

120. Piipari,R., Savela,K., Nurminen,T., Hukkanen,J., Raunio,H., Hakkola,J., Mantyla,T., Beaune,P., Edwards,R.J., Boobis,A.R., Anttila,S., Simons,A.M., Phillips,D.H., and Coleman,D.V. (2000) Expression of CYP1A1, CYP1B1 and CYP3A, and polycyclic aromatic hydrocarbon-DNA adduct formation in bronchoalveolar macrophages of smokers and non-smokers DNA adduct assay in cervical epithelium. Int.J.Cancer, 86, 610-616.

121. Ping Li. Drug-metabolising enzymes in human endometrium. 1996. WVU. Ref Type: Thesis/Dissertation

122. Powell,W.A., Mitchell,B.F., and Challis,J.R. (1986) Effects of steroids on progesterone output by explants of human chorion. Gynecol.Obstet.Invest, 22, 64-72.

123. Rannug,A., Alexandrie,A.K., Persson,I., and Ingelman-Sundberg,M. (1995) Genetic polymorphism of cytochromes P450 1A1, 2D6 and 2E1: regulation and toxicological significance. J.Occup.Environ.Med. , 37, 25-36.

124. Reeves,W.C., Rawls,W.E., and Brinton,L.A. (1989) Epidemiology of genital papillomaviruses and cervical cancer. Rev.Infect.Dis., 11, 426-439.

125. Riou,G., Barrois,M., Sheng,Z.M., Duvillard,P., and Lhomme,C. (1988) Somatic deletions and mutations of c-Ha-ras gene in human cervical cancers. Oncogene, 3, 329-333.

126. Rock,J.A. (1994) Advances in Obstetrics and Gynecology. Mosby, Chicago, IL.. 
127. Rous,P. and Kidd,J.G. (1938) The carcinogenic effects of a papilloma virus on the tarred skin of rabbits. Journal of Exp. Med., 67, 399-424.

128. Roy,D., Strobel,H.W., and Liehr,J.G. (1991) Cytochrome b5-mediated redox cycling of estrogen. Arch.Biochem.Biophys., 285, 331-338.

129. Roy,D., Bernhard,A., Strobel,H.W., and Liehr,J.G. (1991) The microsomal oxidation of estrogen to estrogen quinone is catalyzed by cytochrome p-450 1A1.

Proc.Mt.Am.Assoc.Cancer Res..

130. Roy,D. and Liehr,J.G. (1992) Target organ-specific inactivation of drug metabolizing enzymes in kidney of hamsters treated with estradiol. Mol.Cell Biochem., 110, 3139.

131. Safe,S. and Krishnan,V. (1995) Chlorinated hydrocarbons: estrogens and antiestrogens. Toxicol.Lett., 82-83, 731-736.

132. Safe,S.H. (1995) Environmental and dietary estrogens and human health: is there a problem? [see comments]. Environ.Health Perspect., 103, 346-351.

133. Sakyo,K., Ito,A., and Mori,Y. (1987) Dehydroepiandrosterone sulfate stimulates collagenase synthesis without affecting the rates of collagen and noncollagen protein syntheses by rabbit uterine cervical fibroblasts. Biol.Reprod., 36, 277-281.

134. Sambrook,J., Fritsch,E.F., and Maniatis,T. (1987) Molecular Cloning a laboratory manual, 2nd Ed. Cold Spring Harbor Laboratory Press. Vol 3, B.1-B.28.

135. Savas,U., Bhattacharyya,K.K., Christou,M., Alexander,D.L., and Jefcoate,C.R. (1994) Mouse cytochrome P-450EF, representative of a new 1B subfamily of cytochrome P-450s. Cloning, sequence determination, and tissue expression. J.Biol.Chem., 269, 14905-14911.

136. Schuetz,E.G. and Guzelian,P.S. (1984) Induction of cytochrome P-450 by glucocorticoids in rat liver. II. Evidence that glucocorticoids regulate induction of cytochrome P450 by a nonclassical receptor mechanism. J.Biol.Chem., 259, 2007-2012.

137. Schuetz,E.G., Wrighton,S.A., Safe,S.H., and Guzelian,P.S. (1986) Regulation of cytochrome P-450p by phenobarbital and phenobarbital-like inducers in adult rat hepatocytes in primary monolayer culture and in vivo. Biochemistry, 25, 1124-1133. 
138. Schuetz,J.D., Molowa,D.T., and Guzelian,P.S. (1989) Characterization of a cDNA encoding a new member of the glucocorticoid-responsive cytochromes P450 in human liver. Arch.Biochem.Biophys., 274, 355-365.

139. Schuetz,J.D., Kauma,S., and Guzelian,P.S. (1993) Identification of the fetal liver cytochrome CYP3A7 in human endometrium and placenta. J.Clin.Invest, 92, 10181024.

140. Schwab,E.D. and Pienta,K.J. (1997) Modeling signal transduction in normal and cancer cells using complex adaptive systems. Med.Hypotheses, 48, 111-123.

141. Senler,T.I., Hofmann,G.E., Sanfilippo,J.S., Barrows,G.H., Dean,W.L., and Wittliff,J.L. (1985) Cytochrome P-450 activity in human leiomyoma and normal myometrium. Am.J.Obstet.Gynecol., 153, 551-555.

142. Shamsuddin,A.K. and Gan,R. (1988) Immunocytochemical localization of benzo(a)pyreneDNA adducts in human tissue. Hum.Pathol., 19, 309-315.

143. Shen,A.L., Fahl,W.E., and Jefcoate,C.R. (1980) Metabolism of benzo(a)pyrene by isolated hepatocytes and factors affecting covalent binding of benzo(a)pyrene metabolites to DNA in hepatocyte and microsomal systems. Arch.Biochem.Biophys., 204, 511523.

144. Shimada,T., Martin,M.V., Pruess-Schwartz,D., Marnett,L.J., and Guengerich,F.P. (1989) Roles of individual human cytochrome P-450 enzymes in the bioactivation of benzo(a)pyrene, 7,8-dihydroxy-7,8-dihydrobenzo(a)pyrene, and other dihydrodiol derivatives of polycyclic aromatic hydrocarbons. Cancer Res., 49, 6304-6312.

145. Shimada,T., Yun,C.H., Yamazaki,H., Gautier,J.C., Beaune,P.H., and Guengerich,F.P. (1992) Characterization of human lung microsomal cytochrome P-450 1A1 and its role in the oxidation of chemical carcinogens. Mol.Pharmacol., 41, 856-864.

146. Shiratori,Y., Soma,Y., Maruyama,H., Sato,S., Takano,A., and Sato,K. (1987) Immunohistochemical detection of the placental form of glutathione S-transferase in dysplastic and neoplastic human uterine cervix lesions. Cancer Res., 47, 68066809.

147. Sholl,S.A., Orsini,M.W., and Hitchins,D.J. (1983) Estrogen synthesis and metabolism in the hamster blastocyst, uterus and liver near the time of implantation. J.Steroid Biochem., 19, 1153-1161. 
148. Sierra-Santoyo,A., Hernandez,M., Albores,A., and Cebrian,M.E. (2000) Sex-dependent regulation of hepatic cytochrome P-450 by DDT. Toxicol.Sci., 54, 81-87.

149. Silver,G. and Krauter,K.S. (1988) Expression of cytochromes P-450c and P-450d mRNAs in cultured rat hepatocytes. 3-Methylcholanthrene induction is regulated primarily at the post-transcriptional level. J.Biol.Chem., 263, 11802-11807.

150. Slaughter,R.L. and Edwards,D.J. (1995) Recent advances: the cytochrome P450 enzymes. Ann.Pharmacother., 29, 619-624.

151. Smith,R.E., Salamonsen,L.A., Komesaroff,P.A., Li,K.X., Myles,K.M., Lawrence,M., and Krozowski,Z. (1997) 11 beta-Hydroxysteroid dehydrogenase type II in the human endometrium: localization and activity during the menstrual cycle.

J.Clin.Endocrinol.Metab, 82, 4252-4257.

152. Sogawa,K., Gotoh,O., Kawajiri,K., Harada,T., and Fujii-Kuriyama,Y. (1985) Complete nucleotide sequence of a methylcholanthrene-inducible cytochrome P-450 (P-450d) gene in the rat. J.Biol.Chem., 260, 5026-5032.

153. Spinelli,G., Bardazzi,N., Citernesi,A., Fontanarosa,M., and Curiel,P. (1991) Endometrial carcinoma in tamoxifen-treated breast cancer patients. J.Chemother., 3, 267-270.

154. Spink,D.C., Eugster,H.P., Lincoln,D.W., Schuetz,J.D., Schuetz,E.G., Johnson,J.A., Kaminsky,L.S., and Gierthy,J.F. (1992) 17 beta-estradiol hydroxylation catalyzed by human cytochrome P450 1A1: a comparison of the activities induced by 2,3,7,8tetrachlorodibenzo-p-dioxin in MCF-7 cells with those from heterologous expression of the cDNA. Arch.Biochem.Biophys., 293, 342-348.

155. Spink,D.C., Hayes,C.L., Young,N.R., Christou,M., Sutter,T.R., Jefcoate,C.R., and Gierthy,J.F. (1994) The effects of 2,3,7,8-tetrachlorodibenzo-p-dioxin on estrogen metabolism in MCF-7 breast cancer cells: evidence for induction of a novel 17 betaestradiol 4-hydroxylase. J.Steroid Biochem.Mol.Biol., 51, 251-258.

156. Stehr-Green,P.A., Welty,E., Steele,G., and Steinberg,K. (1986) Evaluation of potential health effects associated with serum polychlorinated biphenyl levels. Environ.Health Perspect., 70, 255-259.

157. Storm,H.H. and Ewertz,M. (1985) Second cancer following cancer of the female genital system in Denmark, 1943-80. Natl.Cancer Inst.Monogr, 68, 331-340. 
158. Sutter,T.R., Tang,Y.M., Hayes,C.L., Wo,Y.Y., Jabs,E.W., Li,X., Yin,H., Cody,C.W., and Greenlee,W.F. (1994) Complete cDNA sequence of a human dioxin-inducible mRNA identifies a new gene subfamily of cytochrome P450 that maps to chromosome 2. J.Biol.Chem., 269, 13092-13099.

159. Takeshima,Y., Seyama,T., Bennett,W.P., Akiyama,M., Tokuoka,S., Inai,K., Mabuchi,K., Land,C.E., and Harris,C.C. (1993) p53 mutations in lung cancers from non-smoking atomic-bomb survivors [published erratum appears in Lancet 1994 May 21;343(8908):1302]. Lancet, 342, 1520-1521.

160. Trevathan,E., Layde,P., Webster,L.A., Adams,J.B., Benigno,B.B., and Ory,H. (1983) Cigarette smoking and dysplasia and carcinoma in situ of the uterine cervix. JAMA, $250,499-502$.

161. Tritscher,A.M., Seacat,A.M., Yager,J.D., Groopman,J.D., Miller,B.D., Bell,D., Sutter,T.R., and Lucier,G.W. (1996) Increased oxidative DNA damage in livers of 2,3,7,8tetrachlorodibenzo-p-dioxin treated intact but not ovariectomized rats. Cancer Lett., 98, 219-225.

162. Vadlamuri,S.V., Glover,D.D., Turner,T., and Sarkar,M.A. (1998) Regiospecific expression of cytochrome P4501A1 and 1B1 in human uterine tissue. Cancer Lett., 122, 143150 .

163. Vogel,C., Donat,S., Dohr,O., Kremer,J., Esser,C., Roller,M., and Abel,J. (1997) Effect of subchronic 2,3,7,8-tetrachlorodibenzo-p-dioxin exposure on immune system and target gene responses in mice: calculation of benchmark doses for CYP1A1 and CYP1A2 related enzyme activities. Arch.Toxicol., 71, 372-382.

164. Walker,N.J., Gastel,J.A., Costa,L.T., Clark,G.C., Lucier,G.W., and Sutter,T.R. (1995) Rat CYP1B1: an adrenal cytochrome P450 that exhibits sex-dependent expression in livers and kidneys of TCDD-treated animals. Carcinogenesis, 16, 1319-1327.

165. Watkins,P.B., Wrighton,S.A., Schuetz,E.G., Maurel,P., and Guzelian,P.S. (1986) Macrolide antibiotics inhibit the degradation of the glucocorticoid-responsive cytochrome $\mathrm{P}-450 \mathrm{p}$ in rat hepatocytes in vivo and in primary monolayer culture. J.Biol.Chem., 261, 6264-6271.

166. Wentz,W.B., Reagan,J.W., Fu,Y.S., Heggie,A.D., and Anthony,D.D. (1981) Experimental studies of carcinogenesis of the uterine cervix in mice. Gynecol.Oncol., 12, S90S97. 
167. Wilbanks,G.D., Leipus,E., and Tsurumoto,D. (1980) Tissue culture of the human uterine cervix. Methods Cell Biol., 21B, 29-50.

168. Yager,J.D. and Liehr,J.G. (1996) Molecular mechanisms of estrogen carcinogenesis. Annu.Rev.Pharmacol.Toxicol., 36, 203-232.

169. Yokota,J., Tsukada,Y., Nakajima,T., Gotoh,M., Shimosato,Y., Mori,N., Tsunokawa,Y., Sugimura,T., and Terada,M. (1989) Loss of heterozygosity on the short arm of chromosome 3 in carcinoma of the uterine cervix. Cancer Res., 49, 3598-3601.

170. Ziel,H.K. and Finkle,W.D. (1975) Increased risk of endometrial carcinoma among users of conjugated estrogens. N.Engl.J.Med., 293, 1167-1170. 
APPENDICES 
Appendix: A

Quality of mRNA from three tissues of uterus

\section{ENDOMETRIUM}

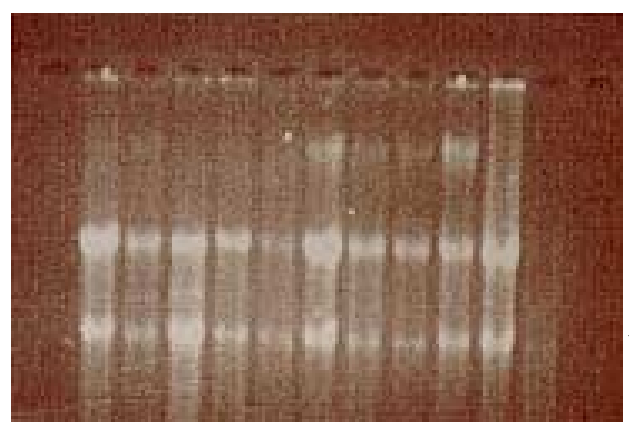

$28 \mathrm{~S}$ $18 \mathrm{~S}$

CERVIX

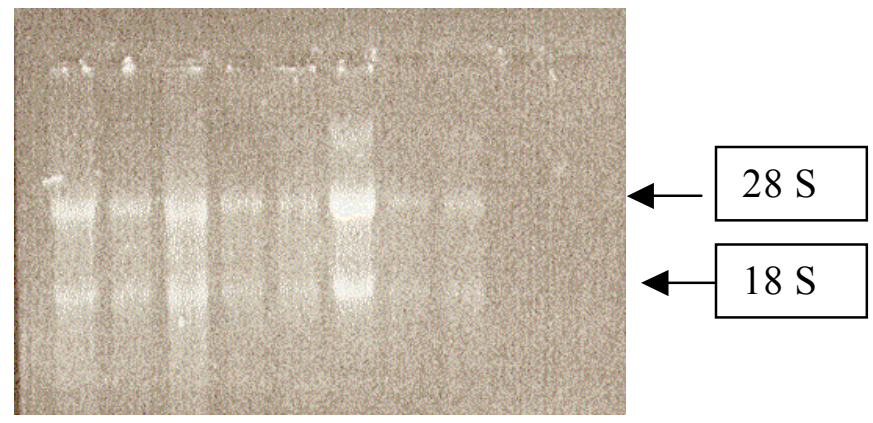

SQUAMOUS

REGION

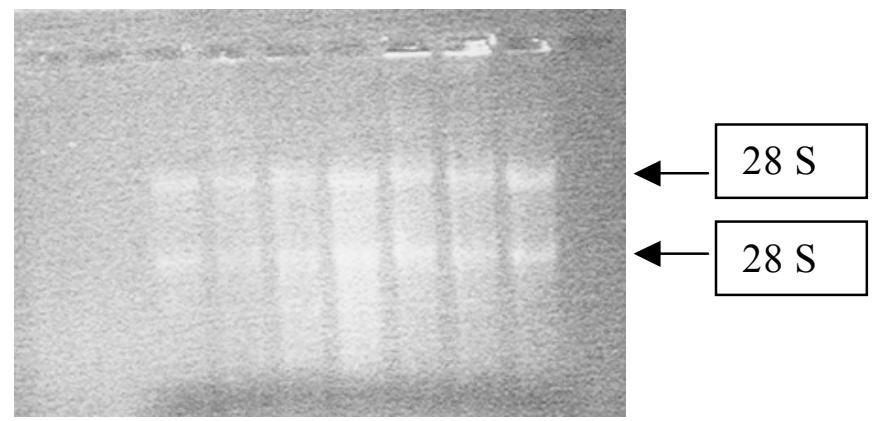


Appendix: B

\section{$\beta$-Actin expression in three regions of uterus}

cervix

endometrium

squamous region
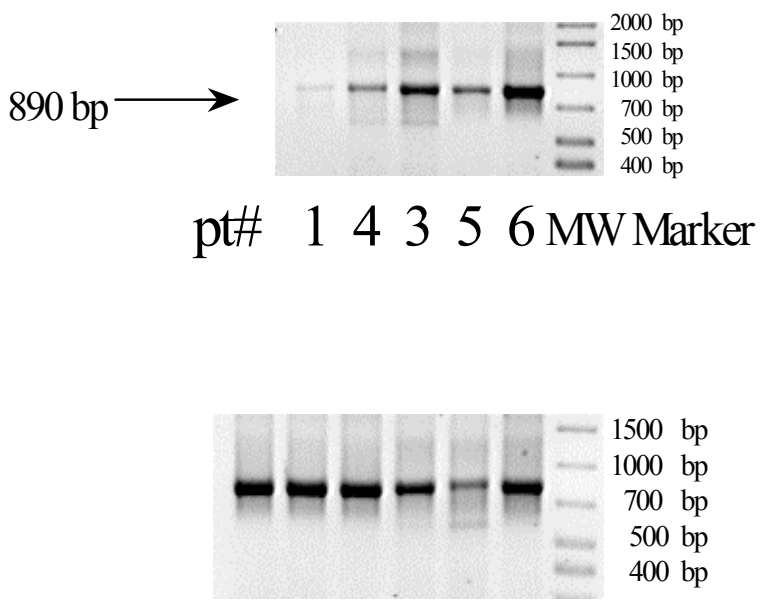

pt\# $112334 \quad 5 \quad 6$ MW Marker

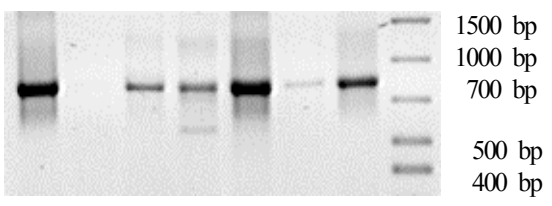

pt\# Ctrl 11244355 MW Marker 
Appendix: C

\section{Titration Analysis}

mRNA of ENDO (E7) and (E11) were taken as representative samples to express CYP1B1 and CYP1A1 for titration study.

Serial dilution was done as follows and PCR amplification was done with similar conditions for

30 cycles and quantification was estimated with densitometric analysis.

Lane 1: $2 \mathrm{ml}$ of cDNA of E11.

Lane $2: 2 \mathrm{ml}$ of $(2 \mathrm{ml}$ of $\mathrm{cDNA}+2 \mathrm{ml}$ DEPC water $)$

Lane 3: $2 \mathrm{ml}$ of $(2 \mathrm{ml}$ of item \#2 $+2 \mathrm{ml}$ DEPC water $)$

Lane 4: $2 \mathrm{ml}$ of $(2 \mathrm{ml}$ of item \# $3+2 \mathrm{ml}$ DEPC water $)$

Lanes 5 to 8 as above with E7

Lane 9: +ve control

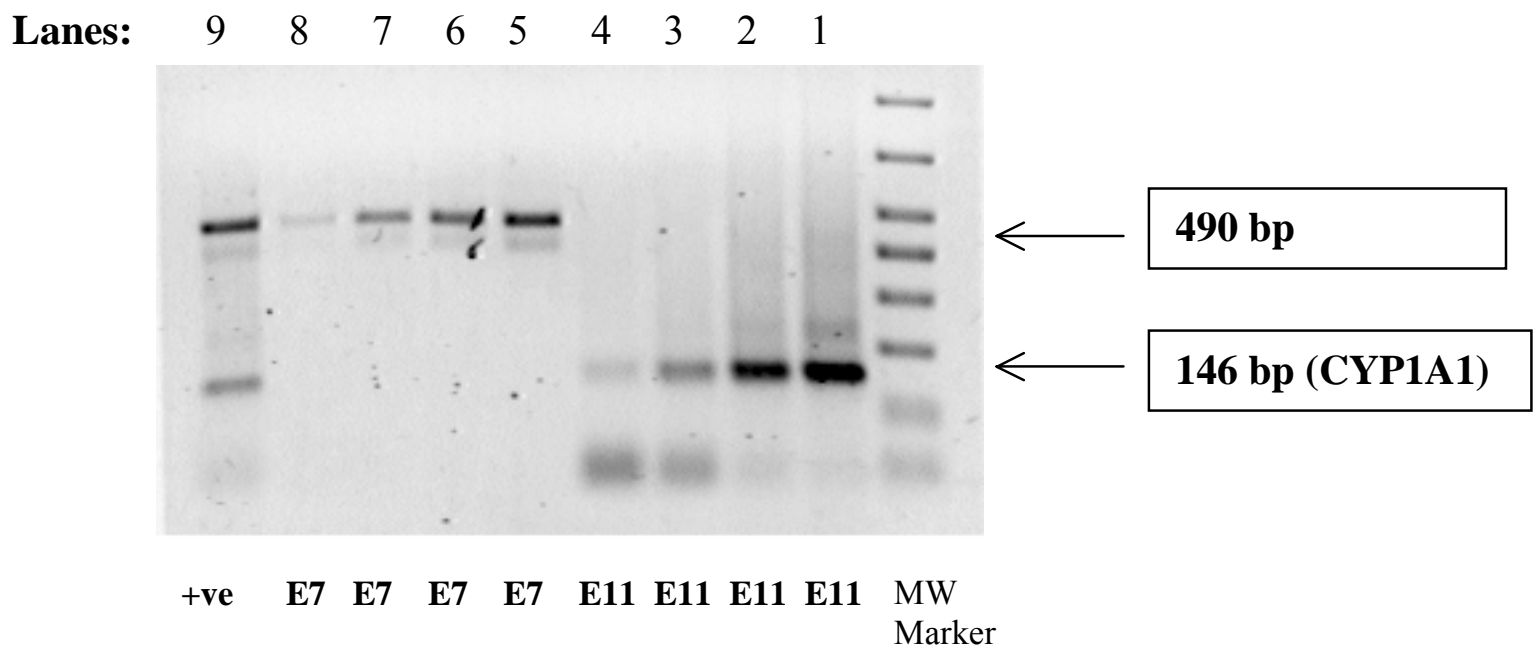


Appendix: D.

\section{Materials and Equipment}

Chloroform (ACS grade)

Isopropanol (ACS grade)

Ethanol (ACS grade)

RNA stat-60 $(100 \mathrm{ml}$ or $200 \mathrm{ml}$ bottle containing a red solution of RNA stat-60 which contains phenol and guanidinium thiocyanate in a monophase solution) obtained from TEL-TEST "B", inc., PO BOX 1421, 1511 County road 129, Friendswood, TX 77546. 1-800-631-0600.)

Liquid nitrogen

Primers designed using oligo and dnasis software and obtained from Gibco-BRL, Gaithersburg, MD, USA.

Reverse Transcription reaction Buffer - Gibco-BRL

M-MLV Reverse Transcriptase - Gibco-BRL

10mM Dithiothreitol (DTT)- Gibco-BRL

Oligo (dT)- Gibco-BRL

DNTP- Gibco-BRL

25mM Magnesium chloride- Gibco-BRL

Taq polymerase - Promega Corporation

Primers for $\square$-Actin - Clonetech, Palo Alto, CA, USA

Control RNA (891-bp CAT derived)- Clonetech, Palo Alto, CA, USA

DNA size markers - Bio-Rad, 
Agarose - FMC

BiS- Acrylamide (N,N'-methylene bisacrylamide )- Sigma

Ammonium per sulphate - Sigma

Temed - sigma

Tris Hydrochloride - Sigma

Qia quick purification kits - Qiagen

Qia quick gel extraction kits - Qiagen

10X SSC

$\alpha-{ }^{32} \mathrm{P}$ dCTP - radionucleotides ( Redivue Nucleotides) - Amersham pharmacia

0.1\% Sodium Dodecyl Sulphate (SDS) -Sigma

Formamide - Sigma

Sodium phosphate (monobasic and dibasic salts) - Fisher Scientific

Sodium Chloride - Fisher Scientific

EthylenediaminetetraaceticAcid (EDTA) solutions - Sigma

Salmon Sperm DNA - Promega Corporation

Random prime kit- Gibco-BRL

5'- End labelling kit - Promega Corporation

Sodium Hydroxide solutions - Fisher Scientific

TBE buffer

Buffered phenol chloroform - Gibco-BRL

Ethidium bromide solution - Sigma

Di Ethyl Pyro carbonate (DEPC) - Sigma 
Formaldehyde - Fisher Scientific

Sodium Acetate - Fisher Scientific

MOPS - Sigma

Eppendorf tubes (centrifuge tubes)

Mortar and pessle

Perkin - Elmer Thermal cycler system 2400 and 480 - PE Biosystems.

Thin walled PCR Tubes- Fisher Scientific, Pittsburgh. PA, USA

Eagles eye software and hardware.

Optimas software,

Phosphor Imager,

Photo plates for Phosphor imager

Imagequant software

Zeta probe Nylon membranes - Bio-rad

G-50 sephadex columns - Boehringer Mannheim

UV Cross linker - Stratagene

Electrophoresis apparatus - Owl apparatus

Hybridization oven - Stovall.

Spectrphotometer - Beckman

Polypropylene tubes 13ml 17X75 mm - Molecular Research center, Inc.

$-70^{\circ} \mathrm{C}$ Freezer

Ultra centrifuge- Beckmann

Pipettors - Eppendorf 


\section{Buffers Used:}

1. Loading Buffer for RNA:

Formamide $-750 \square 1$

20X Mops $-75 ̣ \square 1$

Glycerol - 100 $\square 1$

Formaldehyde $-240 \square 1$

$0.5 \%$ DEPC water $-540 \square 1$

Bromophenol blue - a pinch (about 2.5\%)

2. Formaldehyde Gel (for 14 well large cast)

Agarose - 50ml

Formaldehyde- $2.7 \mathrm{ml}$

Ethydium bromide $-2.0 \square 1$

3.Running Buffer for Formaldehyde Gel

20X mops $30 \mathrm{ml}$

Ethydium Bromide 20 $\square 1$

Formaldehyde $-20 \mathrm{ml}$

0.5\% DEPC water QS - $600 \mathrm{ml}$

4. 10X SSC

3M Sodium chloride - 175 gm

0.3M Sodium Citrate $-88.2 \mathrm{gm}$

Water q.s ----- $200 \mathrm{ml}$

Adjust $\mathrm{PH}$ to 7.0 with $1 \mathrm{M} \mathrm{HCl}$ and make volume to 1 Litre. 
5. MOPS $-20 \mathrm{X}$

0.4M MOPS PH 7.0

0.16M Sodium Acetate

0.02M EDTA PH 8.0

Adjust $\mathrm{PH}$ to 7.0 with $2 \mathrm{~N} \mathrm{NaoH}$

sterile filter with $0.2 \mathrm{~mm}$ millipore filter

6. $0.5 \%$ DEPC water

Add $5 \mathrm{gm}$ of DEPC in 5 litre of milliq water. Keep overnight, filter and autoclave and store at $4^{0} \mathrm{C}$.

7. TBE buffer - 1 litre contains

$100 \mathrm{mM}$ Tris

$90 \mathrm{mM}$ Boric acid

1.0mM EDTA

Reference: Sambrook et al. 1989. 
Appendix: E

\section{PATIENT INFORMATION (SMOKER / NONSMOKER)}

Patients's Name:

Age at the time of Surgery:

Weight:

Race:

Address:

Pre-operative Diagnosis:

Occupation:

Number of cigarettes Smoked:
Hospital ID\#:

Pathology ID\#:

Date of Surgery:
Telephone Number:

Name of Surgeon:

Do any members of the family smoke (indirect impact of smoking)

Alcohol consumption:

Comedication: (Not more than 1 year before surgery)

Medical History

Family History

Number of Years smoking cigarettes 
RNA concentrations from the tissues and their identifications of all patients.

Tissues used for 1A1 and 1B1 expression

$\begin{array}{rcccl}\text { PT \# } & \text { Endometrium } & \text { Squamous } & \text { Cervix } & \text { Name } \\ 1 & 4.288 & 0.967 & 0.345 & \text { BM } \\ 2 & 3.767 & 0.193 & \text { na } & \text { BJ } \\ 3 & 4.443 & 1.028 & 0.633 & \text { WD } \\ 4 & 0.267 & 0.136 & 0.218 & \text { DS } \\ 5 & 1.004 & 1.208 & 0.512 & \text { VL } \\ 6 & 6.329 & 1.042 & 4.409 & \text { GJ } \\ 7 & 8.209 & 1.15 & 3.11 & \text { BG } \\ 8 & 9.57 & 1.65 & 3.53 & \text { WB } \\ 9 & 10.498 & 1.032 & 2.42 & \text { LS } \\ 10 & 7.126 & 2.79 & 2.13 & \text { PC } \\ 11 & 6.413 & 1.64 & 2.06 & \text { ED } \\ 12 & 2.628 & 2.13 & 2.25 & \text { VS } \\ 13 & 3.94 & 1.63 & 1.53 & \text { RN } \\ 14 & 2.01 & 0.308 & 1.45 & \text { BC } \\ 15 & 8.1 & 1.498 & 2.28 & \text { VD } \\ 16 & 1.51 & 1.62 & 3.09 & \mathrm{CH} \\ 17 & 3.305 & 1.16 & \text { NA } & \text { BC } \\ 18 & 1.27 & 0.732 & 3.779 & \text { BL } \\ 19 & 0.458 & 1.038 & 0.364 & \text { VM } \\ 20 & 1.74 & 2.68 & 1.388 & \text { HD } \\ 21 & 0.107 & 2.407 & 1.966 & \text { WD } \\ 22 & 0.813 & \text { NA } & 0.344 & \text { BW }\end{array}$

Tissues used for CYP 3A expression

$\begin{array}{ccccc}\begin{array}{l}\text { Endo } \\ \text { Tissue } \\ \text { Id\# }\end{array} & \text { Conc } & \text { Cerv ID \# } & \text { Conc } & \text { Name } \\ \text { E31 } & 3.247 & \text { C51 } & 1.11 & \text { KS } \\ \text { E32 } & 3.982 & \text { C52 } & 0.96 & \text { DD } \\ \text { E33 } & 4.995 & \text { C53 } & 1.43 & \text { HR } \\ \text { E34 } & 6.161 & \text { C54 } & 1.68 & \text { BG } \\ \text { E35 } & 3.46 & \text { C56 } & 1.17 & \text { LH } \\ \text { E36 } & 2.878 & \text { C57 } & 0.58 & \text { KC } \\ \text { E37 } & 2.74 & \text { C58 } & 0.49 & \text { BC } \\ \text { E38 } & 3.913 & \text { C59 } & 1.56 & \text { LF } \\ \text { E39 } & 3.9 & \text { C60 } & 5.16 & \text { YH } \\ \text { E40 } & 3.175 & \text { C61 } & 1.3 & \text { TD } \\ \text { E41 } & 7.241 & \mathbf{C 6 2} & 4.92 & \text { MP } \\ \text { E42 } & 3.159 & \mathbf{C 6 3} & 1.63 & \text { PK } \\ \text { E43 } & 3.228 & \mathbf{C 6 4} & 1.6 & \text { MR } \\ & & & & 131\end{array}$


Appendix: G.1

\section{Master Data - Expression levels of CYP3A3/A4 and CYP3A7 as ratio to $\beta$ - Actin and the relative differences}

\begin{tabular}{|c|c|c|c|c|c|c|c|c|c|c|}
\hline ID\# & stage & SMNS & En3A3/4 & Cer3A3/4 & Endo3A7 & cerv3A7 & $(E-C) 3 A 3 / L$ & (E-C)3A7 & \multicolumn{2}{|c|}{$E(3 A 3 / 4-3 / C(3 A 3-3 A 7$} \\
\hline BW & $\mathrm{p}$ & SM & 0 & & 0 & & & & 0 & \\
\hline RA & $p$ & NS & 0 & & 0 & & & & 0 & \\
\hline HS & $p$ & SM & 950517 & & 14223601 & & & & $-1.3 \mathrm{E}+07$ & \\
\hline GJ & $p$ & NS & 2152962 & & 91058 & & & & 2061904 & \\
\hline VD & $p$ & NS & 0 & & 0 & & & & 0 & \\
\hline DS & $p$ & NS & 3128568 & & 10664064 & & & & -7535496 & \\
\hline DN & $p$ & SM & 4619279 & & 9430575 & & & & -4811296 & \\
\hline $\mathrm{BL}$ & $p$ & NS & 8971099 & & 2659004 & & & & 6312095 & \\
\hline BM & $p$ & NS & 0 & & 127022 & & & & -127022 & \\
\hline$B G$ & $p$ & SM & 6976845 & & 19244217 & & & & $-1.2 \mathrm{E}+07$ & \\
\hline WB & $p$ & SM & 0 & & 0 & & & & 0 & \\
\hline PC & $p$ & SM & 7769961 & 12748 & 5457450 & 59205 & 7757213 & 5398245 & 2312511 & -46457 \\
\hline WD & s & NS & 4243992 & 18427 & 95210 & 533427 & 4225565 & -438217 & 4148782 & -515000 \\
\hline BJ & s & NS & 2403039 & & 10567 & & & & 2392472 & \\
\hline $\mathrm{BC}$ & $\mathrm{s}$ & SM & 26821 & & 390583 & & & & -363762 & \\
\hline LS & $\mathrm{s}$ & SM & 432695 & 0 & 154682 & 0 & 432695 & 154682 & 278013 & 0 \\
\hline ED & s & SM & 42844 & 30978 & 34066 & 615701 & 11866 & -581635 & 8778 & -584723 \\
\hline RA & s & NS & 6938609 & 0 & 81577 & 922991 & 6938609 & -841414 & 6857032 & -922991 \\
\hline $\mathrm{BC}$ & $s$ & NS & 8473469 & 0 & 114550 & 0 & 8473469 & 114550 & 8358919 & 0 \\
\hline VD & s & NS & 4252467 & 0 & 1146260 & 1111309 & 4252467 & 34951 & 3106207 & -1111309 \\
\hline $\mathrm{CH}$ & s & NS & 5853757 & 0 & 1053534 & 0 & 5853757 & 1053534 & 4800223 & 0 \\
\hline KS & a & NS & 16144.86 & 8260.72 & 593082 & 619157.8 & 7884.14 & -26075.8 & -576937 & -610897 \\
\hline DD & $s$ & SM & 5188.64 & -44.35 & 59660.02 & 35017.32 & 5232.99 & 24642.7 & -54471.4 & -35061.7 \\
\hline $\mathrm{HR}$ & $p$ & NS & 56258.25 & 1754.84 & 1014889 & 18999.14 & 54503.41 & 995890.1 & -958631 & -17244.3 \\
\hline$B G$ & $p$ & NS & २2997.22 & -4.95 & 1032549 & 9095.2 & 23002.17 & 1023453 & -1009551 & -9100.15 \\
\hline $\mathrm{LH}$ & $\mathrm{s}$ & NS & 5060.3 & 1411.7 & 61469.89 & 10089.04 & 3648.6 & 51380.85 & -56409.6 & -8677.34 \\
\hline $\mathrm{KC}$ & s & SM & 109528.2 & 3002.82 & 899699.7 & 19757.01 & 106525.4 & 879942.7 & -790171 & -16754.2 \\
\hline $\mathrm{BC}$ & $\mathrm{s}$ & NS & 374089.3 & -125.59 & 295883.6 & -205.07 & 374214.9 & 296088.7 & 78205.68 & 79.48 \\
\hline LF & $p$ & NS & 33689.78 & -467.82 & 256547.4 & 536.31 & 34157.6 & 256011.1 & -222858 & -1004.13 \\
\hline $\mathrm{YH}$ & a & NS & 53867.4 & 2636.4 & 1521953 & 14631.52 & 51231 & 1507322 & -1468086 & -11995.1 \\
\hline TD & $p$ & NS & 96553.12 & 1422.36 & 428051.7 & 8284.52 & 95130.76 & 419767.2 & -331499 & -6862.16 \\
\hline MP & s & NS & 274711.9 & 29144.06 & 574076.6 & 9226.17 & 245567.8 & 564850.4 & -299365 & 19917.89 \\
\hline PK & $p$ & NS & 68775.67 & 2312.09 & 29237.53 & 14586.55 & 66463.58 & 14650.98 & 39538.14 & -12274.5 \\
\hline MR & s & SM & 279421.2 & 1941.52 & 101713.1 & 7218.67 & 277479.6 & 94494.42 & 177708.1 & -5277.15 \\
\hline
\end{tabular}


Appendix: G.2

The expression of CYP3A3/A4 - Model with no interaction:

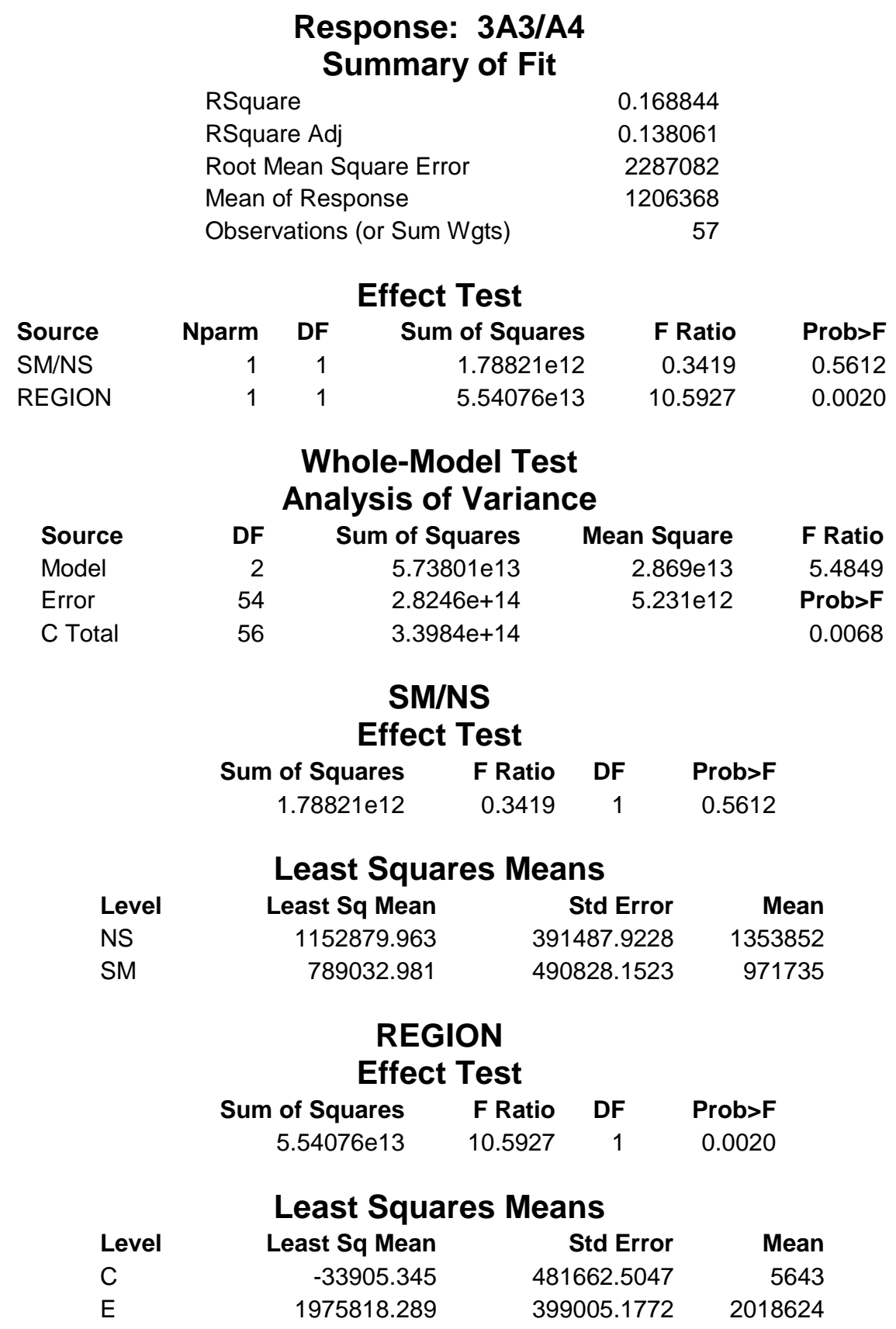


Appendix: G.3

The expression of CYP3A3/A4 - Model with interaction:

\section{Response: 3A3/A4 \\ Summary of Fit}

$\begin{array}{lr}\text { RSquare } & 0.172498 \\ \text { RSquare Adj } & 0.125659 \\ \text { Root Mean Square Error } & 2303477 \\ \text { Mean of Response } & 1206368 \\ \text { Observations (or Sum Wgts) } & 57\end{array}$

Source
SM/NS
REGION
SM/NS*REGION

\section{Effect Test}

$\begin{array}{rrrrr}\text { Nparm } & \text { DF } & \text { Sum of Squares } & \text { F Ratio } & \text { Prob }>\text { F } \\ 1 & 1 & 1.21595 \mathrm{e} 12 & 0.2292 & 0.6341 \\ 1 & 1 & 4.90422 \mathrm{e} 13 & 9.2428 & 0.0037 \\ 1 & 1 & 1.24185 \mathrm{e} 12 & 0.2340 & 0.6305\end{array}$

Whole-Model Test Analysis of Variance

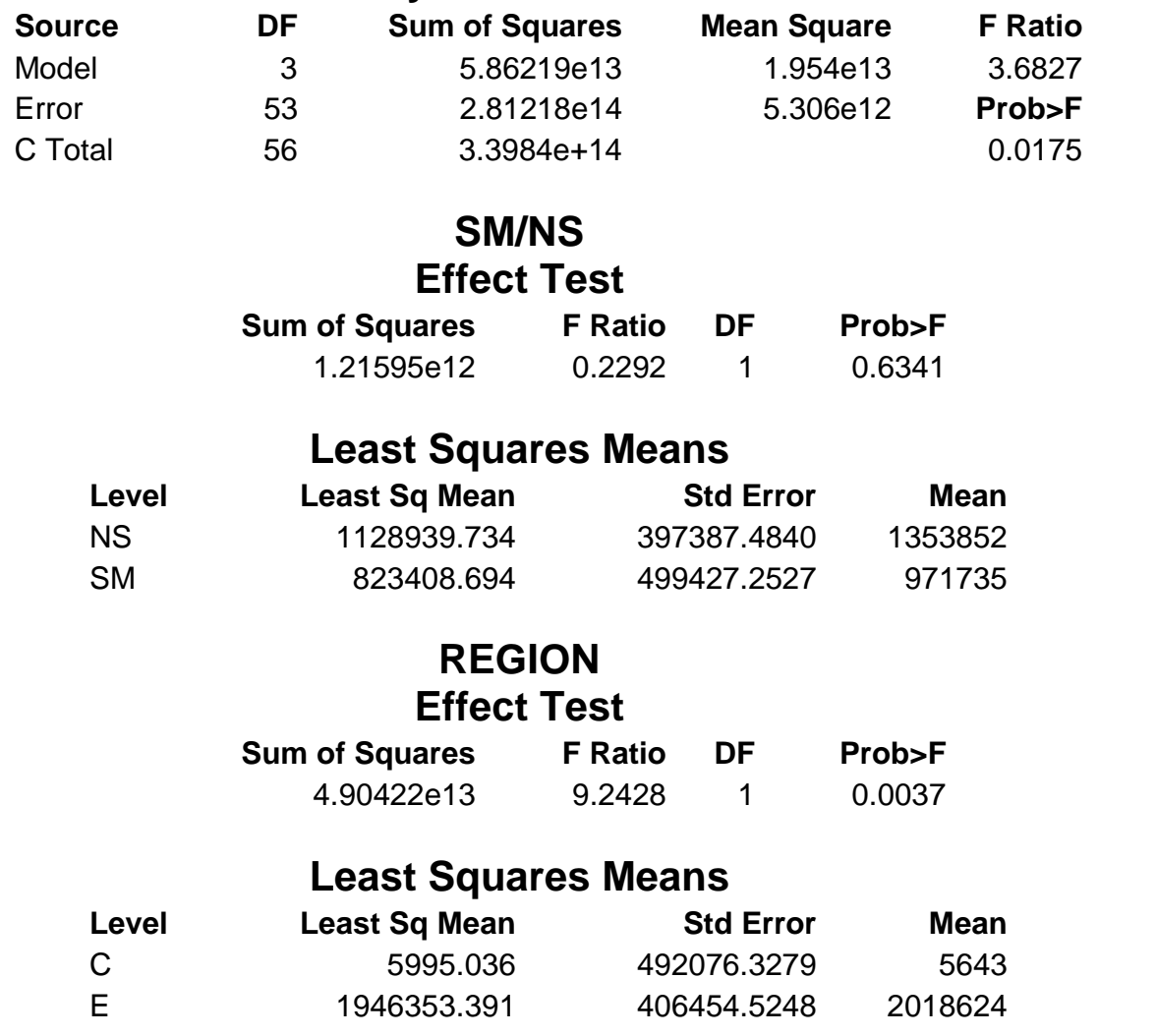




\section{SM/NS*REGION}

\section{Profile Plot}

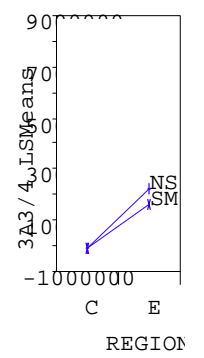

\section{Effect Test}

$\begin{array}{rrrr}\text { Sum of Squares } & \text { F Ratio } & \text { DF } & \text { Prob>F } \\ 1.24185 \mathrm{e} 12 & 0.2340 & 1 & 0.6305\end{array}$

\section{Least Squares Means}

$\begin{array}{lrr}\text { Level } & \text { Least Sq Mean } & \text { Std Error } \\ \text { NS,C } & 4376.772 & 615630.0431 \\ \text { NS,E } & 2253502.695 & 502659.8253 \\ \text { SM,C } & 7613.300 & 767825.5661 \\ \text { SM,E } & 1639204.088 & 638869.4883\end{array}$


Appendix: G.4

The expression of CYP3A7- Model with out interaction:

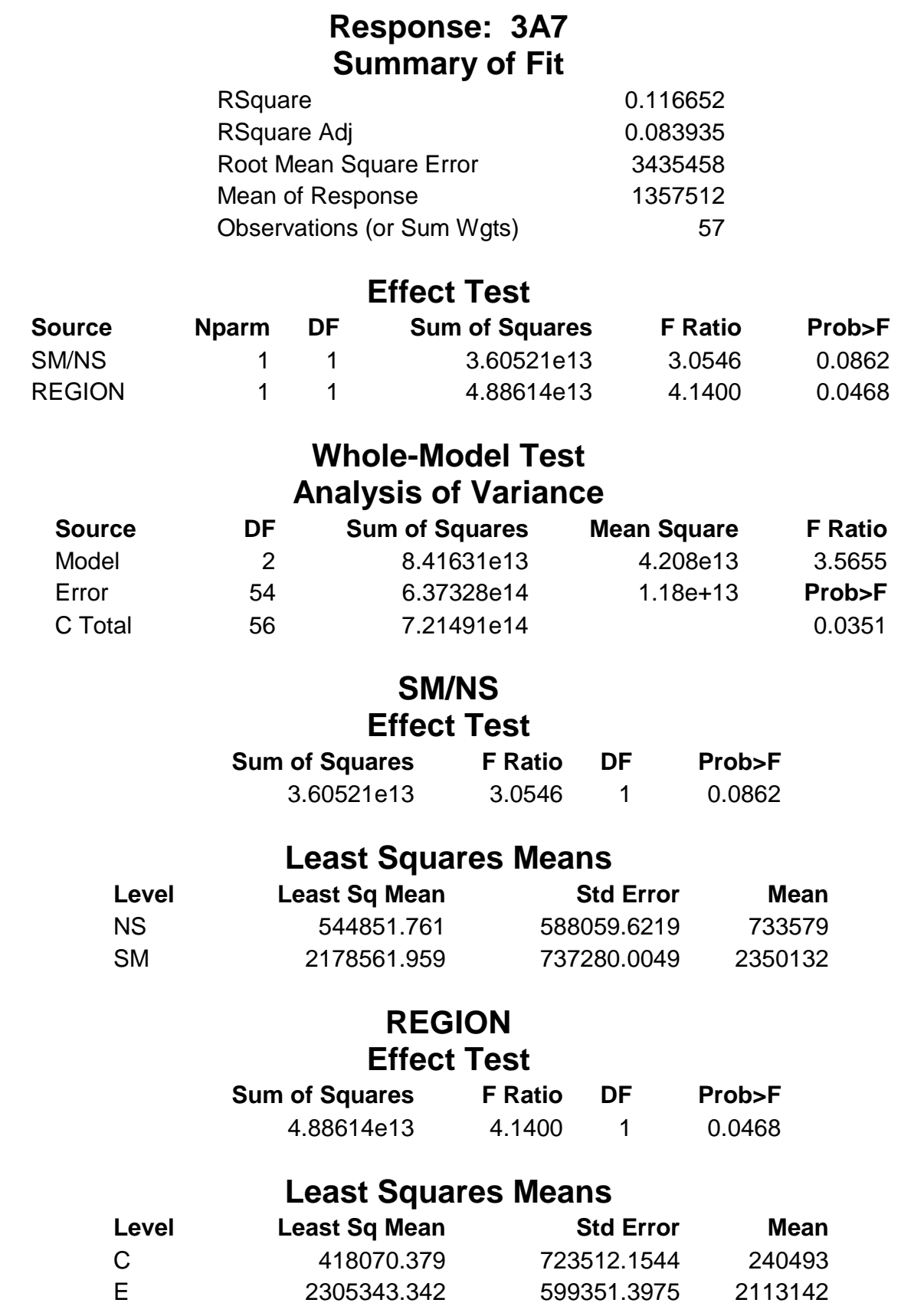


Appendix: G.5

The expression of CYP3A7- Model with interaction:

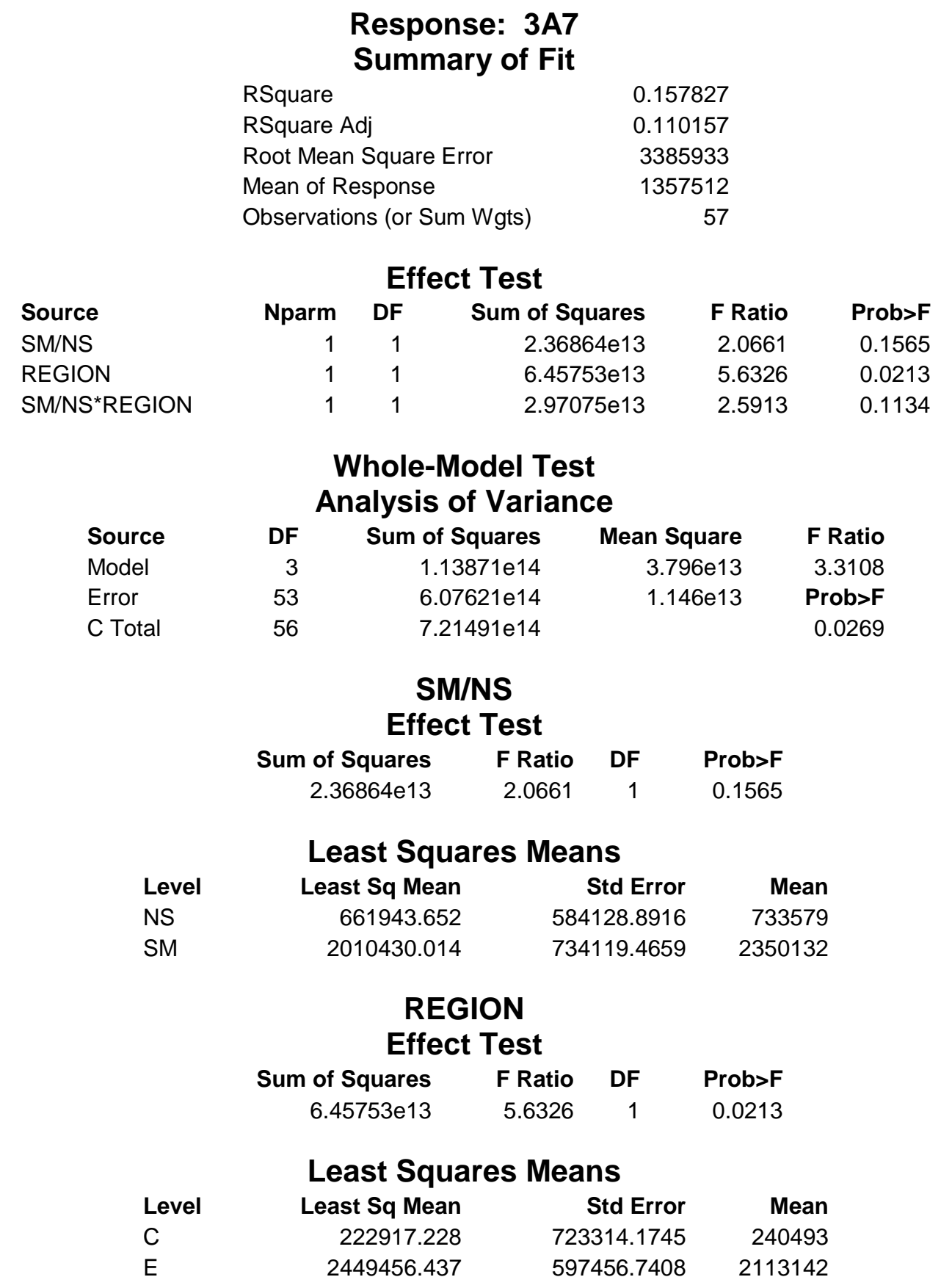




\section{SM/NS*REGION}

\section{Profile Plot}

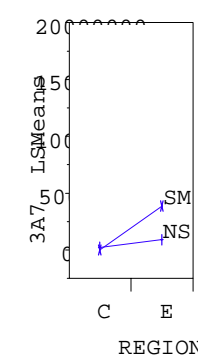

\section{Effect Test}

\begin{tabular}{|c|c|c|c|c|}
\hline & juares & F Ratio & DF & Prob $>F$ \\
\hline & $75 \mathrm{e} 13$ & 2.5913 & 1 & 0.1134 \\
\hline & st Sq & es Mea & & \\
\hline Level & Least & Mean & & td Error \\
\hline NS,C & & 0.621 & & 1928.588 \\
\hline NS,E & 102 & 0.682 & & 3871.098 \\
\hline SM,C & & 7.836 & 112 & 3644.245 \\
\hline SM,E & 387 & 2.193 & & 088.776 \\
\hline
\end{tabular}


Appendix: G.6

\section{The differential expression of CYP3A3/A4 from Endo to Cervix among nonsmokers:}

\begin{tabular}{|c|c|c|}
\hline \multicolumn{3}{|c|}{$\begin{array}{c}\text { 3A3/A4 (Endo - Cerv) } \\
\text { Quantiles }\end{array}$} \\
\hline \multirow[t]{4}{*}{ maximum } & $100.0 \%$ & 8473469 \\
\hline & $99.5 \%$ & 8473469 \\
\hline & $97.5 \%$ & 8473469 \\
\hline & $90.0 \%$ & 7552553 \\
\hline quartile & $75.0 \%$ & 4252467 \\
\hline median & $50.0 \%$ & 95130.8 \\
\hline \multirow[t]{4}{*}{ quartile } & $25.0 \%$ & 34157.6 \\
\hline & $10.0 \%$ & 6189.92 \\
\hline & $2.5 \%$ & 3648.6 \\
\hline & $0.5 \%$ & 3648.6 \\
\hline minimum & $0.0 \%$ & 3648.6 \\
\hline \multicolumn{3}{|c|}{ Moments } \\
\hline \multicolumn{2}{|l|}{ Mean } & 2046645 \\
\hline \multicolumn{2}{|l|}{ Std Dev } & 3018268 \\
\hline \multicolumn{2}{|c|}{ Std Error Mean } & 779313 \\
\hline \multicolumn{2}{|c|}{ Upper 95\% Mean } & 3718102 \\
\hline \multicolumn{2}{|c|}{ Lower 95\% Mean } & 375188 \\
\hline \multicolumn{2}{|c|}{$\mathrm{N}$} & 15 \\
\hline \multicolumn{3}{|c|}{ Sum Weights } \\
\hline \multicolumn{3}{|c|}{ Test Mean=value } \\
\hline \multicolumn{2}{|c|}{ Hypothesized Value } & 0 \\
\hline \multicolumn{2}{|c|}{ Actual Estimate } & 2046645 \\
\hline & t Test \\
\hline \multicolumn{2}{|c|}{ Test Statistic } & 2.6262 \\
\hline \multicolumn{2}{|c|}{ Prob $>|t|$} & 0.0199 \\
\hline \multicolumn{2}{|c|}{ Prob $>t$} & 0.0100 \\
\hline \multicolumn{2}{|c|}{ Prob $<\mathrm{t}$} & 0.9900 \\
\hline \multicolumn{3}{|c|}{$\begin{array}{c}3 A 7 \text { (Endo - Cerv) } \\
\text { Quantiles }\end{array}$} \\
\hline \multirow[t]{4}{*}{ maximum } & $100.0 \%$ & 1507322 \\
\hline & $99.5 \%$ & 1507322 \\
\hline & $97.5 \%$ & 1507322 \\
\hline & $90.0 \%$ & 1235049 \\
\hline & $75.0 \%$ & 995890 \\
\hline median & $50.0 \%$ & 256011 \\
\hline
\end{tabular}

139 


\begin{tabular}{|c|c|c|}
\hline \multirow[t]{4}{*}{ quartile } & $25.0 \%$ & 14651 \\
\hline & $10.0 \%$ & -599496 \\
\hline & $2.5 \%$ & -841414 \\
\hline & $0.5 \%$ & -841414 \\
\hline \multirow[t]{2}{*}{ minimum } & $0.0 \%$ & -841414 \\
\hline & oment & \\
\hline \multicolumn{2}{|l|}{ Mean } & 335116. \\
\hline \multicolumn{2}{|c|}{ Std Dev } & 615457. \\
\hline \multicolumn{2}{|c|}{ Std Error Mean } & 158910. \\
\hline \multicolumn{2}{|c|}{ Upper 95\% Mean } & 675944. \\
\hline \multicolumn{2}{|c|}{ Lower 95\% Mean } & -5711 \\
\hline \multicolumn{2}{|c|}{$\mathrm{N}$} & 15. \\
\hline \multicolumn{3}{|c|}{ Sum Weights } \\
\hline \multicolumn{3}{|c|}{ Test Mean=value } \\
\hline \multicolumn{2}{|c|}{ Hypothesized Value } & \\
\hline \multicolumn{2}{|c|}{ Actual Estimate } & 335116 \\
\hline \multirow{2}{*}{\multicolumn{2}{|c|}{ Test Statistic }} & t Test \\
\hline & & 2.1088 \\
\hline \multicolumn{2}{|c|}{ Prob $>|t|$} & 0.0535 \\
\hline \multicolumn{2}{|c|}{ Prob > t } & 0.0267 \\
\hline \multicolumn{2}{|c|}{ Prob $<\mathrm{t}$} & 0.9733 \\
\hline
\end{tabular}


Appendix: G.7

\section{The differential expression of CYP3A3/A4 from Endo to Cervix among smokers:}

\begin{tabular}{|c|c|c|}
\hline \multicolumn{3}{|c|}{$\begin{array}{c}\text { 3A3/A4 (Endo-Cervix) } \\
\text { Quantiles }\end{array}$} \\
\hline \multirow[t]{4}{*}{ maximum } & $100.0 \%$ & 7757213 \\
\hline & $99.5 \%$ & 7757213 \\
\hline & $97.5 \%$ & 7757213 \\
\hline & $90.0 \%$ & 7757213 \\
\hline quartile & $75.0 \%$ & 2263824 \\
\hline median & $50.0 \%$ & 192003 \\
\hline \multirow[t]{4}{*}{ quartile } & $25.0 \%$ & 10207.7 \\
\hline & $10.0 \%$ & 5232.99 \\
\hline & $2.5 \%$ & 5232.99 \\
\hline & $0.5 \%$ & 5232.99 \\
\hline minimum & $0.0 \%$ & 5232.99 \\
\hline \multicolumn{3}{|c|}{ Moments } \\
\hline \multicolumn{2}{|l|}{ Mean } & 1431835 \\
\hline \multicolumn{2}{|c|}{ Std Dev } & 3103198 \\
\hline \multicolumn{2}{|c|}{ Std Error Mean } & 1266875 \\
\hline \multicolumn{2}{|c|}{ Upper 95\% Mean } & 4688394 \\
\hline \multicolumn{2}{|c|}{ Lower 95\% Mean } & -1824724 \\
\hline \multicolumn{2}{|c|}{$\mathrm{N}$} & \\
\hline \multicolumn{2}{|l|}{ Sum Weight } & \\
\hline
\end{tabular}

Test Mean=value

\begin{tabular}{|c|c|c|}
\hline \multirow{2}{*}{\multicolumn{2}{|c|}{$\begin{array}{l}\text { Hypothesized Value } \\
\text { Actual Estimate }\end{array}$}} & 0 \\
\hline & & 1431835 \\
\hline & & t Test \\
\hline \multicolumn{2}{|c|}{ Test Statistic } & 1.1302 \\
\hline \multicolumn{2}{|c|}{ Prob $>|t|$} & 0.3097 \\
\hline \multicolumn{2}{|c|}{ Prob > t } & 0.1548 \\
\hline \multicolumn{2}{|c|}{ Prob $<t$} & 0.8452 \\
\hline \multicolumn{3}{|c|}{$\begin{array}{c}\text { 3A7 (Endo - Cervix) } \\
\text { Quantiles }\end{array}$} \\
\hline \multirow[t]{4}{*}{ maximum } & $100.0 \%$ & 5398245 \\
\hline & $99.5 \%$ & 5398245 \\
\hline & $97.5 \%$ & 5398245 \\
\hline & $90.0 \%$ & 5398245 \\
\hline quartile & $75.0 \%$ & 2009518 \\
\hline : & & \\
\hline
\end{tabular}




\begin{tabular}{lrr} 
quartile & $25.0 \%$ & -126927 \\
& $10.0 \%$ & -581635 \\
& $2.5 \%$ & -581635 \\
& $0.5 \%$ & -581635 \\
minimum & $0.0 \%$ & -581635 \\
& & \\
\multicolumn{1}{c}{ Moments } & \\
Mean & 995062 \\
Std Dev & 2206636 \\
Std Error Mean & 900856 \\
Upper 95\% Mean & 3310751 \\
Lower 95\% Mean & -1320627 \\
N & 6 \\
Sum Weights & 6
\end{tabular}

\section{Test Mean=value}

Hypothesized Value 0

Actual Estimate 995062

$\begin{array}{lr} & \mathbf{t} \text { Test } \\ \text { Test Statistic } & 1.1046 \\ \text { Prob }>|\mathrm{t}| & 0.3196 \\ \text { Prob }>\mathrm{t} & 0.1598 \\ \text { Prob }<\mathrm{t} & 0.8402\end{array}$


Appendix: G.8

\section{The differential expression from CYP3A3/A4 to CYP3A7 among nonsmokers:}

\begin{tabular}{|c|c|c|}
\hline \multicolumn{3}{|c|}{$\begin{array}{c}\text { Endo (3A3-3A7) } \\
\text { Quantiles }\end{array}$} \\
\hline \multirow[t]{4}{*}{ maximum } & $100.0 \%$ & 8358919 \\
\hline & $99.5 \%$ & 8358919 \\
\hline & $97.5 \%$ & 8358919 \\
\hline & $90.0 \%$ & 6693551 \\
\hline quartile & $75.0 \%$ & 3366851 \\
\hline median & $50.0 \%$ & 0 \\
\hline \multirow[t]{4}{*}{ quartile } & $25.0 \%$ & -392858 \\
\hline & $10.0 \%$ & $-1.33 \mathrm{e} 6$ \\
\hline & $2.5 \%$ & $-7.54 \mathrm{e} 6$ \\
\hline & $0.5 \%$ & $-7.54 \mathrm{e} 6$ \\
\hline minimum & $0.0 \%$ & $-7.54 \mathrm{e} 6$ \\
\hline \multicolumn{3}{|c|}{ Moments } \\
\hline \multicolumn{2}{|l|}{ Mean } & 1162251 \\
\hline \multicolumn{2}{|c|}{ Std Dev } & 3439126 \\
\hline \multicolumn{2}{|c|}{ Std Error Mean } & 733224 \\
\hline \multicolumn{2}{|c|}{ Upper $95 \%$ Mean } & 2687062 \\
\hline \multicolumn{2}{|c|}{ Lower $95 \%$ Mean } & -362560 \\
\hline \multicolumn{2}{|c|}{$\mathrm{N}$} & 22 \\
\hline \multicolumn{2}{|c|}{ Sum Weights } & 22 \\
\hline \multicolumn{3}{|c|}{ Test Mean=value } \\
\hline \multicolumn{2}{|c|}{ Hypothesized Value } & 0 \\
\hline \multicolumn{2}{|c|}{ Actual Estimate } & 1162251 \\
\hline & t Test \\
\hline \multicolumn{2}{|c|}{ Test Statistic } & 1.5851 \\
\hline \multicolumn{2}{|c|}{ Prob $>|t|$} & 0.1279 \\
\hline \multicolumn{2}{|c|}{ Prob $>t$} & 0.0639 \\
\hline \multicolumn{2}{|c|}{ Prob $<\mathrm{t}$} & 0.9361 \\
\hline \multicolumn{3}{|c|}{$\begin{array}{c}\text { Cervix (3A3-3A7) } \\
\text { Quantiles }\end{array}$} \\
\hline \multirow[t]{4}{*}{ maximum } & $100.0 \%$ & 19917.9 \\
\hline & $99.5 \%$ & 19917.9 \\
\hline & $97.5 \%$ & 19917.9 \\
\hline & $90.0 \%$ & 8014.84 \\
\hline \multirow{4}{*}{$\begin{array}{l}\text { quartile } \\
\text { median } \\
\text { quartile }\end{array}$} & $75.0 \%$ & 0 \\
\hline & $50.0 \%$ & -9100.2 \\
\hline & $25.0 \%$ & -515000 \\
\hline & 143 & \\
\hline
\end{tabular}




\begin{tabular}{lrr} 
& $10.0 \%$ & -998318 \\
& $2.5 \%$ & $-1.11 \mathrm{e} 6$ \\
& $0.5 \%$ & $-1.11 \mathrm{e} 6$ \\
minimum $\quad 0.0 \%$ & $-1.11 \mathrm{e} 6$ \\
& & \\
\multicolumn{1}{c}{ Moments } & \\
Mean & -213823.8 \\
Std Dev & 381793.3 \\
Std Error Mean & 98578.6 \\
Upper 95\% Mean & -2394.2 \\
Lower 95\% Mean & -425253.4 \\
N Sum Weights & 15.0 \\
Sum & 15.0
\end{tabular}

\section{Test Mean=value}

Hypothesized Value 0

Actual Estimate $\quad-213824$

t Test

Test Statistic $\quad-2.1691$

Prob $>|t| \quad 0.0478$

Prob $>\mathrm{t} \quad 0.9761$

Prob $<\mathrm{t} \quad 0.0239$ 
Appendix: G.9

\section{The differential expression from CYP3A3/A4 to CYP3A7 among smokers:}

\begin{tabular}{|c|c|c|}
\hline \multicolumn{3}{|c|}{$\begin{array}{c}\text { Endo (3A3-3A7) } \\
\text { Quantiles }\end{array}$} \\
\hline \multirow[t]{4}{*}{ maximum } & $100.0 \%$ & 2312511 \\
\hline & $99.5 \%$ & 2312511 \\
\hline & $97.5 \%$ & 2312511 \\
\hline & $90.0 \%$ & 1702162 \\
\hline quartile & $75.0 \%$ & 135476 \\
\hline median & $50.0 \%$ & $-2.72 \mathrm{e} 4$ \\
\hline \multirow[t]{4}{*}{ quartile } & $25.0 \%$ & $-3.81 e 6$ \\
\hline & $10.0 \%$ & $-1.3 e+7$ \\
\hline & $2.5 \%$ & $-1.33 e 7$ \\
\hline & $0.5 \%$ & $-1.33 e 7$ \\
\hline minimum & $0.0 \%$ & $-1.33 e 7$ \\
\hline \multicolumn{3}{|c|}{ Moments } \\
\hline \multicolumn{2}{|l|}{ Mean } & $-23985 \subseteq$ \\
\hline \multicolumn{2}{|c|}{ Std Dev } & 510782 \\
\hline \multicolumn{2}{|c|}{ Std Error Mean } & 147450 \\
\hline \multicolumn{2}{|c|}{ Upper 95\% Mean } & 84677 \\
\hline \multicolumn{2}{|c|}{ Lower 95\% Mean } & -564396 \\
\hline \multicolumn{2}{|c|}{$\mathrm{N}$} & \\
\hline \multicolumn{2}{|l|}{ Sum Weight } & \\
\hline
\end{tabular}

Test Mean=value

\begin{tabular}{|c|c|c|}
\hline Hypothesi & ed Value & 0 \\
\hline Actual Est & nate & $-2.4 e+6$ \\
\hline & & t Test \\
\hline Test St & tistic & -1.6267 \\
\hline Prob > & & 0.1321 \\
\hline Prob > & & 0.9340 \\
\hline Prob < & & 0.0660 \\
\hline Cervi & $\begin{array}{r}\text { x (3A3 } \\
\text { uantile }\end{array}$ & \\
\hline maximum & $100.0 \%$ & 0 \\
\hline & $99.5 \%$ & 0 \\
\hline & $97.5 \%$ & 0 \\
\hline & $90.0 \%$ & 0 \\
\hline quartile & $75.0 \%$ & -3958 \\
\hline median & $50.0 \%$ & -25908 \\
\hline quartile & $25.0 \%$ & -181024 \\
\hline & $10.0 \%$ & -584723 \\
\hline & 145 & \\
\hline
\end{tabular}




$\begin{array}{lrr} & 2.5 \% & -584723 \\ \text { minimum } \quad 0.5 \% & -584723 \\ & 0.0 \% & -584723 \\ & & \\ & \text { Moments } & \\ \text { Mean } & -114712.2 \\ \text { Std Dev } & 230930.2 \\ \text { Std Error Mean } & 94276.9 \\ \text { Upper 95\% Mean } & 127630.7 \\ \text { Lower 95\% Mean } & -357055.1 \\ \text { N } & 6.0 \\ \text { Sum Weights } & 6.0\end{array}$

\section{Test Mean=value}

Hypothesized Value 0

Actual Estimate $\quad-114712$

t Test

Test Statistic $\quad-1.2168$

Prob $>|\mathrm{t}| \quad 0.2780$

Prob $>t \quad 0.8610$

Prob $<\mathrm{t} \quad 0.1390$ 


\section{VITA}

Name: $\quad$ Satya Vijayanand Vadlamuri

Father: $\quad$ Lakshmana Swamy Vadlamuri

Mother: Bhagyavati

Wife: $\quad$ Ramani Anand

Son: $\quad$ ChakraTeja

Daughter: $\quad$ Sree Kirthi Bhagya.

Date of Birth: $\quad$ August 08, 1954.

Birth Place: $\quad$ Kakinada, Andhra Pradesh, India.

\section{Schools Attended:}

Sri Saraswati Vidyalaya(Primary), Pithapuram, India.

$1959-64$

R.R.Bh.R.Govt. Higher Secondary School, Pithapuram, India. 1964-70

R.R.Bh.R.Govt. Junior College, Pithapuram, India. 1970-72

A.P.Agrl University, College of Vetrinary Science, Tirupati, India 1972-77

Indian Institute of Management, Ahmedabad, India. 1981-83

West Virginia University, Morgantown, USA.

1994-2001

\section{Degrees/ Diplomas Received:}

1. B.V.Sc., (Batchelor of Veterinary Science), College of Veterinary Science, Tirupati Andhra Pradesh Agricultural University, Hyderabad. 1972-77

2. PGDM- Post Graduate Diploma in Management(Agriculture) Indian Institute of Management, Ahmedabad.1981-83 
3. Certificate in Health Administration, West Virginia University, Moragantown.1996

4. M.S. (Master of Science in Agricultural and Resource economics), West Virginia University, Morgantown.1994-96

\section{Honors and Scholarships:}

1. National Merit Scholarship - 1972-77.

2. National Poultry judging Competition - 3rd in India.

3. Silver Medal in All India Essay competition for Veterinary students by Indian council of Indigenous Veterinary medicines.

4. Represented University in All India Inter University National Service Scheme program.

5. Awards of Excellence from Glaxo laboratories- Animal Health Division.

6. Indian Council of Agricultural Research (ICAR) - Earn while you learn program Scholarship 1975-76.

7. Represented University in All India Inter University tournments - Chess, Nagapur, India1976.

8. Second in All India Inter Veterinary College Championships - Table Tennis, GB Pant University, Pantnagar, U.P., India- 1976.

\section{Membership in Professional Societies:}

1. American Association for Advancement in Science, USA

2. Environmental Mutagen Society, USA

3. Society for International Development, Rome, Italy.

4. American Cancer Society, USA.

5. International economics club, WVU. USA.

\section{Service Activity:}

Indian Red Cross-Organized blood donation camps- 1986-88.

Student Leader- NSS, Adult literacy project - 1972-77. 
Public health project- Immunization and health education campaigns - 1972-77.

Organized self helf groups for rural development - 1991-93.

\section{PUBLICATIONS:}

1. Vadlamuri, S.V., Glover, D.D, Turner, T and Sarkar, M.A. Regiospecific expression of Cytochrome P4501A1 and 1B 1 in human uterine tissue CANCER LETTERS (1998); 122; 143-150.

2. Ghosh, M., Wang, Y., Ebert, E., Vadlamuri, S and Beattie, D.S. Substituting Leucine for Alanine -86 in the Tether region of the Iron- Sulfur Protein of the Cytochrome bc(1) complex affects the mobility of the [2Fe2S] domain. BIOCHEMISTRY (2001); 40 (2): $327-$ 335 .

3. Sarkar M.A, Satya VV and Glover DD: Expression of CYP3A4 and CYP3A7 in human endometrium. (submitted to Steroid Biochemistry and Molecular Biology).

4. Vadlamuri, S.V., Glover, D.D., Turner, T., Hobbs, G. and Sarkar. M.A. Influence of Menstrual Phase and Smoking Status on Expression of CYP1A1 and CYP IBI in different regions of the Uterus - Submitted for publication - under review.

5. Vadlamuri, S.V., Glover, D.D., Turner, T and Sarkar, M.A. Variations and expression of Cytochrome P450 isozymes in different regions of uterus in smokers and nonsmokers. (Under preparation.)

6. Ghosh, M., Vadlamuri, S.V., Wang, Y and Beattie, D.S. Aspartate - 186 located in the Iron Sulfur Protein of the yeast Mitochondrial Cytochrome bc1 complex is not involved in Proton Translocation - under review. 


\section{PRESENTATIONS:}

1. Vadlamuri, S.V., Nseyo, U and Sarkar, M.A. (1996). Expression of CYP 1A1, CYPIA2 and CYP3A3 mRNA in human bladder tissues. XI th International Symposium on microsomes and drug oxidations.

2. Vadlamuri, S.V., Glover, D.D., Turner, T and Sarkar, M.A. (1997). Regiospecific expression of CYPIAI and CYP1B1 in human uterine tissue. AACR Proceedings. \# 2266

3. Sarkar, M.A., Vadlamuri, S.V, Douglas D. Glover and Tommy Turner. (1998). The effect of menstrual phase on CYP3A expression in human endometrium. AACR Proceedings. \# 2627.

4. Sarkar, M.A., Vadlamuri, S.V., Glover, D.D and Turner, T. (1998). Differential expression of CYP1A1 and CYP1B1 in Human uterine tissue from smokers and nonsmokers. AACR Proceedings. \# 3323.

5. Ghosh, M., Wang, Y., Ebert,C.E., Vadlamuri, S.V and Beattie, D.S. (2000). Mutating Alanine-86 located in the linker region of the yeast Iron Sulfur Protein interferes with movement of the Head Domain during Electron Transfer. - (Poster presented on WVU research day).

6. SV Vadlamuri, LC Vona-Davis, DW McFadden. (2000) PYY inhibits VEGF production in pancreatic cancer cells. Abstract submitted to Digestive Disease Week.

7. Alice Yu, MD, Linda Vona-Davis, Ph.D., Ponnandai Somasundar, MD, Amy Rose, M.D., Satya Vadlamuri, David McFadden, MD, FACS.(2001) Vitamin E and Peptide YY decrease prostate cancer cell growth and alter VEGF production in vitro. Abstract submitted to meeting of the West Virginia American College of Surgeons., White Sulphur Springs, WV

8. Alice Yu, MD, Linda Vona-Davis, Ph.D., Ponnandai Somasundar, MD, Amy Rose, M.D., Satya Vadlamuri, David McFadden, MD, FACS.(2001) Leptin inhibits human pancreatic cancer growth. Abstract submitted to Surgical Forum, American College of Surgeons. 